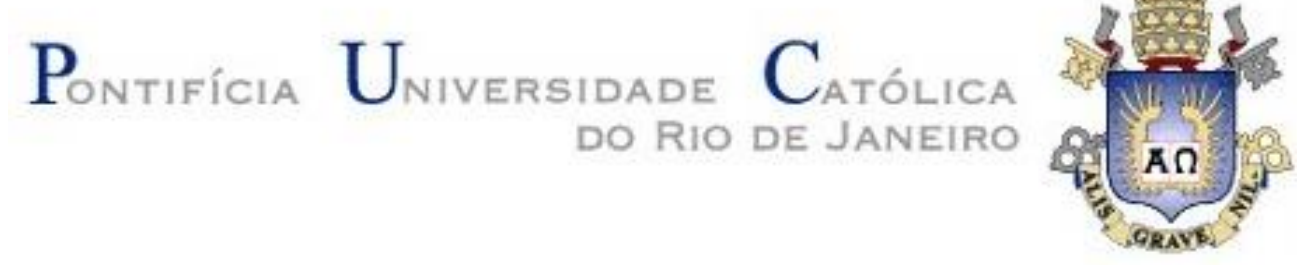

Klaus Piaia Kiffer

\begin{abstract}
Remoção do Clonazepam em águas para consumo humano por Processos Oxidativos Avançados
\end{abstract}

(POAs)

\begin{abstract}
Dissertação de Mestrado
Dissertação apresentada como requisito parcial para obtenção do grau de Mestre pelo Programa de Pós-Graduação em Engenharia de Materiais e de Processos Químicos e Metalúrgicos do Departamento de Engenharia Química e de Materiais da PUC-Rio.
\end{abstract}

Orientador: Prof. Luiz Alberto Cesar Teixeira Co-orientador: Prof. Jorge Vinícius Fernandes Lima Cavalcanti

Rio de Janeiro

Agosto de 2019 


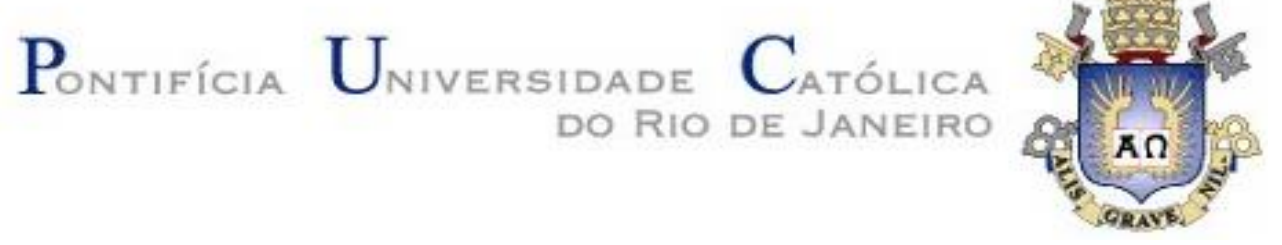

Klaus Piaia Kiffer

\section{Remoção do Clonazepam em águas para consumo humano por Processos Oxidativos Avançados (POAs)}

Dissertação apresentada como requisito parcial para obtenção do grau de Mestre pelo Programa de Pós-Graduação em Engenharia de Materiais e de Processos Químicos e Metalúrgicos do Departamento de Engenharia Química e de Materiais da PUCRio. Aprovada pela Comissão Examinadora abaixo.

Prof. Luiz Alberto Cesar Teixeira

Orientador e Presidente

Departamento de Engenharia Química e de Materiais - PUC-Rio

Prof?. Ana Rosa Martins

Departamento de Engenharia Química e de Materiais - PUC-Rio

Prof ${ }^{2}$. Lídia Yokoyama

Escola de Química - UFRJ

Rio de Janeiro, 13 de agosto de 2019 
Todos os direitos reservados. É proibida a reprodução total ou parcial do trabalho sem autorização da universidade, do autor e do orientador.

\section{Klaus Piaia Kiffer}

Graduado em Engenharia Química pela Universidade Federal de Pernambuco (UFPE) em 2017, membro do Grupo de Processos e Tecnologias Ambientais (GPTA-UFPE) e bolsista de Mestrado pelo Conselho Nacional de Desenvolvimento Científico e Tecnológico (CNPq).

Ficha Catalográfica

Kiffer, Klaus Piaia

Remoção do Clonazepam em águas para consumo humano por Processos Oxidativos Avançados (POAs) / Klaus Piaia Kiffer; orientadores: Luiz Alberto Cesar Teixeira, Jorge Vinícius Fernandes Lima Cavalcanti. - 2019.

99 f. : il. color. ; $30 \mathrm{~cm}$

Dissertação (mestrado) - Pontifícia Universidade Católica do Rio de Janeiro, Departamento de Engenharia Química e de Materiais, 2019.

Inclui bibliografia

1. Engenharia Química e de Materiais - Teses. 2. Clonazepam. 3. FotoFenton. 4. Sistema H2O2/Óxidos de Ferro. 5. Fotólise. I. Teixeira, Luiz Alberto Cesar. II. Cavalcanti, Jorge Vinícius Fernandes Lima. III. Pontifícia Universidade Católica do Rio de Janeiro. Departamento de Engenharia Química e de Materiais. IV. Título.

CDD: 620.11 
Dedico esse trabalho a todos aqueles que contribuíram para que eu me tornasse quem sou hoje.

Em especial, meus pais, Sandra e Iran, e meus irmãos, Matheus, Guilherme e Valentina.

Todo amor do mundo é menor do que meu sentimento por vocês. 


\section{Agradecimentos}

Agradeço inicialmente a Deus por todo dia me dar forças para perseguir o objetivo de ser um indivíduo melhor.

Aos meus pais, Sandra e Iran, pela oportunidade e o privilégio de frequentar as melhores instituições possíveis na minha formação.

Aos meus familiares, em especial meus avós Piaia e Onedia, que me incentivaram a estudar um pouco mais a fundo o Clonazepam.

A PUC-Rio, ao CNPq e à UFPE pelo respaldo em confiar na minha capacidade de desenvolver este trabalho.

Aos professores Luiz Alberto e Jorge, pela orientação, camaradagem e os conselhos que vão ficar marcados para sempre na minha memória.

Aos amigos do LCI, Nickolly, Valmir, Prof. Schuler, pelos momentos e conhecimentos compartilhados.

Aos amigos ao longo da trajetória do mestrado, muito obrigado pelo apoio nas horas de dificuldade.

Aos amigos de sempre, da época de infância, do CMR, da UFPE e os que sempre me levaram adiante.

O presente trabalho foi realizado com apoio da Coordenação de Aperfeiçoamento de Pessoal de Nível Superior - Brasil (CAPES) - Código de Financiamento 001. 


\section{Resumo}

Kiffer, Klaus Piaia; Teixeira, Luiz Alberto Cesar (Orientador); Cavalcanti, Jorge Vinícius Fernandes Lima (Co-orientador). Remoção do Clonazepam em águas para consumo humano por Processos Oxidativos Avançados (POAs). Rio de Janeiro, 2019. 99 p. Dissertação de Mestrado - Departamento de Engenharia Química e de Materiais, Pontifícia Universidade Católica do Rio de Janeiro.

O presente trabalho tem por objetivo analisar a degradação do fármaco Clonazepam (CZP), um dos remédios controlados mais vendidos no mundo e um possível contaminante emergente das águas residuais e de superfície. Foi realizada a degradação do composto a partir da fotólise UVC do peróxido de hidrogênio, das reações de Fenton fotoassistida (Foto-Fenton) por lâmpadas UVA, UVC, e por radiação solar, assim como pelo Sistema $\mathrm{H}_{2} \mathrm{O}_{2} /$ Óxidos de Ferro, para efeito de comparação. Todas as análises foram conduzidas por cromatografia líquida de alta eficiência (CLAE) com detector UV. Os resultados alcançaram conversões acima de $85 \%$ em boa parte dos experimentos e indicaram a cinética, em sua maioria, com ordem aparente próxima a 2 e $\mathrm{k}=0,95 \mathrm{mg} \cdot \mathrm{L}^{-1} \cdot \mathrm{min}^{-1}$ no Foto-Fenton UVC e $\mathrm{k}=0,02 \mathrm{mg} \cdot \mathrm{L}^{-}$ ${ }^{1}$. min $^{-1}$ no Sistema $\mathrm{H}_{2} \mathrm{O}_{2} /$ Óxidos de Ferro. Além disso, foi feita a análise de toxicidade utilizando sementes de alface para o $\mathrm{H}_{2} \mathrm{O}_{2} /$ Óxidos de $\mathrm{Fe}$, a fotólise UVC e para o FotoFenton com lâmpada UVC, com valores de inibição de crescimento de até $44 \%$.

\section{Palavras-chave}

Clonazepam; Foto-Fenton; Sistema $\mathrm{H}_{2} \mathrm{O}_{2} /$ Óxidos de Ferro; Fotólise 


\section{Abstract}

Kiffer, Klaus Piaia; Teixeira, Luiz Alberto Cesar (Advisor); Cavalcanti, Jorge Vinícius Fernandes Lima (Co-advisor). Removal of Clonazepam from water for human uses by Advanced Oxidation Processes (AOPs). Rio de Janeiro, 2019. 99 p. Dissertação de Mestrado - Departamento de Engenharia Química e de Materiais, Pontifícia Universidade Católica do Rio de Janeiro.

The present work aims at analyzing the degradation of the drug Clonazepam (CZP), one of the best-selling controlled drugs in the world and a possible emerging contaminant of surface and wastewater. Compound degradation was performed by UVC photolysis of hydrogen peroxide, photo-assisted Fenton reactions (Photo-Fenton) by UVA, UVC lamps, and solar radiation, as well as by the $\mathrm{H}_{2} \mathrm{O}_{2}$ /Iron Oxides System for comparison purposes. All analyses were conducted by high performance liquid chromatography (HPLC) with UV detector. The results reached conversions above $85 \%$ in most of the experiments and indicated the kinetics, mostly, with apparent order close to 2 and $\mathrm{k}=0.95 \mathrm{mg}$. $\mathrm{L}^{-1} \cdot \mathrm{min}^{-1}$ in Photo-Fenton UVC and $\mathrm{k}=0.02 \mathrm{mg} \cdot \mathrm{L}^{-1} \cdot \mathrm{min}^{-1}$ in $\mathrm{H}_{2} \mathrm{O}_{2}$ /Iron Oxides. In addition, toxicity analysis was carried out using lettuce seeds for $\mathrm{H}_{2} \mathrm{O}_{2}$ /Iron Oxides, UVC photolysis and UVC lamp Photo-Fenton, with growth inhibition values of up to $44 \%$.

\section{Keywords}

Clonazepam; Photo-Fenton; $\mathrm{H}_{2} \mathrm{O}_{2}$ /Iron Oxides System; Photolysis 


\section{Sumário}

$\begin{array}{lr}\text { 1. Introdução } & 18\end{array}$

2. Objetivos 21

3. Revisão bibliográfica 22

3.1. Contaminantes emergentes 22

3.2. Fármacos em matrizes aquosas 24

3.3. Benzodiazepínicos 26

3.4. Clonazepam 28

3.5. Processos oxidativos avançados 34

3.5.1. Fotólise $U V / \mathrm{H}_{2} \mathrm{O}_{2}$

3.5.2. Processo Fenton 38

3.5.3. Processo Foto-Fenton 40

3.5.4. Sistema $\mathrm{H}_{2} \mathrm{O}_{2} /$ Óxidos de Fe 41

3.6. Planejamento experimental e análise de variância 42

3.7. Modelo cinético oxidativo 44

4. Materiais e métodos 46

4.1. Preparação do Efluente Simulado 46

4.2. Curva analítica $\quad 47$

4.3. Preparação das soluções a serem degradadas 49

4.3.1. Fotólise UVC 53

4.3.2. Foto-Fenton UVA/UVC 53

4.3.3. Foto-Fenton com radiação UV Solar 54

4.3.4. Sistema $\mathrm{H}_{2} \mathrm{O}_{2} / O$ Óxidos de $\mathrm{Fe}$

4.4. Condições cinéticas do experimento 56

4.5. Tratamento dos dados obtidos nas análises 57

4.6. Análise de toxicidade 57 
5. Resultados e discussão 60

5.1. Curva analítica para o método de análise em HPLC 60

5.2. Fotólise UVC 61

5.3. Foto-Fenton UVA 62

5.4. Foto-Fenton UVC 66

$\begin{array}{ll}\text { 5.5. Foto-Fenton Solar } & 69\end{array}$

5.6. Comparação gráfica entre os métodos Foto-Fenton 73

5.7. Sistema $\mathrm{H}_{2} \mathrm{O}_{2} / O$ Óxidos de Fe 75

5.8. Análise de variância dos experimentos 81

5.9. Análise cinética dos métodos estudados 82

5.10. Análise de toxicidade 86

5.11. Análise comparativa entre os métodos 87

5.12. Comparação dos resultados obtidos com os de outros trabalhos realizados 88

$\begin{array}{ll}\text { 6. Conclusão } & 90\end{array}$

7. Sugestões para trabalhos futuros 92

8. Referências bibliográficas 93 


\section{Lista de figuras}

Figura 1. Rotas dos poluentes emergentes no meio ambiente. Fonte: TEODOSIU et al., 2018

Figura 2. Quantidade de fármacos detectados em matrizes aquosas por país. FONTE: BEEK et al., 2016

Figura 3. Fórmula química dos BZD. Fonte: SILVA, 2006 apud CRUZ, 2016

Figura 4. Estrutura das três classes de benzodiazepínicos. Fonte:

MAGALHÃES, 2012

Figura 5. Molécula do clonazepam. Fonte: PUBCHEM, 2019

Figura 6. Rota de síntese do clonazepam. Fonte: VARDANYAN et al., 2006

Figura 7. Rotas metabólicas para o CZP. Fonte: TÓTH et al., 2016

Figura 8. Tipos de Processos Oxidativos Avançados. FONTE: BIN; SOBERA-MADEJ, 2012

Figura 9. Comprimentos de onda característicos de lâmpadas de baixa pressão. FONTE: MALLET; ROCHETTE, 2013

Figura 10. Diagrama de Pourbaix para o sistema $\mathrm{Fe}-\mathrm{H}_{2} \mathrm{O}$ a $25^{\circ} \mathrm{C}$.

FONTE: OLIVEIRA et al., 2018

Figura 11. Cartucho de água ultrapura 
Figura 12. Banho Maria QUIMIS ${ }^{\circledR}$

Figura 13. Filtração da solução de CZP

Figura 14. Balança Analítica Metter Toledo

Figura 15. Cromatógrafo líquido de alta precisão

Figura 16. Palha de aço queimando em atmosfera redutora

Figura 17. Óxido finamente dividido

Figura 18. Reator fotocatalítico utilizado para degradação do CZP

52

Figura 19. Degradação do CZP por Foto-Fenton Solar com uso de tubos de quartzo para armazenar as amostras

Figura 20. Agitador utilizado para o Sistema $\mathrm{H}_{2} \mathrm{O}_{2} /$ Óxidos de Ferro 55

Figura 21. pHmetro utilizado nas análises 56

Figura 22. Análise de toxicidade a partir de sementes de alface germinadas em papel de filtro com amostras degradadas de CZP

Figura 23. Curva analítica para método em HPLC

Figura 24. Degradação do CZP pela Fotólise UVC ([H2O2 - ] = 1,15 mg.L-1; [H2O2 0] = 2,02 mg.L-1; [H2O2 +] = 2,88 mg.L-1)

Figura 25. Cinética do método Foto-Fenton UVA ([H2O2 - ] = $1,15 \mathrm{mg} . \mathrm{L}-1 ;[\mathrm{H} 2 \mathrm{O} 2 \mathrm{0}]=2,02 \mathrm{mg} \cdot \mathrm{L}-1 ;[\mathrm{H} 2 \mathrm{O} 2+]=2,88 \mathrm{mg} \cdot \mathrm{L}-1 \mathrm{e}$ $[\mathrm{Fe}-]=0,30 \mathrm{mg} \cdot \mathrm{L}-1 ;[\mathrm{Fe} \mathrm{0}]=7,65 \mathrm{mg} \cdot \mathrm{L}-1 ;[\mathrm{Fe}+]=15,00 \mathrm{mg} \cdot \mathrm{L}-1)$ 
Figura 26. Gráfico de Pareto para conversão final do CZP pelo

Foto-Fenton UVA $\left(R^{2}=0,95809\right.$ e Adj ANOVA $\left.=0,93015\right)$

Figura 27. Superfície de Resposta para a conversão do CZP através do Foto-Fenton UVA (X1: Fe2+ e X2: H2O2)

65

Figura 28. Cinética de conversão do CZP a partir do método Foto-Fenton UVC ([H2O2 - ] = 1,15 mg.L-1; [H2O2 0] = 2,02 mg.L-1; $[\mathrm{H} 2 \mathrm{O} 2+]=2,88 \mathrm{mg} \cdot \mathrm{L}-1$ e $[\mathrm{Fe}-]=0,30 \mathrm{mg} \cdot \mathrm{L}-1 ;[\mathrm{Fe} \mathrm{0}]=$ 7,65 mg.L-1; $[\mathrm{Fe}+]=15,00 \mathrm{mg} \cdot \mathrm{L}-1)$

Figura 29. Gráfico de Pareto para conversão do CZP pelo Foto-Fenton UVC $\left(R^{2}=0,93198\right.$ e Adj ANOVA $\left.=0,88663\right)$

Figura 30. Superfície de Resposta para a conversão do CZP através do Foto-Fenton UVC (X1: Fe2+ e X2: H2O2)

Figura 31. Cinética de conversão da degradação do CZP pelo método Foto-Fenton Solar ([H2O2 - ] = 1,15 mg.L-1; [H2O2 0] = 2,02 mg.L-1; $[\mathrm{H} 2 \mathrm{O} 2+]=2,88 \mathrm{mg} \cdot \mathrm{L}-1$ e $[\mathrm{Fe}-]=0,30 \mathrm{mg} \cdot \mathrm{L}-1 ;[\mathrm{Fe} 0]=7,65 \mathrm{mg} \cdot \mathrm{L}-1$; $[\mathrm{Fe}+]=15,00 \mathrm{mg} \cdot \mathrm{L}-1)$

Figura 32. Gráfico de Pareto para o método Foto-Fenton Solar $\left(R^{2}=0,99662\right.$ e Adj ANOVA $\left.=0,99437\right)$

Figura 33. Superfície de Resposta para a conversão do CZP através do Foto-Fenton Solar (X1: Fe2+ e X2: H2O2)

Figura 34. Comparação gráfica dos métodos Foto-Fenton com relação à radiação e suas conversões ao longo do tempo

Figura 35. Análise de DRX para a palha de aço após pirólise com atmosfera redutora de $\mathrm{CO} 2$ 
Figura 36. Gráfico das fases presentes no catalisador após pirólise com atmosfera de $\mathrm{CO} 2$

Figura 37. Cinética de conversão do CZP a partir do Sistema

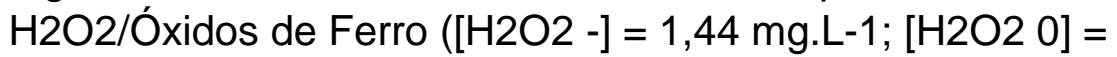
$2,88 \mathrm{mg} \cdot \mathrm{L}-1 ;[\mathrm{H} 2 \mathrm{O} 2+]=4,32 \mathrm{mg} \cdot \mathrm{L}-1$ e $[\mathrm{Fe}-]=15,00 \mathrm{mg} \cdot \mathrm{L}-1 ;[\mathrm{Fe} \mathrm{0}]=$ $57,50 \mathrm{mg} \cdot \mathrm{L}-1 ;[\mathrm{Fe}+]=100,00 \mathrm{mg} \cdot \mathrm{L}-1)$

Figura 38. Condição final (A) e inicial (B) das amostras submetidas ao Sistema H2O2/Óxidos de Ferro

Figura 39. Gráfico de Pareto para o Sistema H2O2/Óxidos de Ferro $\left(R^{2}=0,99921\right.$ e Adj ANOVA $\left.=0,99869\right)$

Figura 40. Superfície de Resposta para a degradação do CZP através do Sistema H2O2/Óxidos de Ferro (X1: $\mathrm{Fe} 2+$ e X2: H2O2)

Figura 41. Cinética Experimental vs Ajuste Cinético obtido pelo software OriginPro 8 para ordem $n$ 


\section{Lista de tabelas}

Tabela 1. Classificação de alguns BZD de acordo com a duração da ação. Fonte: Adaptação de LACERDA et al., 2011 e KIM;

NEDELJKOVIC, 2017

Tabela 2. Eventos adversos ocorridos em $\geq 5 \%$ dos pacientes em pelo menos um dos grupos de tratamento ativo. Fonte: ROCHE (2016)

Tabela 3. Potencial Redox das espécies oxidantes. FONTE: TEIXEIRA e JARDIM, 2004

Tabela 4. Diluições para construção da curva analítica

Tabela 5. Intensidade de Radiação Solar

52

Tabela 6. Planejamento experimental para a Fotólise UVC do CZP

Tabela 7. Planejamento experimental para Foto-Fenton UVA/UVC

Tabela 8. Condições utilizadas para o Sistema $\mathrm{H}_{2} \mathrm{O}_{2} / \mathrm{Óxidos} \mathrm{de} \mathrm{Fe}$

Tabela 9. Tempo decorrido de cada análise e seus intervalos

Tabela 11. Parâmetros estatísticos obtidos através do software STATISTICA 10 para o Foto-Fenton UVA 
Tabela 12. Parâmetros estatísticos obtidos através do software STATISTICA 10 para o Foto-Fenton UVC

Tabela 13. Parâmetros estatísticos obtidos através do software STATISTICA 10 para o Foto-Fenton Solar

Tabela 14. Parâmetros estatísticos obtidos através do software STATISTICA 10 para o Sistema $\mathrm{H}_{2} \mathrm{O}_{2} /$ Óxidos de Ferro

Tabela 15. Coeficientes estatísticos obtidos na análise da variância

Tabela 16. Parâmetros obtidos através da modelagem cinética

Tabela 17. Inibição do crescimento das sementes de alface 


\section{Lista de Abreviações}

OPAS - Organização Pan Americana da Saúde

OMS - Organização Mundial da Saúde

POA - Processos Oxidativos Avançados

ETE - Estação de Tratamento de Efluentes/Esgoto

DBO - Demanda Bioquímica de Oxigênio

COT - Carbono Orgânico Total

BZD - Benzodiazepínicos

SNGPC - Sistema Nacional de Gerenciamento de Produtos Controlados

ANVISA - Agência Nacional de Vigilância Sanitária

CZP - Clonazepam

7-AC - 7-aminoclonazepam

SNC - Sistema Nervoso Central

EPI - Equipamento de Proteção Individual

TNT - Trinitrotolueno

HPLC - High Performance Liquid Chromatography

CLAE - Cromatografia Líquida de Alta Eficiência

CONAMA - Conselho Nacional de Meio Ambiente

DRX - Difração de Raios X 
"Ninguém faz samba só porque prefere..."

João Nogueira

(1941-2000) 


\section{Introdução}

Consideradas por muitos como os males do século, as doenças e distúrbios psicológicos têm gerado aflição em boa parte da sociedade devido aos seus sintomas e métodos de tratamento. Depressão, desordens de ansiedade, crise bipolar e síndrome do pânico são alguns dos transtornos que, atualmente, afetam parte significativa da população. Segundo a OPAS, estes transtornos mentais, em geral, são caracterizados por comportamentos anormais, angústia, tristeza, falta de interesse, baixa autoestima e disfunções de sono e apetite. A duração destes quadros pode ser permanente ou intermitente.

Trazendo para uma realidade mais próxima, de acordo com um relatório da OMS em 2017, o número de brasileiros que vivem com depressão ultrapassa 11 milhões de pessoas, o que corresponde a 5,8\% dos habitantes do país. Em níveis mundiais, mais de 300 milhões de pessoas sofrem com os efeitos da depressão e isto significa um aumento de $18 \%$ do período de 2005 a 2015 . Outro dado alarmante é em relação à quantidade de pessoas afetadas por distúrbios de ansiedade: cerca de 19 milhões de brasileiros, ou 9,3\% da população. Em comparação com outros países das Américas, o Brasil aparece como líder em prevalência neste tipo de desordem.

Com estes números e impacto na sociedade é natural o avanço de pesquisas e tratamentos para estas doenças. Além de um acompanhamento psicossocial e psiquiátrico, diversos casos requerem o uso de medicamentos que agem no sistema nervoso. Ansiolíticos são os mais receitados entre as drogas no combate aos transtornos mentais. Como consequência do aumento de pessoas afligidas por esses males, houve um crescimento exponencial no consumo desta classe de remédios.

Entre estes medicamentos, está o clonazepam, popularmente vendido sob a marca registrada Rivotril ${ }^{\circledR}$, da Roche, que alcançou em 2011 o número de mais de 14 milhões de caixas vendidas, segundo o Sistema Nacional de Gerenciamento de Produtos Controlados da Anvisa, o que o torna um dos medicamentos mais comercializados no país, mesmo sendo classificado como tarja preta. Além da prescrição para tratamentos específicos, o clonazepam é utilizado de forma corriqueira por pessoas que sentem as angústias e estresses do dia a dia como 
válvula de escape. Quantidades significantes do fármaco vão parar nos mananciais aquáticos e, consequentemente, nas águas para consumo humano.

Os processos oxidativos avançados (POA) são descritos assim pela alta capacidade de degradação de compostos orgânicos pelo radical hidroxila, bem como sua baixa seletividade. Os métodos tradicionais de oxidação compreendem o uso de micro-organismos aeróbios e anaeróbios ou o de agentes químicos clássicos, tais quais halogênios e permanganato.

Os POA surgiram no fim do século XIX, mas foi ao longo da segunda metade do século $\mathrm{XX}$ que se tornou cientificamente popular. $\mathrm{O}$ termo avançado refere-se, além da alta reatividade dos radicais, à modernidade com relação aos métodos tradicionais. São divididos em homogêneos e heterogêneos, bem como pela presença de radiação ou não.

Para matéria orgânica pouco recalcitrante (por processos biológicos), a oxidação praticada em ETEs é suficiente para a degradação. Entretanto, compostos que possuem ligações mais estáveis (covalente dupla, tripla, anéis aromáticos etc) exigem mais potência para degeneração. Entre eles estão cosméticos, produtos de higiene pessoal, agrotóxicos, hormônios e, claro, os fármacos.

Estes materiais são denominados contaminantes emergentes e, além do caráter mais resistente à oxidação tradicional, apresentam-se em concentrações muito pequenas nas matrizes aquosas. Muitas vezes em escalas de micro, nano ou até picograma, o que dificulta a identificação em diversas amostras.

Os benzodiazepínicos são considerados contaminantes emergentes e tem ganhado atenção da comunidade científica devido aos efeitos crônicos da exposição continuada à fauna e à flora do meio poluído, podendo assim atingir os seres humanos, seja por consumo direto da água, seja por ingestão indireta através da cadeia alimentar.

À luz de todo esse quadro, há uma preocupação crescente entre os pesquisadores não só ao potencial risco farmacológico, mas aos efeitos ambientais que podem vir à esteira desse aumento do uso de benzodiazepínicos. Além do efluente gerado na própria indústria farmacêutica, o descarte inapropriado e o 
excremento da metabolização no corpo humano são potenciais contaminadores do meio ambiente, em especial dos mananciais aquáticos.

Com isso, é adequado avaliar o uso dos processos oxidativos avançados para a remediação do efluente não só industrial relacionado à produção desta classe de fármacos, bem como no tratamento do esgoto sanitário urbano e no tratamento de água para consumo humano, vendo-os como potenciais métodos de solucionar este problema recorrente em matrizes aquosas ao longo do planeta.

Este trabalho procura investigar e comparar métodos de oxidação avançada como a Fotólise $/ \mathrm{H}_{2} \mathrm{O}_{2}$ com lâmpada UVC, Foto-Fenton UVA/UVC/Solar e Sistema $\mathrm{H}_{2} \mathrm{O}_{2} /$ Óxidos de Ferro na remoção do clonazepam de efluentes simulados, bem como a avaliação dos parâmetros que afetam o desempenho dos respectivos processos por análise estatística e cinética. Outro alvo do trabalho é avaliar a toxicidade gerada pelos métodos utilizados, não só pelos reagentes inseridos, mas dos possíveis compostos intermediários gerados. 


\section{Objetivos}

O trabalho a seguir tem como objetivo geral a mineralização parcial/total do clonazepam de matrizes aquosas, em especial para águas de consumo humano, através de processos oxidativos avançados (POAs). Entre os diversos tipos de oxidação avançada existentes, foram escolhidos 3: a Fotólise UVC, o Foto-Fenton e o Sistema $\mathrm{H}_{2} \mathrm{O}_{2} /$ Óxidos de Ferro. Assim, os objetivos específicos desta dissertação são:

1- Analisar a cinética de cada um dos processos.

2- Investigar as variáveis que mais afetam cada um dos processos.

3- Comparar qual dos processos é o mais eficiente.

4- Discutir a cinética dos processos utilizados.

5- Analisar a toxicidade residual de cada um dos processos. 


\section{Revisão bibliográfica}

\section{1}

\section{Contaminantes emergentes}

Os contaminantes emergentes, poluentes emergentes ou micropoluentes são termos que designam substâncias químicas ou biológicas de uso diário que estão em excesso no meio ambiente, segundo Bell et al. (2011). Outras definições, como a de Sauvé e Desrosiers (2014), definem poluentes emergentes como materiais naturais ou químicos, manufaturados pelo homem, que estão presentes em vários ecossistemas, cuja toxicidade ou persistência é capaz de alterar o metabolismo de um ser vivo. Estes compostos são produtos como cosméticos, medicamentos, pesticidas, surfactantes, plastificantes, entre outros que são de difícil depuração (WILKINSON et al., 2017).

Apesar de existir uma classificação mais ampla, Houtman (2010) segmentou em 3 grupos os micropoluentes: substâncias novas introduzidas do meio ambiente, tais como componentes industriais recentemente desenvolvidos; substâncias já presentes no meio ambiente só que detectadas a pouco tempo e componentes conhecidos qualitativamente e quantitativamente, porém que foram reconhecidos como potenciais causadores de efeitos adversos a pouco tempo.

$\mathrm{O}$ alcance dos contaminantes emergentes em matrizes aquosas, principais vetores de propagação destes compostos no meio ambiente, é dado, basicamente, a partir destas fontes: o efluente gerado na produção industrial do produto que o contenha, o uso dos produtos que gera um excedente a ser descartado (pesticidas na agricultura, dermocosméticos de uso pessoal e fármacos vencidos) e a parte não metabolizada de substâncias que animais e seres humanos ingerem. A Figura 1 mostra as possíveis rotas que os micropoluentes percorrem (BILA; DEZOTTI, 2003). 


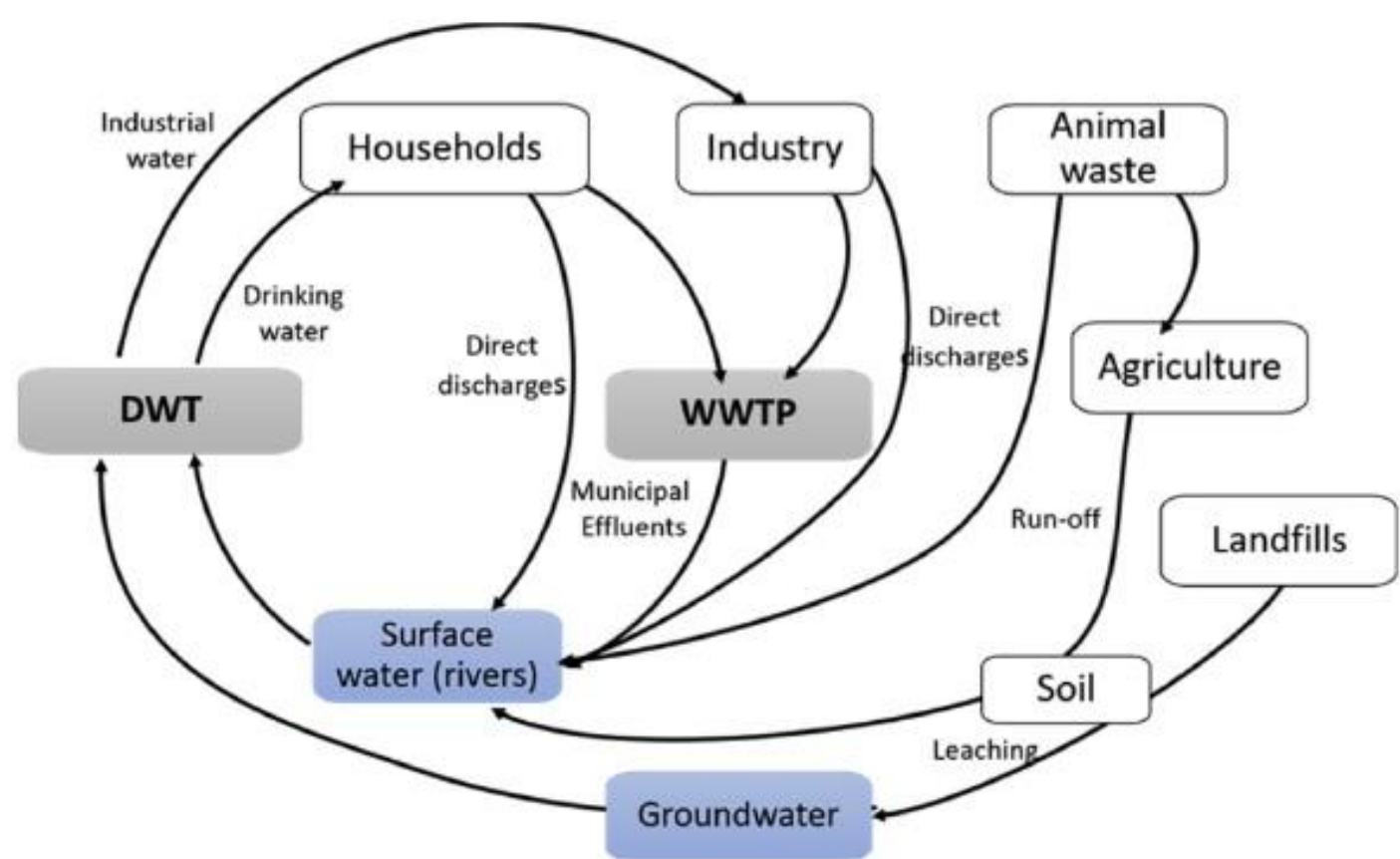

Figura 1. Rotas dos poluentes emergentes no meio ambiente. Fonte: TEODOSIU et al., 2018.

Graças aos avanços tecnológicos das técnicas analíticas nos últimos anos, conferindo a elas maior precisão, acurácia e exatidão, foi possível determinar e quantificar boa parte dos contaminantes emergentes que se tem conhecimento atualmente (SANTOS, 2015).

Apesar de não haver uma diretriz mundial sobre o assunto, países da Europa e da América do Norte, que aparecem como vanguarda na questão dos poluentes emergentes, já discutem projetos para minimizar o descarte destes compostos no meio ambiente. As principais melhorias estão relacionadas à eficiência das estações de tratamento de efluentes (ETEs) das unidades fabris que lançam resíduos de sua produção nos corpos hídricos (TAHERAN et al., 2018).

A razão da baixa eficiência das ETEs é o foco delas em determinado tipo de tratamento: biológico (para redução de DBO ou COT) ou físico-químico (com enfoque em cor, turbidez, por exemplo), que são aqueles demandados na legislação ambiental já vigente (TAHERAN et al., 2018).

Os métodos mais promissores de tratamento de micropoluentes são aqueles que usam sistemas híbridos, que combinam técnicas convencionais, como os lodos ativados com oxidação avançada. A utilização de aparatos de separação, tal como 
ultrafiltração ou osmose inversa, tem que ser analisada com cuidado devido ao possível surgimento de uma corrente de saída ainda mais contaminada do que o material filtrado (ZHANG et al., 2006).

Outra precaução que deve ser tomada é a possibilidade de formação de intermediários mais tóxicos do que os próprios contaminantes emergentes a serem atacados. Durante as diversas oxidações que ocorrem nas etapas do tratamento do efluente, compostos mais agressivos ao meio podem ser gerados, prejudicando assim a eficiência dos processos, o ecossistema que recebe estes produtos e, em último caso, outros membros das cadeias alimentares, devido à bioacumulação (TEODOSIU et al., 2018).

\section{2}

\section{Fármacos em matrizes aquosas}

Os fármacos são uma das substâncias classificadas como contaminantes emergentes, como visto no tópico anterior, que mais preocupam os especialistas da área devido ao aumento exponencial do seu consumo nos últimos anos. A percepção de que estes compostos estão presentes nas águas subterrâneas e de superfície já ultrapassa os 40 anos, e o número de trabalhos na área de contaminação por micropoluentes farmacêuticos vem crescendo nas duas últimas décadas (BEEK et $a l ., 2016)$.

Um dos trabalhos de maior relevância sobre a presença de um medicamento em águas de superfície e suas consequências foi a partir da identificação do etilnilestradiol (usado como anticoncepcional) por Snyder et al. (1999). Nesta pesquisa associou-se a presença da substância ao impacto na reprodução dos peixes da região afetada, gerando uma população de fêmeas ou hermafroditas superior à de machos.

Ternes et al. (1999) identificaram a presença de estrogênios naturais e sintéticos em efluentes e esgoto sanitário na Alemanha, Canadá e no Brasil. Especificamente no caso do último, tomou-se como referência amostras de influentes e efluentes da ETE da Penha/RJ. Stumpf et al. (1997) também detectaram fármacos (antilipêmicos, anti-inflamatórios e outros metabólitos) presentes no 
esgoto, efluentes de ETE e águas de superfície no estado do Rio de Janeiro com concentração média de $0,02-1 \mu \mathrm{g} . \mathrm{L}^{-1}$.

A partir desses casos, diversos estudos foram desenvolvidos com a premissa de detectar os fármacos que estariam alcançando as matrizes aquosas, bem como os efeitos aos ecossistemas atingidos. Segundo Beek et al. (2016), os medicamentos mais comumente analisados são antibióticos, analgésicos e estrógenos. Outra constatação foi a presença de 16 substâncias nas águas de cada uma das regiões estudadas ao longo do planeta (África, Ásia, Europa, Américas e Caribe), estando entre estas as 3 classes supracitadas, assim como: antiepilépticos e redutores de lipídeos. A Figura 2 mostra um mapa da quantidade de fármacos presentes nas águas de superfície e subterrâneas.

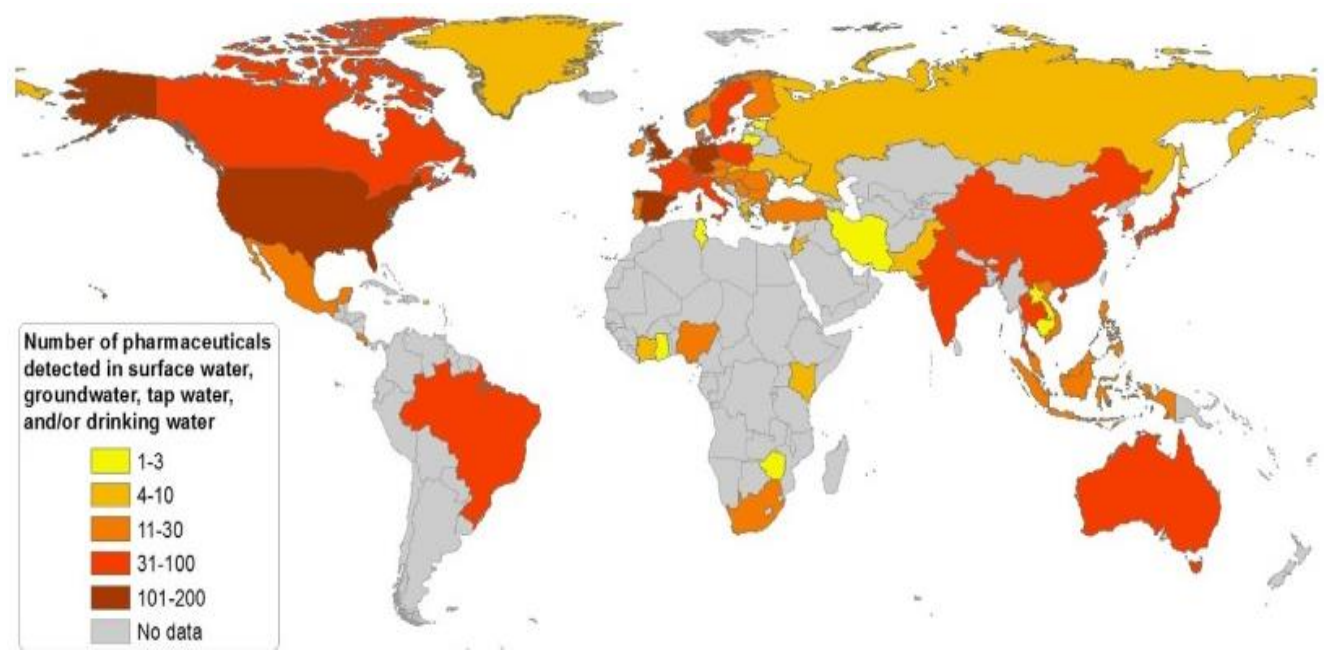

Figura 2. Quantidade de fármacos detectados em matrizes aquosas por país. FONTE: BEEK et al., 2016.

Para os fármacos, a principal fonte de contaminação das águas continua sendo o esgotamento sanitário urbano, seguido dos efluentes hospitalares, que carregam consigo uma alta carga de medicamentos e que deveriam ter um controle mais rigoroso dessas emissões. Muitas das unidades de saúde lançam seus dejetos na própria rede de coleta urbana (BEEK et al., 2016).

E qual seria o efeito desses fármacos no meio? De acordo Bila e Dezotti (2003), essas substâncias podem causar efeitos adversos em qualquer nível de hierarquia biológica, mesmo em concentrações ínfimas. Além dos estudos de Snyder et al. (1999) mencionados anteriormente, McKeon et al. (1995), Miranda et 
al. (1998), Jorgensen et al. (2000) e Kolár et al. (2001) citam a resistência bacteriana desenvolvida em diversas situações quando diferentes tipos de organismos são sujeitos a presença de antibióticos. Outro grupo de pesquisadores (Wu [1995], Smith et al. [1996] e Chien et al. [1999]) avaliaram a presença de perturbadores endócrinos nos sistemas aquáticos com resultados que corroboram o efeito negativo sobre organismos ali presentes.

\section{3}

\section{Benzodiazepínicos}

Os benzodiazepínicos são drogas de uso em larga escala como tranquilizantes, hipnóticos, anticonvulsionantes, antiepiléticos e relaxantes musculares (RUST et al., 2012). Esses medicamentos pertencem a uma classe de compostos que são quimicamente caracterizados por um anel de benzeno ligado a um anel diazepínico de 7 membros (Figura 3). Eles surgiram na década de 1950 e substituíram os compostos barbitúricos nos tratamentos de doenças psicotrópicas. O primeiro BZD a ser lançado foi o clordiazepóxido (SILVA, 1999 apud CRUZ, 2016). Este foi sintetizado acidentalmente pela Hoffman-La Roche, em 1955 e seus efeitos abalaram o mercado farmacêutico que alavancou suas vendas (ASHTON, 2005).<smiles>[R7]c1ccc2c(c1)C(c1ccccc1[R2])=NCC([R])N2[R]</smiles>

Figura 3. Fórmula química dos BZD. Fonte: SILVA, 2006 apud CRUZ, 2016.

Os motivos de toda essa euforia por parte de médicos, farmacêuticos e, por consequência, dos pacientes, foram: a presença de poucos efeitos colaterais, baixa 
toxicidade e grande eficácia. Com isso, em 1970, o diazepam, um dos BZD mais conhecidos, já havia se tornado o medicamento mais prescrito no mundo (BERNIK, 1999).

Então, de remédios extremamente prestigiados, os BZD começaram a ser vistos por outro prisma. Relatos em diversos países afirmam que os usuários desta classe de drogas tornaram-se dependentes químicos, além do uso indiscriminado. Métodos de controle à venda foram implementados (DIEHL, 2011).

Diversos países como Reino Unido (1988), França (1990), Alemanha (1993) e Dinamarca (2008) tomaram políticas públicas contra os usos indiscriminados dos BZD, bem como a conscientização da população quanto aos males causados por esses medicamentos (MENDES, 2015).

No Brasil, desde 2007, a Agência Nacional de Vigilância Sanitária (ANVISA) implantou o Sistema Nacional de Gerenciamento de Produtos Controlados (SNGPC). Esse programa visa a obtenção de dados para controle, proposição de políticas públicas e fiscalização sobre toda cadeia consumidora de substâncias, desde a produção à comercialização, que necessitam de um regime especial, tais como os BZD (BRASIL, 2013; MENDES, 2015).

Os BZD podem ser divididos em três classes: derivados da 1,4benzodiazepina; derivados da 1,5-benzodiazepina; e derivados da triazolo-1,4benzodiazepina (Figura 4). Os primeiros são ditos benzodiazepínicos clássicos e compõem os principais produtos prescritos no Brasil (MAGALHÃES, 2012).

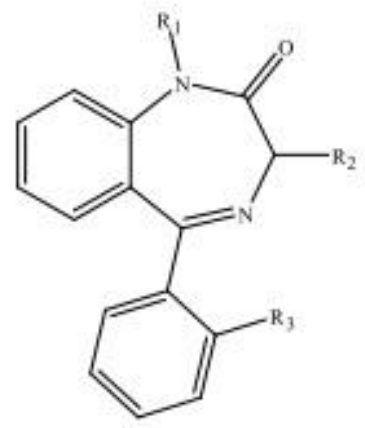

1,4-benzodiazepina

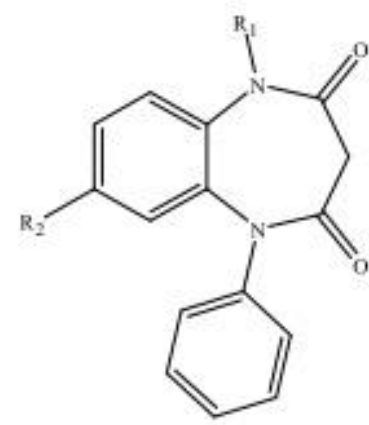

1,5-benzodiazepina

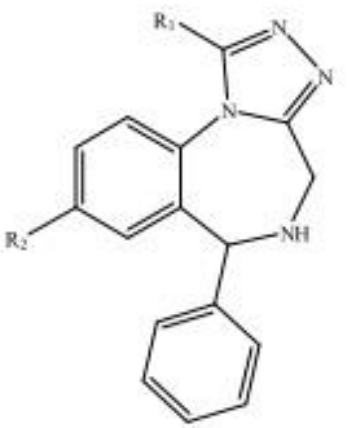

Triazolo-1,4-benzodiazepina

Figura 4. Estrutura das três classes de benzodiazepínicos. Fonte: MAGALHÃES, 2012. 
Em termos farmacocinéticos, os BZD entram no sistema nervoso central rapidamente. Entretanto, podem variar de acordo com o tempo de ação no organismo. Por isso são classificados de acordo com a Tabela 1.

Tabela 1. Classificação de alguns BZD de acordo com a duração da ação. Fonte: Adaptação de LACERDA et al., 2011 e KIM; NEDELJKOVIC, 2017.

\begin{tabular}{cccc}
\hline Benzodiazepínico & T pico (h) & T 1/2(h) & Duração da Ação \\
\hline Diazepam & $0,5-1,5$ & 20 a 40 & Longa \\
Clonazepam & $1-4$ & 30 a 40 & Longa \\
Alprazolam & $1-2$ & 6 a 12 & Média \\
Lorazepam & 2,5 & 6 a 12 & Curta \\
Midazolam & 0,5 & 2 a 4 & Curta \\
\hline
\end{tabular}

\section{4}

\section{Clonazepam}

O clonazepam é um benzodiazepínico sintético utilizado no tratamento de distúrbios epilépticos, transtornos de ansiedade e de humor, síndromes psicóticas, entre outras aplicações (ROCHE, 2016). Ele foi aprovado em 1975 e desde então se tornou uma das principais alternativas aos tratamentos de males psicotrópicos, tanto que se tornou um dos 5 medicamentos controlados mais vendidos no Brasil, segundo o Sistema Nacional de Gerenciamento de Produtos Controlados (BRASIL, 2013).

Este fármaco tem como nome químico o 5- (o-clorofenil) -1,3-diidro-7nitro-2H-1,4-benzodiazepina-2-ona $\left(\mathrm{C}_{15} \mathrm{H}_{10} \mathrm{ClN}_{3} \mathrm{O}_{3}\right)$, como mostrado na Figura 5, e é classificado como um derivado da 1,4-benzodiazepina. É conhecido comercialmente como Rivotril $^{\circledR}$ ou Klonopin ${ }^{\circledR}$, dependendo da região. Tem peso molecular de 315,713 g. mol ${ }^{-1}$ e se apresenta na forma sólida a $25^{\circ} \mathrm{C}$ e 1 bar. Tem forma de um pó cristalino, coloração de esbranquiçada a amarelada e odor fraco. O 
ponto de fusão do $\mathrm{CZP}$ é próximo a $237^{\circ} \mathrm{C}$. Ele é muito pouco solúvel em água e levemente solúvel em acetona, clorofórmio e metanol (PUBCHEM, 2019).

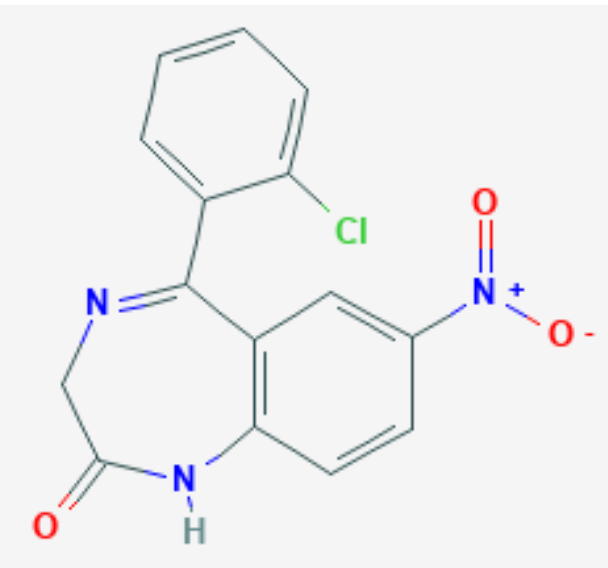

Figura 5. Molécula do clonazepam. Fonte: PUBCHEM, 2019.

Sua síntese se inicia com a redução do 2-cloro-2-nitrobenzofenona a 2cloro-2-aminobenzofenona, através de uma hidrogenação catalisada por níquel Raney. Então, o derivado amino é exposto à uma amidação pelo 2-bromoacetil brometo, formando um radical bromoacetamida na molécula que rapidamente é convertida em aminoacetamida devido à presença da amônia na reação. Após esta etapa, ocorre a reação do composto com a piridina gerando o 5- (2-clorofenil) -2,3dihidro-1H-1,4-benzodiazepina-2-ona, que depois de uma nitração em condições brandas (nitrato de potássio em meio ácido) resulta na molécula do clonazepam (VARDANYAN et al., 2006). A Figura 6 demonstra a rota percorrida até a síntese do CZP.

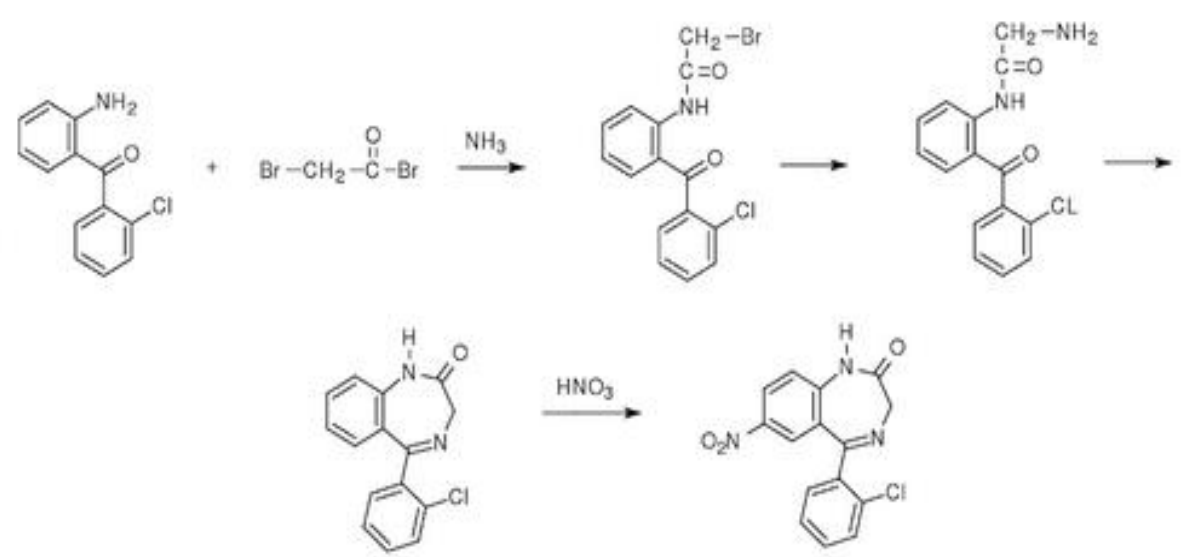

Figura 6. Rota de síntese do clonazepam. Fonte: VARDANYAN et al., 2006. 
O clonazepam é vendido em três apresentações: comprimidos $(0,5 \mathrm{mg}$ e 2 $\mathrm{mg})$, comprimido sublingual $(0,25 \mathrm{mg})$ e solução oral $\left(2,5 \mathrm{mg} . \mathrm{mL}^{-1}\right)$. Farmacologicamente, este medicamento tem biodisponibilidade absoluta de $90 \%$, cuja metabolização é hepática. A meia-vida de absorção é de aproximadamente 25 minutos, atingindo o pico de concentração sanguínea no período de 1 a 4 horas após a ingestão. Naturalmente, a taxa de absorção da solução oral é mais veloz do que as das demais apresentações. Entretanto, os comprimidos possuem a mesma bioequivalência absortiva da solução oral. É comprovado que o uso diário do CZP aumenta o acúmulo no organismo. Comparando a administração de uma única dose com uma dose por dia, percebe-se o aumento de 3 vezes na concentração de equilíbrio. A relação entre dose ingerida e concentração plasmática é linear (ROCHE, 2016).

O clonazepam se distribui rapidamente entre órgãos e tecidos do corpo, principalmente em estruturas do cérebro. Seu volume de distribuição $\left(V_{D}\right)$, que reflete como e com que velocidade se espalha o medicamento no organismo, é de 3 L. $\mathrm{Kg}^{-1}$ ou aproximadamente $200 \mathrm{~L}$ para um ser humano de $70 \mathrm{Kg}$, que pode ser considerado um valor alto. $\mathrm{O}$ fato de a concentração plasmática ser baixa (na ordem de nanograma por $\mathrm{mL}$ ) deve-se, além do alto volume de distribuição, à alta fixação do CZP às proteínas plasmáticas de tecidos específicos (82\% a 86\%) (FOYE et al., 2012; ROCHE, 2016).

A metabolização das benzodiazepinas acontecem em geral no fígado. A Figura 7 mostra as possíveis rotas metabólicas do clonazepam no organismo (DE PAULA et al., 2015; TÓTH et al., 2016). 


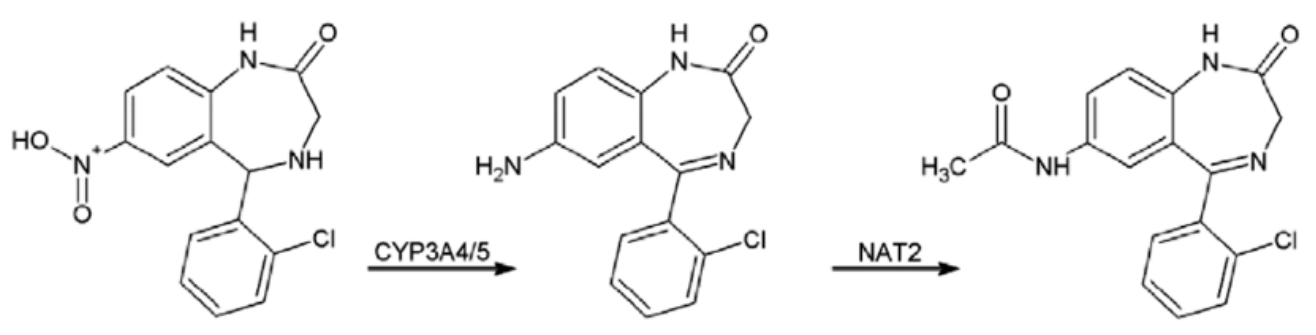

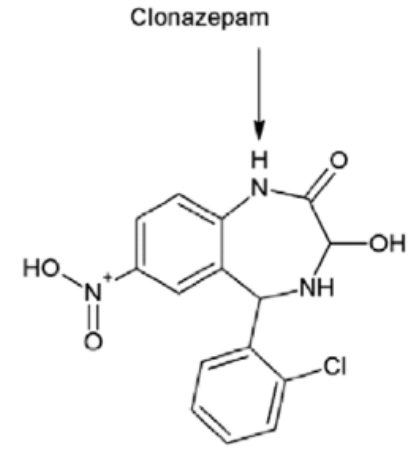

3-hydroxy-clonazepam

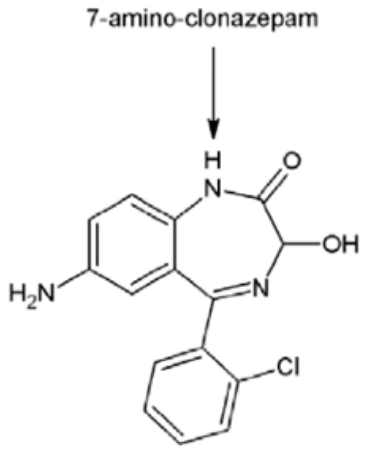

3-hydroxy-7-amino-clonazepam

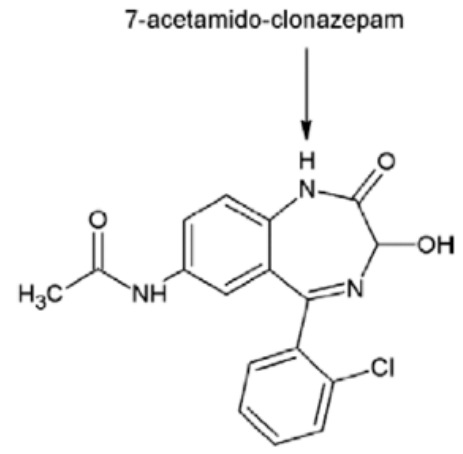

3-hydroxy-7-acetamido-clonazepam

Figura 7. Rotas metabólicas para o CZP. Fonte: TÓTH et al., 2016.

A eliminação do clonazepam e seus metabólitos ocorrem pela urina (50$70 \%$ ) e fezes (10-30\%). Cerca de $2 \%$ do CZP aparece inalterado na urina. O tempo de meia vida de eliminação deste fármaco está compreendido entre 30 a 40 horas com depuração de 55 mL.min ${ }^{-1}$. Não se observa também diferenciação no tempo de meia-vida do CZP em relação a adultos e crianças (ROCHE, 2016).

A forma mais usual de determinar a presença de clonazepam em um organismo é através da presença do composto inalterado ou seu metabólito majoritário (7-AC) na urina. Apesar de o sangue ter a matriz mais confiável, sua depuração é mais veloz, o que não permite análises após certo tempo. Segundo Chèze et al. (2004), duas voluntárias saudáveis fizeram a ingestão de uma única dose de $2 \mathrm{mg}$ de CZP e foram coletadas amostras de urina destas pessoas durante 6 dias após a administração do medicamento. Notou-se a presença do 7-AC na urina ao final dos 6 dias com concentração de aproximadamente $15 \mathrm{ng} \cdot \mathrm{mL}^{-1}$.

Storhaug et al. (2012) coletaram amostras de urina de uma paciente, que fazia uso contínuo de CZP, durante um período de 9 dias após a última dose e analisou a presença do 7-AC nestas matrizes. Observou-se que a principal taxa de declínio do 7-AC acontece entre 60-70 horas após a ingestão da última dose. Outra consideração importante é a detecção de altas concentrações (97 ng.mL $\left.\mathrm{mL}^{-1}\right)$ do metabólito em paciente com uso contínuo, mesmo depois de 9 dias. 
O clonazepam apresenta uma série de advertências ao seu uso. Desde a realização de atividades que demandam concentração e agilidade, passando pelo uso concomitante com álcool ou drogas, onde se observa casos de perda de até $30 \%$ na atividade anticonvulsionante do composto, sedação grave, e supressão relevante na capacidade do sistema cardiovascular/respiratório. Outras situações como intolerância a lactose e porfiria podem ocorrer em alguns casos (ROCHE, 2016).

A administração durante a gravidez e a lactação também exige muita cautela, pois em outros BZD foi sugerida má formação congênita do feto por pacientes com quadros de epilepsia e, apesar de em pequenas concentrações, o leite materno pode conter traços do medicamento (ROCHE, 2016). Entretanto, segundo Lin et al. (2004), em um estudo realizado com 166 crianças expostas a drogas anticonvulsionantes durante a gravidez, sendo 52 ao CZP e 43 como terapia única, apenas uma má formação presente foi detectada (3\% do total). Apesar destes resultados, pelo fato de a amostra não ser tão significativa, não se deve descartar as orientações médicas sobre a veiculação em grávidas e lactantes, bem como não se pode afirmar que o CZP não é teratogênico.

Todavia, a principal preocupação no uso dos benzodiazepínicos é a alta capacidade desta classe de medicamentos de causar dependência psíquica e física. A OMS estima que o uso contínuo durante 4 a 6 semanas de BZDs já é o suficiente para apontar um quadro de dependência, logicamente relacionado à quantidade ingerida. Isso recai em um problema de saúde pública que é de difícil controle, pois o uso indiscriminado está intrinsecamente ligado à prescrição indevida do medicamento por médicos, visto que os BZDs são drogas de venda controlada (MENDES, 2015).

Em tratamentos prolongados com o uso de benzodiazepínicos, é necessário que, para sua interrupção, haja uma descontinuação gradual do medicamento, devido aos sintomas de abstinência. Estes incluem psicoses, ansiedade, sudorese, distúrbios do sono entre outros. O uso de drogas e álcool também é um catalisador para que os efeitos da retirada ab-rupta sejam mais intensos (ROCHE, 2016).

Em termos dos efeitos que o CZP apresenta durante sua ação no organismo, destacam-se os relacionados ao SNC, tais como sonolência, cefaleia e vertigem. A Tabela 2 destaca os principais eventos ocorridos em diversas doses. 
Tabela 2. Eventos adversos ocorridos em $\geq 5 \%$ dos pacientes em, pelo menos, um dos grupos de tratamento ativo. Fonte: ROCHE, 2016.

\begin{tabular}{|c|c|c|c|c|}
\hline Evento adverso & $\begin{array}{c}\text { Placebo } \\
(\%)\end{array}$ & $\begin{array}{c}1 \text { a } 2 \\
\text { mg.dia }^{-1} \\
(\%)\end{array}$ & $\begin{array}{c}2 \mathrm{a}<3 \\
\operatorname{mg.dia}^{-1}(\%)\end{array}$ & $\begin{array}{c}>3 \mathrm{mg} . \\
\operatorname{dia}^{-1}(\%)\end{array}$ \\
\hline Sonolência & 15,6 & 42,6 & 58,4 & 54,9 \\
\hline Cefaleia & 24,8 & 13,2 & 15,9 & 21,3 \\
\hline $\begin{array}{c}\text { Infecção de vias aéreas } \\
\text { superiores }\end{array}$ & 9,5 & 11,6 & 12,4 & 11,9 \\
\hline Fadiga & 5,8 & 10,1 & 8,8 & 9,8 \\
\hline Gripe & 7,1 & 4,7 & 7,1 & 9,4 \\
\hline Depressão & 2,7 & 10,1 & 8,8 & 9,4 \\
\hline Vertigem & 5,4 & 5,4 & 12,4 & 8,9 \\
\hline Irritabilidade & 2,7 & 7,8 & 5,3 & 8,5 \\
\hline Insônia & 5,1 & 3,9 & 8,8 & 8,1 \\
\hline Ataxia & 0,3 & 0,8 & 4,4 & 8,1 \\
\hline Perda de equilíbrio & 0,7 & 0,8 & 4,4 & 7,2 \\
\hline Náusea & 5,8 & 10,1 & 9,7 & 6,8 \\
\hline Coordenação anormal & 0,3 & 3,1 & 4,4 & 6,0 \\
\hline $\begin{array}{c}\text { Sensação de cabeça } \\
\text { leve }\end{array}$ & 1,0 & 1,6 & 6,2 & 4,7 \\
\hline Sinusite & 3,7 & 3,1 & 8,0 & 4,3 \\
\hline $\begin{array}{c}\text { Concentração } \\
\text { prejudicada }\end{array}$ & 0,3 & 2,3 & 5,3 & 3,8 \\
\hline
\end{tabular}




\section{5}

\section{Processos oxidativos avançados}

Os processos oxidativos avançados (POAs) são designados como tais devido à formação do radical hidroxila $(\cdot \mathrm{OH})$ ao longo de suas reações. Essa é a principal diferença entre os processos de oxidação química previamente já conhecidos, tais como os que envolvem reações de transferência de elétrons envolvendo matéria orgânica (aeróbios ou anaeróbios) ou o uso do cloro como agente oxidante (ANDREOZZI et al., 1999).

Os estudos sobre oxidação avançada remontam ao fim do século XIX, quando Meritens (1886) usou $\mathrm{O}_{3}$ como agente desinfetante. Logo depois, em 1903 (Nice, França), houve a primeira planta de ozonização como método de tratamento de águas residuais. Em 1973, a expressão "Oxidação Avançada” caiu em uso para processos que utilizam radical hidroxila como oxidante, durante o $1^{\circ}$ Simpósio Internacional em Ozônio para Tratamento de Águas e Efluentes. A partir da década de 1980, houve um aumento do interesse sobre assuntos relacionados à área ambiental que alavancou ainda mais os estudos na área de POA (TEIXEIRA e JARDIM, 2004).

Devido ao alto potencial de redução (Tabela 3$)$ do radical hidroxila $($ Eh $=$ 2,8 V) e sua baixa seletividade, este tipo de oxigênio reativo torna-se uma opção viável e eficiente para a mineralização parcial ou completa de diversos compostos de difícil oxidação diante das demais técnicas de degradação, tornando compostos refratários em biodegradáveis. Além disso, é possível associar os POAs com os demais processos convencionais de tratamento, sendo utilizado como etapa de pré/pós-tratamento (NASCIMENTO; BARROS; ABDALA, 2017).

Por se tratar um método geralmente limpo que tem como reagentes prioritários o peróxido de hidrogênio ou o ozônio, ganha um apelo ainda mais forte. Para completar, é possível o uso dessa técnica nas diferentes matrizes (sólidas, aquosas e gasosas) e in situ (NASCIMENTO; BARROS; ABDALA, 2017). 
Tabela 3. Potencial Redox das espécies oxidantes. FONTE: TEIXEIRA e JARDIM, 2004.

\begin{tabular}{cc}
\hline Espécie & Potencial Redox em Estado Padrão (V) \\
\hline Flúor & 3,03 \\
Radical Hidroxila & 2,80 \\
Oxigênio Singlet & 2,42 \\
Ozônio & 2,07 \\
Peróxido de Hidrogênio & 1,78 \\
Íon Permanganato & 1,68 \\
Dióxido de Cloro & 1,57 \\
Cloro & 1,36 \\
Iodo & 0,54 \\
\hline
\end{tabular}

Outro fator que torna interessante o uso dos radicais hidroxila, é a velocidade de reação que estes possuem quando interagem com moléculas orgânicas. Não são difíceis encontrar taxas entre $10^{6}-10^{9} \mathrm{M}^{-1} \cdot \mathrm{s}^{-1}$ para compostos como benzeno, tolueno e outros aromáticos (U.S. EPA, 1998).

Por outro lado, algumas desvantagens são relacionadas ao uso dos POAs, tais como: o custo do tratamento devido a equipamentos adicionais e custos com reagentes, lâmpadas, energia; a presença de compostos oxidantes que podem interferir nas análises das substâncias; o ataque do radical hidroxila às outras etapas do tratamento, em especial ao lodo do tratamento biológico (JARDIM e CANELA, 2004).

Existem vários tipos de processos denominados POAs que basicamente se dividem em homogêneos e heterogêneos. A Figura 8 mostra quais são e como são classificados esses métodos. Outra classificação possível são as que envolvem a presença ou não de radiação ultravioleta (BIN; SOBERA-MADEJ, 2012). 
Entre os homogêneos, destacam-se os baseados na reação de Fenton $\left(\mathrm{H}_{2} \mathrm{O}_{2} / \mathrm{Fe}^{2+}\right)$ e os que têm o ozônio como reagente principal. Já nos processos heterogêneos, pode-se afirmar que a fotocatálise com $\mathrm{TiO}_{2}$ é o método mais comumente utilizado. Outros catalisadores como $\mathrm{ZnO}$ e $\mathrm{CdS}$ também são empregados, mas sem o mesmo prestígio (TEIXEIRA e JARDIM, 2004).

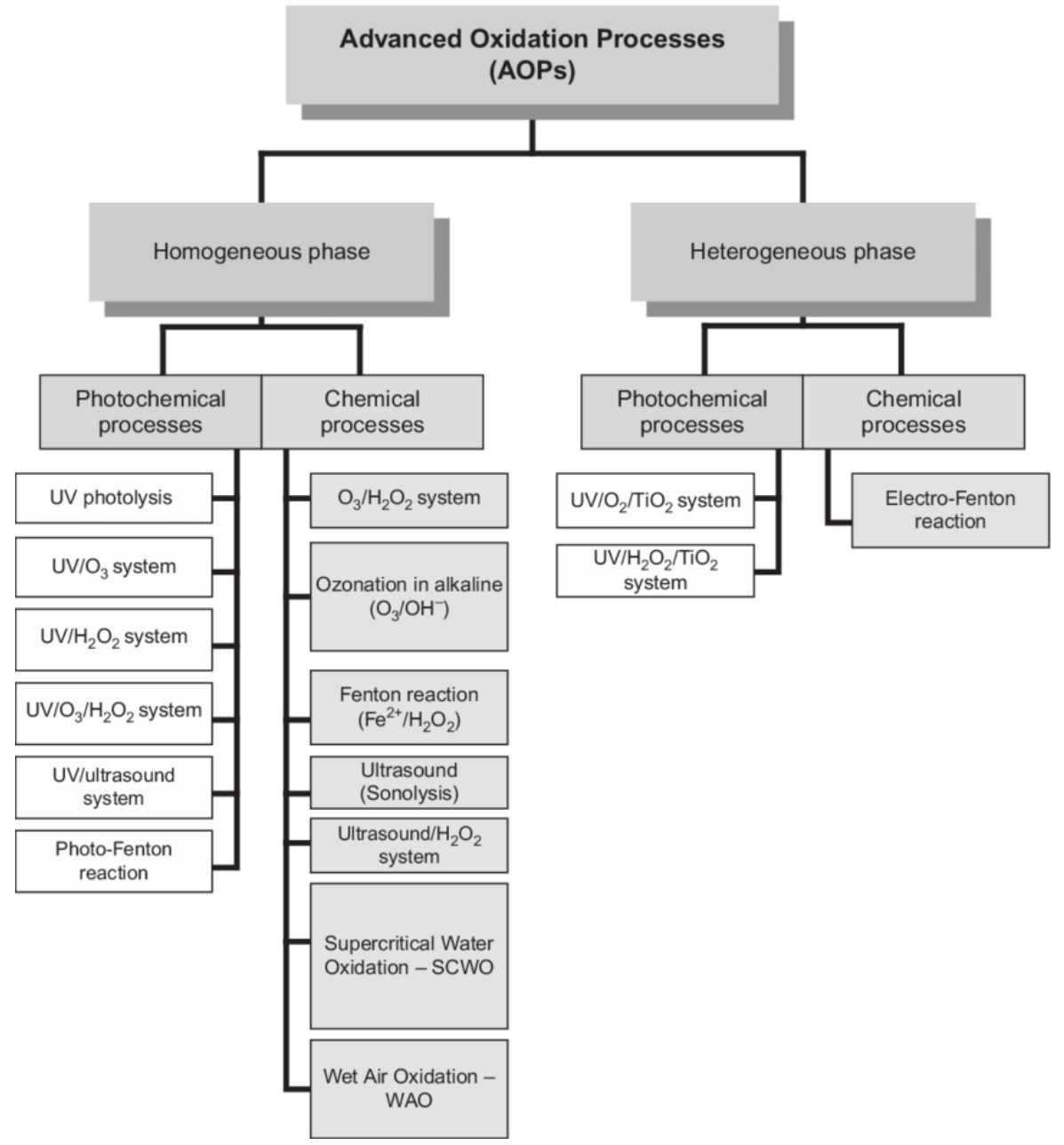

Figura 8. Tipos de processos oxidativos avançados. FONTE: BIN; SOBERA-MADEJ, 2012. 


\subsection{1}

\section{Fotólise $\mathrm{UV} / \mathrm{H}_{2} \mathrm{O}_{2}$}

Método mais aplicado comercialmente, a fotólise do peróxido de hidrogênio, utilizando radiação UV, gera radicais hidroxila a partir da quebra do $\mathrm{H}_{2} \mathrm{O}_{2}$, como descreve a equação 1 :

$$
\mathrm{H}_{2} \mathrm{O}_{2} \stackrel{U V}{\rightarrow} 2 \cdot \mathrm{OH}
$$

O mecanismo de ação ocorre devido às lâmpadas de baixa e média pressão de mercúrio, que emitem radiação ultravioleta, operarem em uma faixa de 250-400 nm. Essa radiação é capaz de fazer a cisão nas ligações $\mathrm{O}-\mathrm{O}$ do peróxido de hidrogênio, gerando os radicais hidroxila (ROCHA, 2017). Geralmente a radiação UV é dividida em UV-A, UV-B e UV-C, considerando as faixas de emissão da seguinte forma (Figura 9):

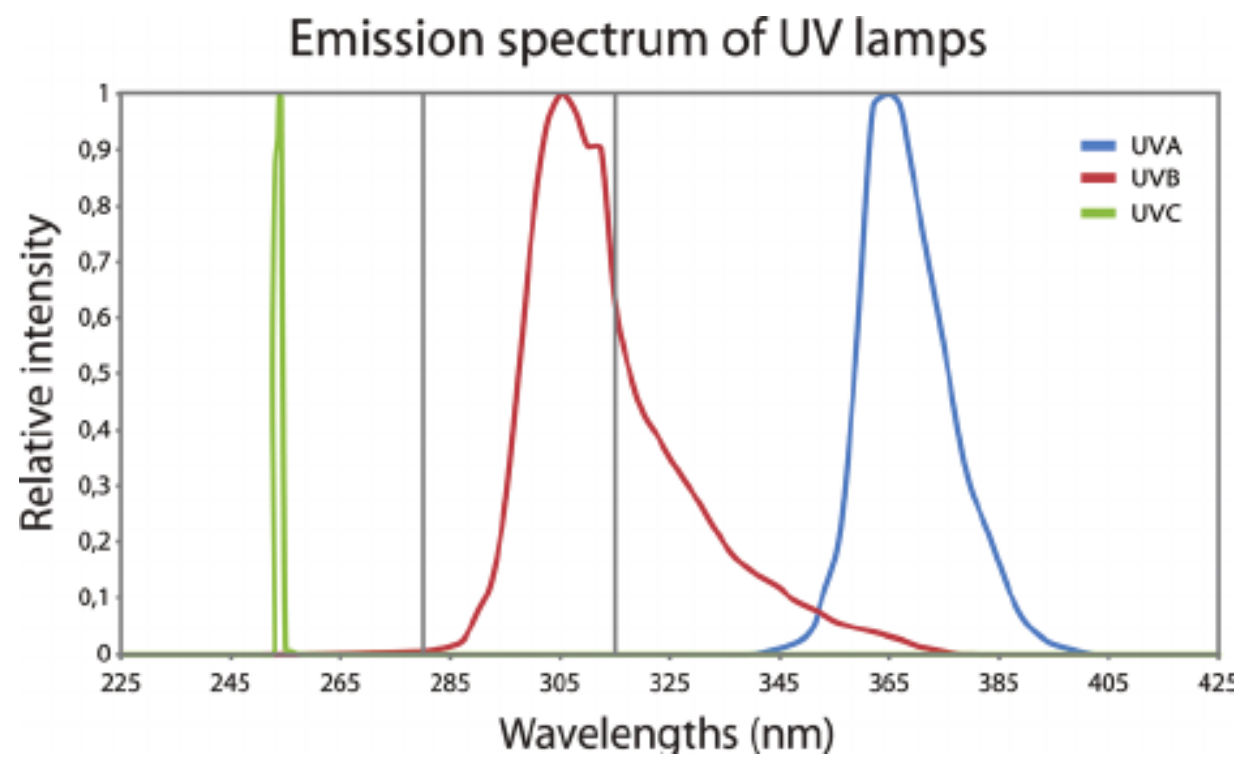

Figura 9. Comprimentos de onda característicos de lâmpadas de baixa pressão. FONTE: MALLET; ROCHETTE, 2013.

A radiação UVA não é indicada para esse tipo de procedimento devido ao fato de na faixa que atinge seu comprimento de onda não ocorrer a absorção da energia emitida pela ligação O-O. Com isso, não há a formação dos radicais hidroxila. Diferentemente do que ocorre com a radiação UVC, que tem comprimentos de onda mais baixos, consequentemente mais energia para quebrar a 
ligação, gerando mais radicais disponíveis para o ataque das moléculas recalcitrantes (U.S. EPA, 1998).

Como alternativa às lâmpadas de mercúrio, pode-se usar lâmpadas de xenônio, que atingem comprimentos de ondas na faixa de 210-240 nm. A ligação O-O tem seu ponto máximo de absorbância em $220 \mathrm{~nm}$, o que tornaria o processo ainda mais eficiente. Entretanto, é necessário fazer uma análise econômica do uso desta ferramenta, pois o custo da lâmpada de xenônio é bem mais elevado do que a tradicional de mercúrio (NASCIMENTO; BARROS; ABDALA, 2017).

Outro ponto importante de se destacar é que o próprio peróxido de hidrogênio atua como sequestrador de radicais hidroxila, com isso gerando radicais hidroperoxila, que são menos potentes do que os $\cdot \mathrm{OH}$ e que também os consome para retornar ao estado de $\mathrm{H}_{2} \mathrm{O}_{2}$. Então, a dosagem de peróxido de hidrogênio necessária para o ataque à molécula recalcitrante em questão deve ser bem controlada para obtenção da maior eficiência possível do processo (ROCHA, 2017).

Algumas condições são capazes de influenciar na eficiência do processo de fotólise do $\mathrm{H}_{2} \mathrm{O}_{2}$, tais como $\mathrm{pH}$, presença de sequestradores de radicais, temperatura, cor, turbidez, outros oxidantes e a estrutura químicas dos próprios contaminantes a serem degradados (NASCIMENTO; BARROS; ABDALA, 2017).

\section{5 .2}

\section{Processo Fenton}

A reação de Fenton foi descoberta em 1894 pelo pesquisador Henry John Fenton que, em estudo publicado, descreveu como os íons ferrosos $\left(\mathrm{Fe}^{2+}\right)$ na presença de agentes oxidantes aumentavam sua capacidade de degradação. Entretanto, atualmente, toma-se como reação de Fenton a formação de radicais hidroxila a partir do peróxido de hidrogênio, catalisado com íons ferrosos, tal como na equação 2 (BARBUSIŃSKI, 2009). Apesar de ter sido descoberta no século XIX, a reação de Fenton só começou a ser estudada realmente como meio de oxidação de compostos orgânicos quarenta anos depois (NOGUEIRA et al., 2007).

$$
\mathrm{H}_{2} \mathrm{O}_{2}+\mathrm{Fe}^{2+} \rightarrow \cdot \mathrm{OH}+\mathrm{Fe}^{3+}+\mathrm{OH}^{-}
$$


Conforme Teixeira e Jardim (2004), as utilizações da reação de Fenton vão desde a degradação de clorofenóis, surfactantes, lixiviados e corantes até a redução de recalcitrância de compostos orgânicos mais complexos. Outro fato relevante é que o $\mathrm{pH}$ cumpre um papel muito importante nos sistemas de Fenton. Isso por conta da forma em que o Fe se encontra disponível em cada faixa, de acordo com o diagrama de Pourbaix (Figura 10). Em meio ácido, aumenta-se a disponibilidade de íons ferrosos $\left(\mathrm{Fe}^{2+}\right)$ para catalisar a reação. Em caso de maior presença de íons férricos $\left(\mathrm{Fe}^{3+}\right)$, há a decomposição do peróxido de hidrogênio em radicais hidroperoxila (equações 3-4), o que torna a reação menos potente e, consequentemente, menos eficiente (ROCHA, 2017).

$$
\begin{aligned}
& \mathrm{Fe}^{3+}+\mathrm{H}_{2} \mathrm{O}_{2} \rightarrow \mathrm{FeOOH}^{2+}+\mathrm{H}^{+} \\
& \mathrm{FeOOH}{ }^{2+}+\mathrm{H}^{+} \rightarrow \mathrm{Fe}^{2+}+\mathrm{HO}_{2} .
\end{aligned}
$$

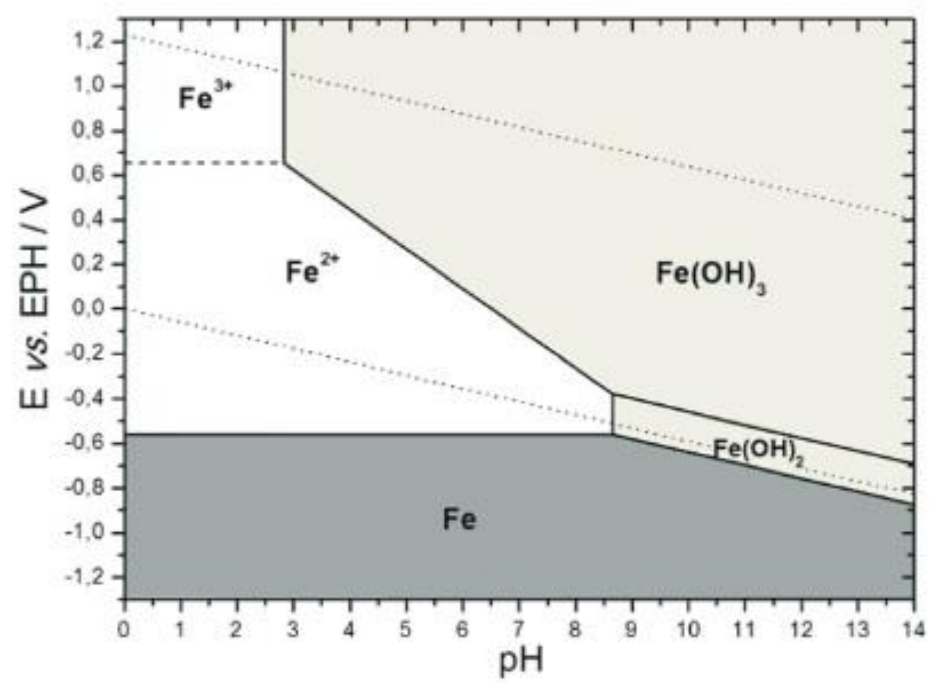

Figura 10. Diagrama de Pourbaix para o sistema $\mathrm{Fe}-\mathrm{H}_{2} \mathrm{O}$ a 25ㅇ. FONTE: OLIVEIRA et al., 2018.

Uma das vantagens do uso do processo Fenton é a sua fácil operacionalidade, sem presença de radiação, a temperatura ambiente e a pressão atmosférica. Por outro lado, é necessária atenção à quantidade de lodo gerada devido à possível coagulação promovida pelos sais de ferro formados na hidrólise. O uso de polímeros na etapa de coagulação química de um possível sistema de tratamento convencional pode ser benéfico. Além do natural cuidado que se deve 
ter ao associar a geração de radicais hidroxila a sistemas biológicos (TEIXEIRA e JARDIM, 2004).

\section{5 .3}

\section{Processo Foto-Fenton}

Se o uso de cada uma das duas técnicas apresentadas anteriormente é capaz de remover boa parte dos contaminantes, a associação entre elas tornou-se uma opção lógica e viável. Além do papel que cada uma cumpre, há um efeito sinérgico na aplicação simultânea. O processo Foto-Fenton combina a radiação com a reação de Fenton. Há 3 pontos chaves para entender como esse procedimento ocorre (U.S. EPA, 1998):

A. Fotorredução do $\mathrm{Fe}^{3+} a \mathrm{Fe}^{2+}-\mathrm{A}$ presença da radiação possibilita a redução do $\mathrm{Fe}^{3+}$ a $\mathrm{Fe}^{2+}$ e gera um radical hidroxila adicional, a partir da equação 5. A abundância de íons ferrosos aumenta a produção de radicais hidroxila em detrimento da produção de radicais hidroperoxila provenientes de uma catálise com íons férricos.

$$
\mathrm{Fe}(\mathrm{OH})^{2+}+h v \rightarrow \mathrm{Fe}^{2+}+\cdot \mathrm{OH}
$$

B. Foto-descarboxilação dos complexos de carboxilato férrico - Os íons férricos formam complexos com carboxilatos/policarboxilatos durante o processo Foto-Fenton, que são fotoquimicamente ativos e geram $\mathrm{Fe}^{2+}$ apropriados para a geração de radicais hidroxila, de acordo com a equação 6.

$$
\mathrm{Fe}(\mathrm{III})\left(\mathrm{RCO}_{2}\right)^{2+}+\mathrm{hv} \rightarrow \mathrm{Fe}^{2+}+\mathrm{CO}+\mathrm{R}
$$

$\mathrm{O}$ radical $\mathrm{R} \cdot$ gerado pode reagir com o oxigênio dissolvido e degradar posteriormente.

C. Fotólise do $\mathrm{H}_{2} \mathrm{O}_{2}$ - Pode ocorrer a fotólise direta do peróxido de hidrogênio em radicais hidroxila. Entretanto, este efeito é o menos considerado por duas razões: uma porque boa parte dos efluentes tem alta absorbância em regiões abaixo de $300 \mathrm{~nm}$, o que cria uma competição junto ao $\mathrm{H}_{2} \mathrm{O}_{2}$ para geração de radicais hidroxila. $\mathrm{O}$ outro fator deve-se aos complexos férricos 
absorverem grande parte da radiação, fazendo com que a fotólise tenha um papel mínimo no processo Foto-Fenton.

Assim como no processo Fenton, o pH mais uma vez cumpre um papel importante na disponibilidade de íons ferrosos $\left(\mathrm{Fe}^{2+}\right)$ e consequentemente na velocidade da degradação. Trata-se a faixa ideal de $\mathrm{pH}$ entre 2,5 - 3,0, com o limite de cima em função da solubilidade do Fe e o limite inferior pelo sequestro do radical hidroxila para protonação $\left(\mathrm{H}^{+}\right)$que termina na geração de $\mathrm{H}_{2} \mathrm{O}$ (NOGUEIRA et al., 2007).

Outra melhoria de processo que pode ser aplicada é a utilização de radiação natural solar como fonte UV. A radiação solar chega à atmosfera da Terra combinando todas as faixas: UVA/UVB/UVC. Entretanto, a radiação UVC é retida imediatamente pela camada de ozônio existente. Logo, as faixas que chegam à superfície são UVA e UVB (260-400 nm). É comum encontrar a comercialização de protetores e bloqueadores solar que amenizam os efeitos destas faixas de radiação e não contemplam a UVC. Como o uso desta última é mais restrito, é necessária a utilização de equipamentos de proteção individual (EPI) para o seu manuseio. Roupas, óculos e viseiras são necessários para o trabalho com radiação UVC, já que sua intensidade de radiação é maior devido ao comprimento de onda ser menor.

\section{5 .4}

\section{Sistema $\mathrm{H}_{2} \mathrm{O}_{2} /$ Óxidos de Ferro}

$\mathrm{O}$ Sistema $\mathrm{H}_{2} \mathrm{O}_{2} /$ Óxidos de Ferro trata de dar um toque heterogêneo à Reação de Fenton, sendo os óxidos de ferro a fonte do catalisador. Normalmente os processos Fenton homogêneos usam sais de ferro como fonte de catalisador. A facilidade de operação e o reuso de materiais geralmente tratados como resíduos são algumas das vantagens deste método. Em contrapartida, a geração de lodo, principalmente de precipitados de sais e hidróxidos de ferro, é algo que ainda precisa ser otimizada (ROCHA, 2017).

$\mathrm{O} \mathrm{H}_{2} \mathrm{O}_{2} /$ Óxidos de Ferro têm como fundamento a reação de Fenton. Entretanto, como os óxidos se apresentam no estado sólido é necessário que haja uma forma de dispor os íons de ferro em meio aquoso para que a reação seja 
processada. O fato da maior parte dos óxidos de ferro apresentarem o ferro no estado de oxidação 3+ é um inconveniente para o processo e a disponibilidade dos íons ferrosos é intrinsecamente dependente do $\mathrm{pH}$ para óxidos caracterizados com $\mathrm{Fe}^{3+}$, como já foi mostrado no diagrama de Pourbaix (Figura 10). Em óxidos cujos íons apresentam o ferro em estado de oxidação $2+$, essa modificação ao pH não se faz necessária. Outra característica do Fenton heterogêneo é que a catálise idealmente ocorreria na superfície do óxido e não na suspensão da solução (OLIVEIRA; FABRIS; PEREIRA, 2013), entretanto, o que estudos mais recentes revelaram é que a fonte de ferro heterogênea libera ferro para a solução e esse então atua conforme o Fenton homogêneo convencional. As equações 7, 8 e 9 mostram o caminho do óxido até os íons.

$$
\begin{gathered}
\mathrm{Fe}_{3} \mathrm{O}_{4}+4 \mathrm{H}_{2} \mathrm{O} \rightarrow \mathrm{Fe}(\mathrm{OH})_{2}+2 \mathrm{Fe}(\mathrm{OH})_{3} \\
\mathrm{Fe}(\mathrm{OH})_{2} \stackrel{\mathrm{H}^{+}}{\rightarrow} \mathrm{Fe}^{2+}+2 \mathrm{OH}^{-} \\
\mathrm{Fe}(\mathrm{OH})_{3} \stackrel{\mathrm{H}^{+}}{\rightarrow} \mathrm{Fe}^{3+}+3 \mathrm{OH}^{-}
\end{gathered}
$$

\section{6}

\section{Planejamento fatorial e análise de variância}

O planejamento fatorial de experimentos é uma ferramenta estatística de máxima importância, pois ele permite avaliar simultaneamente o efeito de um grande número de variáveis, a partir de um número reduzido de ensaios experimentais, quando comparados aos processos univariados (BARROS NETO et al., 2002; PERALTA-ZAMORA et al., 2005).

Alguns conceitos importantes, a seguir descritos, são necessários para o entendimento do planejamento fatorial (CUNICO et al., 2008).

- $\quad$ Fator: cada variável do sistema em estudo. No caso deste trabalho, os fatores são a concentração do peróxido de hidrogênio e a concentração dos íons ferrosos;

- $\quad$ Nível: condição operacional dos fatores, ou seja, o valor das concentrações do oxidante e do catalisador e o tipo de incidência da radiação UV, em níveis minorados (-1), intermediários (0) e majorados (+1); 
- Modelo estatístico: modelo matemático oriundo do método de ajuste por mínimos quadrados, que correlaciona os fatores isoladamente $\left(x_{1}\right.$ e $\left.x_{2}\right)$, ou entre si $\left(x_{1} x_{2}\right)$, em equações lineares, quadráticas, cúbicas etc., e quantifica a sua variável de resposta $(a)$, que no caso do planejamento fatorial desenvolvido nesta pesquisa foi a redução percentual da concentração de clonazepam;

- $\quad$ Efeito: qualquer mudança ocorrida na resposta $(a)$ em função de uma mudança de nível.

O modelo estatístico presente neste trabalho será um modelo quadrático, considerando as interações entre os fatores, do tipo (Equação 10):

$$
a=b_{0}+b_{1} x_{1}+b_{2} x_{2}+b_{3} x_{1}{ }^{2}+b_{4} x_{2}{ }^{2}+b_{5} x_{1} x_{2}
$$

Sendo estes coeficientes ( $b_{0}$ a $b_{5}$ ) determinados pelo método de ajuste dos mínimos quadrados (95\% de confiança) por uso do software Statistica 10.

O método dos mínimos quadrados consiste em diminuir ao máximo a diferença existente entre os valores experimentais obtidos $\left(a_{i}\right)$ e os valores preditos pelo modelo matemático $\left(\hat{a}_{i}\right)$, tornando mínimo o resíduo $\left(e_{i}\right)$, ou seja, a diferença entre o valor observado e o valor predito $\left(e_{i}=a_{i}-\hat{a}_{i}\right)$.

Além de calcular os coeficientes da equação do modelo estatístico, pode-se realizar um estudo dos efeitos provocados pelos fatores na variável resposta. Para isto, pode-se obter um gráfico de Pareto, que indicará quantitativamente esta influência das variáveis. O software Statistica 10 também pode ser usado para concretizar este estudo.

A análise de variância (ANOVA) é uma ferramenta que permite avaliar a qualidade do ajuste de um determinado modelo aos resultados observados.

Para o estudo sobre a análise de variância, alguns conceitos sobre soma quadrática são importantes.

O primeiro é a soma quadrática devido à regressão $\left(S Q_{R}\right)$, que relaciona os valores preditos pelo modelo $\left(\hat{a}_{i}\right)$ e a média global de todos os resultados experimentais $(\bar{a})$, conforme descreve a Equação 11 .

$$
S Q_{R}=\sum_{i}^{m} \sum_{j}^{n_{i}}\left(\hat{a}_{i}-\bar{a}\right)^{2}
$$


O segundo é a soma quadrática devido aos resíduos $\left(S Q_{r}\right)$, que relaciona os valores experimentais $\left(a_{i j}\right)$, no $i$ ésimo nível com a $j$ ésima repetição, e os preditos pelo modelo $\left(\hat{a}_{i}\right)$, conforme descreve a Equação 12.

$$
S Q_{r}=\sum_{i}^{m} \sum_{j}^{n_{i}}\left(a_{i j}-\hat{a}_{i}\right)^{2}
$$

O terceiro conceito é a soma quadrática devido à falta de ajuste ( $\left.S Q_{f a j}\right)$, que relaciona os valores preditos pelo modelo $\left(\hat{a}_{i}\right)$ e a média experimental no $i$ ésimo nível $\left(\bar{a}_{i}\right)$, ou seja, no ponto de estudo, conforme descreve a Equação 13.

$$
S Q_{f a j}=\sum_{i}^{m} \sum_{j}^{n_{i}}\left(\hat{a}_{i}-\bar{a}_{i}\right)^{2}
$$

Finalmente, o último conceito é a soma quadrática devido à falta do erro puro $\left(S Q_{e p}\right)$, que relaciona os valores experimentais $\left(a_{i j}\right)$, no $i$ ésimo nível com a $j$ ésima repetição, e a média experimental no $i$ ésimo nível $\left(\bar{a}_{i}\right)$, conforme descreve a Equação 14.

$$
S Q_{e p}=\sum_{i}^{m} \sum_{j}^{n_{i}}\left(a_{i j}-\bar{a}_{i}\right)^{2}
$$

Calcula-se o percentual de variação explicada, que é o valor percentual do ajuste do modelo, sendo este representado pelo quociente $S Q_{R} /\left(S Q_{R}+S Q_{r}\right)$. Também se calcula o percentual de máxima variação explicável, que é o valor percentual máximo que poderia ter sido obtido, sendo este representado pelo quociente $\left(S Q_{R}+S Q_{r}-S Q_{e p}\right) /\left(S Q_{R}+S Q_{r}\right)$.

\section{7}

\section{Modelo cinético oxidativo}

Da cinética homogênea clássica decorre que em uma reação contendo dois reagentes $\mathrm{A}$ e $\mathrm{B}$, neste caso $[\mathrm{CZP}]$ e $\left[\mathrm{H}_{2} \mathrm{O}_{2}\right]$, respectivamente, a taxa de reação química, $\mathrm{r}_{\mathrm{A}}$, é dada de maneira semiempírica pela Equação 15. Em que $n$ e $m$ são as ordens aparentes da reação em respeito aos compostos A e B, respectivamente.

$$
r_{A}=\frac{d[C Z P]}{d t}=-k^{\prime}[C Z P]^{n}\left[H_{2} O_{2}\right]^{m}
$$

Considerando de maneira simplificada o excesso de peróxido de hidrogênio no início da reação, o termo $\left[\mathrm{H}_{2} \mathrm{O}_{2}\right]^{m}$ pode ser incorporado à constante de velocidade $\left(k^{\prime}\right)$, e o modelo torna-se, comumente, de primeira ordem, $\mathrm{n}=1$, de 
segunda ordem, $\mathrm{n}=2$, ou de uma ordem $n$ determinada, conforme apresentam as Equações 16, 17 e 18.

$$
\begin{gathered}
\frac{d[C Z P]}{d t}=-k[C Z P]^{1} \rightarrow[C Z P]=[C Z P]_{0} e^{-k t} \\
\frac{d[C Z P]}{d t}=-k[C Z P]^{2} \rightarrow \frac{1}{[C Z P]}=\frac{1}{[C Z P]_{0}}+k t \\
\frac{d[C Z P]}{d t}=-k[C Z P]^{n} \rightarrow[C Z P]=\left[C Z P_{0}^{(-n+1)}+(-n+1)(-k t)\right]^{\frac{1}{(-n+1)}}
\end{gathered}
$$

Estas três últimas equações foram correlacionadas com modelos prédeterminados pelo software OriginPro 8, para determinação da ordem aparente e da constante de velocidade. 


\section{Materiais e métodos}

O capítulo subsequente discorrerá sobre os materiais utilizados, tais como reagentes, equipamentos, e os métodos realizados para a confecção deste trabalho.

\section{1}

\section{Preparação do efluente simulado}

Soluções de 3 L de água ultrapura padrão Mili-Q (Figura 11) adicionadas a $15 \mathrm{mg}$ de clonazepam adquirido junto à Farmácia de Manipulação Roval com pureza de 99\%. As soluções eram agitadas durante 4 horas em um agitador mecânico de hélice naval acoplado a um Banho Maria QUIMIS ${ }^{\circledR}$ (Figura 12) que foi mantido em temperatura ambiente (aproximadamente $25^{\circ} \mathrm{C}$ ) e depois filtradas em um papel de filtro faixa branca (Figura 13) que fora pesado anteriormente enquanto seco em uma balança de precisão analítica Mettler Toledo (Figura 14). Com isso, obteve-se uma concentração de 4,2 mg. $\mathrm{L}^{-1}$ de CZP em cada solução.

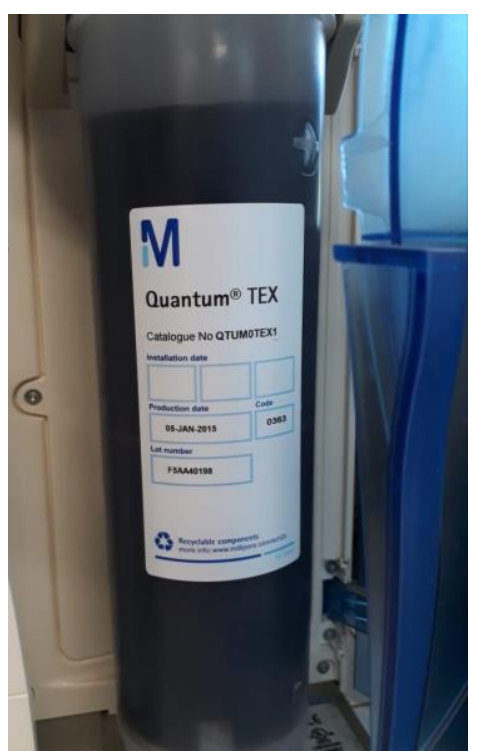

(11)

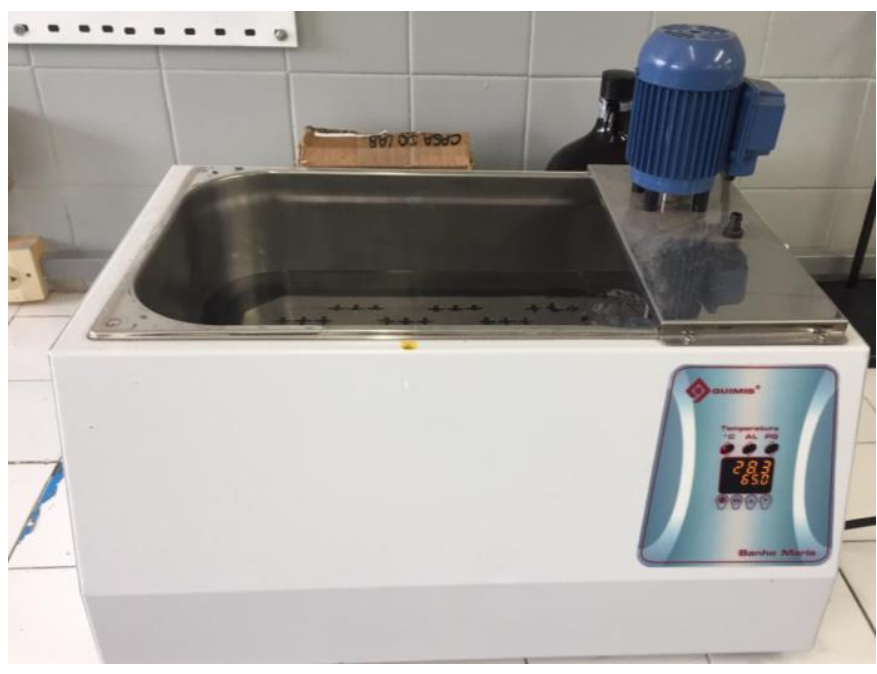

(12)

Figuras 11 e 12. Cartucho de água ultrapura e Banho Maria QUIMIS ${ }^{\circledR}$ 


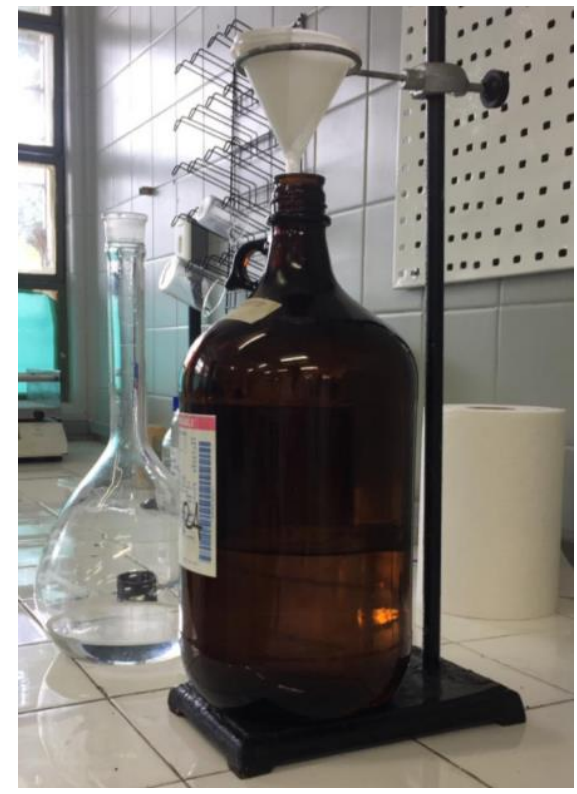

(13)

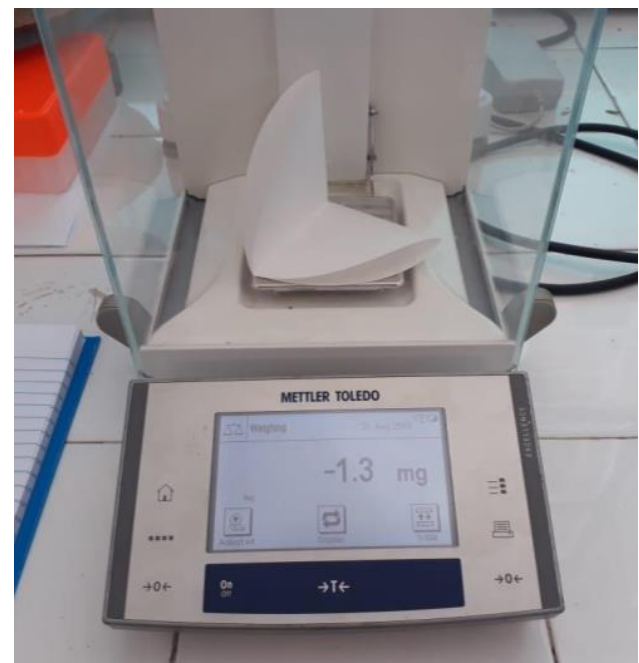

(14)

Figuras 13 e 14. Filtração da solução de CZP e Balança Analítica Metter Toledo

Após preparadas as soluções, elas foram condicionadas em frascos âmbar para evitar qualquer efeito de luz solar ou artificial.

\section{2}

\section{Curva analítica}

Com a solução estoque preparada, foi feita uma curva analítica para o método de análise em cromatografia líquida de alta eficiência (CLAE ou, do inglês, HPLC). Foram feitas sucessivas diluições da solução com água ultrapura em balões volumétricos de $50 \mathrm{~mL}$ para avaliar se o equipamento utilizado tinha a sensibilidade correta. A Tabela 4 mostra as diluições feitas.

Tabela 4. Diluições para construção da curva analítica

\begin{tabular}{cccc}
\hline Diluição & $\begin{array}{c}\text { Solução Estoque } \\
(\mathbf{m L})\end{array}$ & $\begin{array}{c}\text { Água ultrapura } \\
(\mathbf{m L})\end{array}$ & $\begin{array}{c}\text { Concentração Final } \\
\left(\mathbf{m g . L ^ { - 1 }}\right)\end{array}$ \\
\hline 10 & 10 & 40 & 0,84 \\
20 & 20 & 30 & 1,68
\end{tabular}


30

40

50
40

50
20

10

0
2,52

3,36

4,20

O cromatógrafo utilizado para análise é composto de uma válvula injetora onde se colocava a amostra a ser analisada a partir de uma agulha específica da marca Hamilton para HPLC. Esta válvula opera em duas posições: uma com a passagem apenas da fase móvel, outra com eluição da amostra na fase móvel. Uma bomba GC480-E HPLC da marca CG Instrumentos Científicos que operou em uma vazão de $0,8 \mathrm{~mL} \cdot \mathrm{min}^{-1}$ da amostra eluída em fase móvel composta de metanol/água em razão 7:3. Essa mistura foi bombeada para uma coluna C-18 Phenomenex Luna de fase reversa com dimensões de $250 \mathrm{~mm}$ de comprimento x 4,60 $\mathrm{mm}$ de diâmetro interno e $5 \mu \mathrm{m}$ de espessura da fase estacionária. A coluna foi mantida em um controlador de temperatura Phenomenex Thermasphere TS- 130 a $40^{\circ} \mathrm{C}$ para evitar influência de possíveis oscilações da temperatura ambiente durante a análise. Após a separação dentro da coluna, a amostra foi enviada para um detector UV HP 1050 de arranjo de diodos com varredura espectral que quantificou a presença do CZP nas soluções previamente preparadas. O comprimento de onda característico da substância de interesse foi de $254 \mathrm{~nm}$. O sinal analítico era enviado para um conversor de sinal que transformava este em dados para um computador acoplado ao equipamento. A Figura 15 mostra o equipamento detalhado acima. 


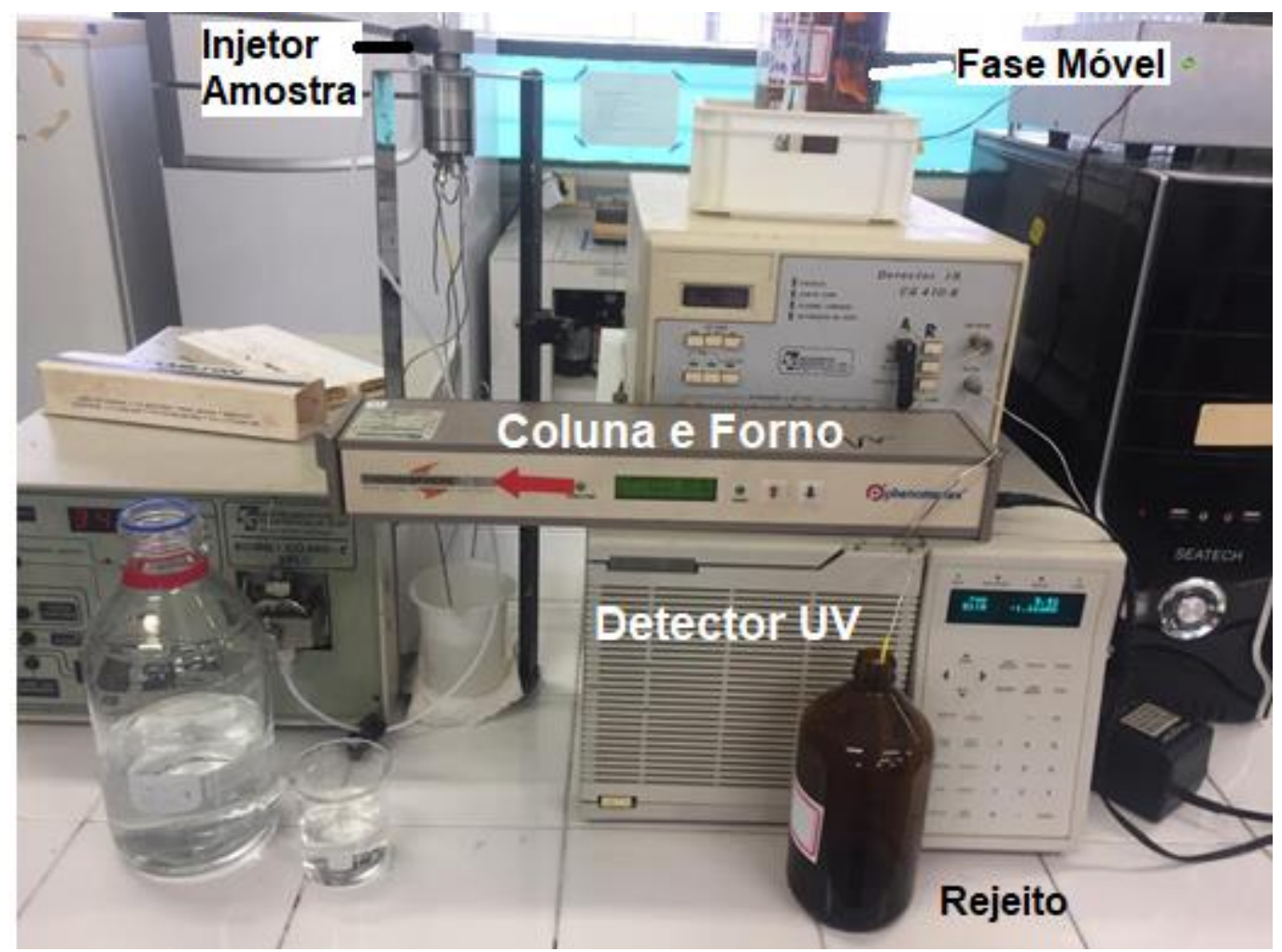

Figura 15. Cromatógrafo líquido de alta precisão

\section{3}

\section{Preparação das soluções a serem degradadas}

Para as soluções degradadas por meio dos métodos de fotólise e foto-Fenton foram utilizadas soluções com volume total de $50 \mathrm{~mL}$, sendo seu conteúdo variado de acordo com o planejamento experimental e o método usado. O efluente simulado sempre se aproximou da concentração de 4,20 mg.L $\mathrm{L}^{-1}$ de CZP. Os parâmetros que compunham as amostras e que variaram foram a concentração de peróxido de hidrogênio e a concentração de íons ferrosos/ferro zero.

A solução utilizada de peróxido de hidrogênio foi preparada semanalmente a partir de uma solução estoque de $30 \%$ v/v, que foi padronizada a partir da titulação com permanganato de potássio, contendo, aproximadamente, 8,47 mols de $\mathrm{H}_{2} \mathrm{O}_{2} \mathrm{e}$ diluída de 1:1000, sendo assim, com conteúdo final de $8,47 \mathrm{mmol}$. L $\mathrm{L}^{-1}$ ou $288 \mathrm{mg}$. $\mathrm{L}^{-1}$. Esta concentração foi definida de forma subestequiométrica, pois testes com a concentração estequiométrica mostraram uma velocidade de reação, demasiadamente rápida, incompatível com o estudo cinético. Outra consideração é 
o fato do estudo focar em mineralizar de forma parcial/total o fármaco, não sendo necessário a dose estequiométrica do oxidante. Tanto a solução estoque quanto as soluções preparadas foram acondicionadas em local refrigerado para minimizar as possíveis alterações sofridas em temperatura ambiente, tal qual a degradação do peróxido de hidrogênio em $\mathrm{H}_{2} \mathrm{O}$ ou íons hidroxila. A quantidade de peróxido de hidrogênio utilizada foi determinada a partir da quantidade estequiométrica. Para os experimentos ocorridos dentro do reator fotocatalítico e no experimento solar, foram utilizadas as concentrações de peróxido foram $1,15 \mathrm{mg} . \mathrm{L}^{-1}, 2,02 \mathrm{mg}$. $\mathrm{L}^{-1} \mathrm{e}$ 2,88 mg. $\mathrm{L}^{-1}$. No $\mathrm{H}_{2} \mathrm{O}_{2} /$ Óxidos de Ferro, as concentrações de $\mathrm{H}_{2} \mathrm{O}_{2}$ aplicadas foram 1,44 mg. L $\mathrm{L}^{-1}, 2,88 \mathrm{mg}$. $\mathrm{L}^{-1}$ e $4,32 \mathrm{mg}$. $\mathrm{L}^{-1}$.

Uma solução de íon ferroso foi preparada a partir de uma solução estoque de sulfato ferroso hepta-hidratado $\left(\mathrm{FeSO}_{4} .7 \mathrm{H}_{2} \mathrm{O}\right) 750 \mathrm{mg}$. L ${ }^{-1}$. Esta solução estoque foi utilizada para preparação de efluentes com $15 \mathrm{mg}$. L $\mathrm{L}^{-1}$ (limite da Resolução CONAMA No 430/2011). A solução preparada foi diluída em 1:50, finalizando 0,3 mg. $\mathrm{L}^{-1}$ no efluente simulado (limite da Portaria de Consolidação $\mathrm{N}^{\circ}$ 5/2017 do Ministério da Saúde). O volume utilizado para cada amostra também foi de $1 \mathrm{~mL}$. No ponto central, utilizou-se metade do volume determinado para a condição 15 mg. $\mathrm{L}^{-1}(0,51 \mathrm{~mL})$ da solução estoque.

No experimento $\mathrm{H}_{2} \mathrm{O}_{2}$ /Óxidos de Ferro, foi utilizada lã de aço como fonte de catalisador para a reação ocorrer. A lã de aço de marca comercial tem em sua composição apenas aço-carbono. Então queimou-se a palha de aço na presença de dióxido de carbono e do carbono presente no aço (Equação 1) para gerar uma atmosfera mais redutora $(\mathrm{CO})$ e obter um óxido mais finamente dividido (Figura 16 e 17). Foi feita análise de BET e DRX como forma de caracterizar o catalisador.

$$
\mathrm{CO}_{2(g)}+C_{(s)} \rightarrow 2 \mathrm{CO}_{(g)}
$$




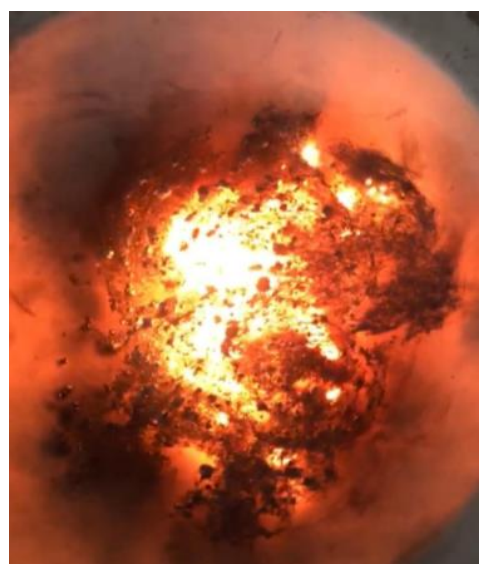

(16)

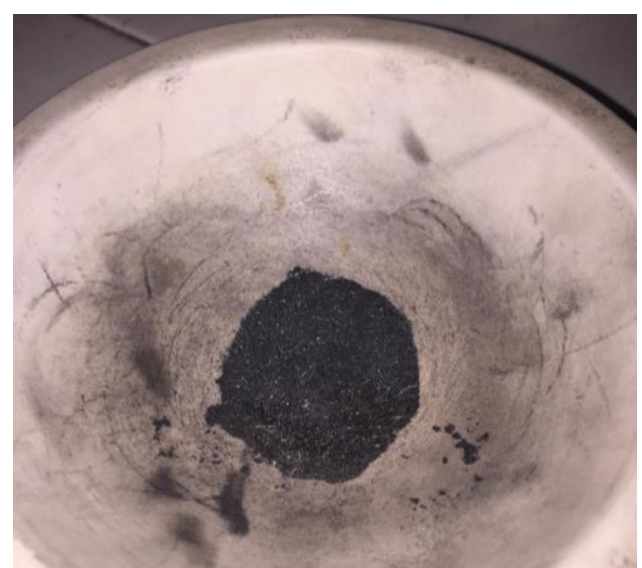

(17)

\section{Figuras 16 e 17. Palha de aço queimando em atmosfera redutora e óxido finamente dividido}

Um reator fotocatalítico composto de uma caixa vedada com suporte para 2 lâmpadas de radiação UV com papel laminado em suas paredes e um espelho na sua base para aproveitar toda intensidade de cada uma das fontes foi utilizado para avaliação da radiação artificial (Figura 18). Tanto as lâmpadas UVA quanto as lâmpadas UVC tinham potência nominal de $8 \mathrm{~W}$ e foram medidas, com o auxílio de dois medidores de ultravioleta: um o INSTRUTHERM MRU-201 com resposta espectral de 290 a $390 \mathrm{~nm}$ para lâmpadas UVA e UVB e outro o EMPORIONET UVC-254 com resposta espectral em $254 \mathrm{~nm}$ para lâmpadas UVC. As intensidades de cada uma delas, respectivamente, tendo a lâmpada UVA $217 \mu \mathrm{W} . \mathrm{cm}^{-2}$ e a lâmpada UVC $1049 \mu \mathrm{W} . \mathrm{cm}^{-2}$. Vale ressaltar que um par de lâmpadas de cada tipo (UVA e UVC) foi utilizado separadamente para os experimentos especificados. A intensidade de radiação solar total e TURV (que mede apenas a radiação UVA + UVB) foi feita a partir de uma média dos dias em que os experimentos foram conduzidos, utilizando dados do piranômetro da EPPLEY PSP com resposta espectral entre 285 e $2800 \mathrm{~nm}$ pertencente ao DEN-UFPE (Departamento de Engenharia Nuclear da Universidade Federal de Pernambuco) como referência (Tabela 5). O reator ainda possui um suporte para apoiar até 3 tubos de quartzo que contêm a amostra em questão e que foram utilizados para a degradação devido ao fato de o vidro absorver boa parte da radiação UV emitida pelas lâmpadas. 


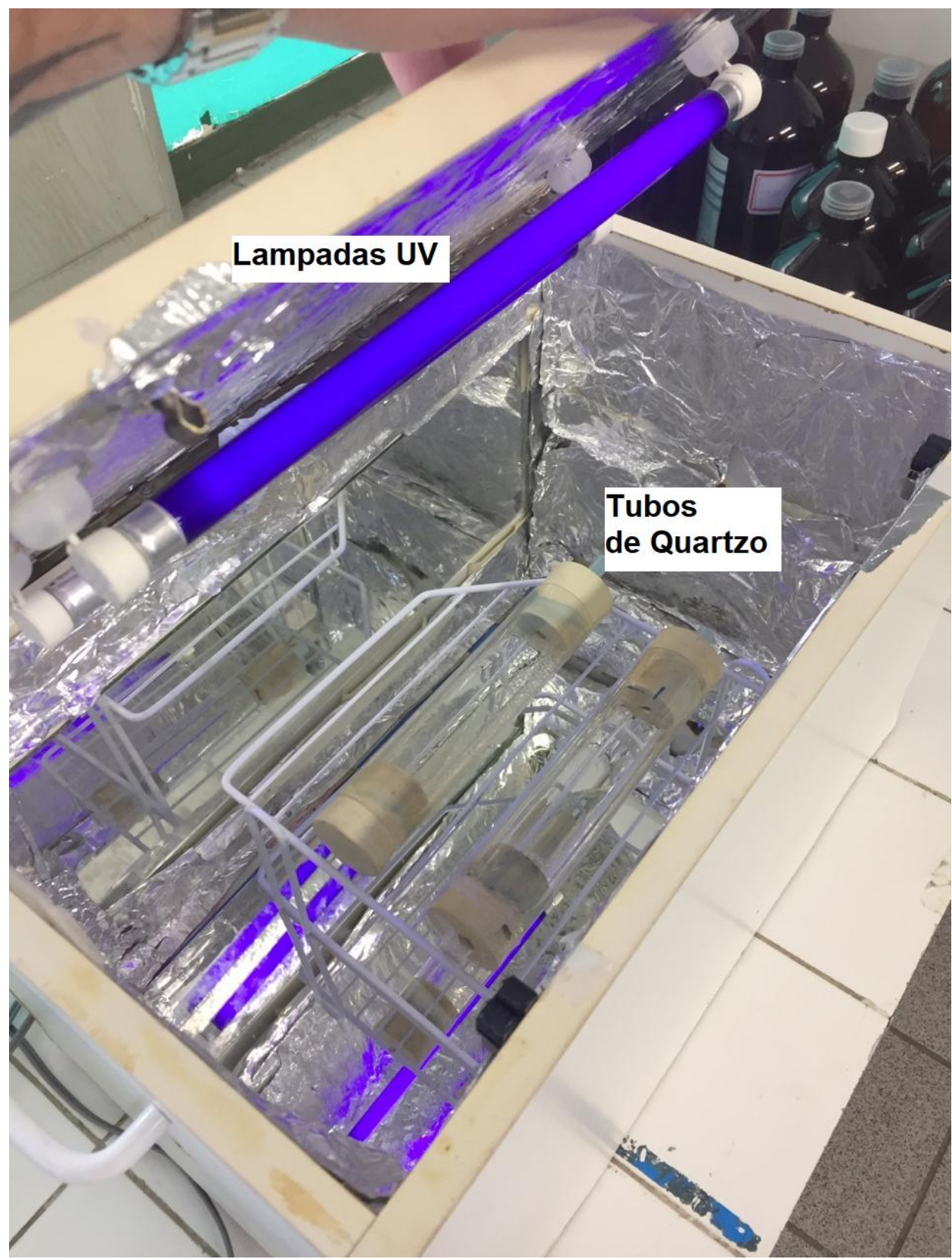

Figura 18. Reator fotocatalítico utilizado para degradação do CZP

Tabela 5. Intensidade de radiação solar

\begin{tabular}{ccc}
\hline Dias & Radiação total $\left(\boldsymbol{\mu W} \cdot \mathbf{c m}^{-2}\right)$ & Radiação TURV $\left(\boldsymbol{\mu W} \cdot \mathbf{c m}^{-2}\right)$ \\
\hline 15/mar & 80722 & 2224 \\
26/mar & 63638 & 1812 \\
02/abr & 89188 & 2415 \\
04/abr & 81394 & 2184 \\
05/abr & 77800 & 2124
\end{tabular}


08/abr $\quad 2076$

09/abr $\quad 69387 \quad 1900$

\subsection{1}

\section{Fotólise UVC}

A fotólise é um método que usa apenas a solução contendo o clonazepam $(\mathrm{pH}=5,4)$, o peróxido de hidrogênio e a radiação em questão para a degeneração da substância desejada dentro do reator fotocatalítico. O planejamento experimental para esse procedimento foi feito da seguinte forma (Tabela 6).

Tabela 6. Planejamento experimental para a fotólise UVC do CZP

\begin{tabular}{cc}
\hline Condição & Concentração $\mathbf{H}_{\mathbf{2}} \mathbf{O}_{\mathbf{2}}\left(\mathbf{m g}\right.$. $\left.\mathbf{L}^{\mathbf{- 1}}\right)$ \\
\hline-1 & 1,15 \\
0 & 2,02 \\
+1 & 2,88 \\
\hline
\end{tabular}

\subsection{2}

\section{Foto-Fenton UVA/UVC}

O método Foto-Fenton utiliza um incremento em relação ao método anteriormente descrito de fotólise: a adição do catalisador $\mathrm{Fe}^{2+}$ na reação do efluente simulado. Desta vez, além da radiação UVC, foi utilizada a radiação UVA. Para o peróxido de hidrogênio os volumes utilizados foram mantidos iguais. Para o planejamento experimental deste procedimento é considerada uma matriz $2^{2} \mathrm{com}$ um ponto central, de acordo com a Tabela 7. O pH é outra medida importante para a disponibilidade dos íons ferrosos em solução. Além disso, como o $\mathrm{Fe}^{2+}$ foi preparado a partir de uma solução ácida, essa tende a baixar o pH em concentrações maiores do íon em questão. 
Tabela 7. Planejamento experimental para Foto-Fenton UVA/UVC

\begin{tabular}{cccc}
\hline Condição & {$\left[\mathbf{H}_{2} \mathbf{O}_{2}\right]\left(\mathbf{m g} . \mathbf{L}^{-\mathbf{1}}\right)$} & {$\left[\mathbf{F e}^{\mathbf{2 +}}\right]\left(\mathbf{m g} . \mathbf{L}^{-\mathbf{1}}\right)$} & $\mathbf{p H}$ do efluente \\
\hline$-1 /-1$ & 1,15 & 0,30 & 4,50 \\
$-1 /+1$ & 1,15 & 15,00 & 4,00 \\
$+1 /-1$ & 2,88 & 0,30 & 4,50 \\
$+1 /+1$ & 2,88 & 15,00 & 4,00 \\
$0 / 0$ & 2,02 & 7,65 & 4,20 \\
\hline
\end{tabular}

\subsection{3}

\section{Foto-Fenton com Radiação UV Solar}

Além dos métodos utilizando radiação artificial de lâmpadas UV, fez-se o uso da radiação natural do sol para avaliar sua eficiência na degradação. O procedimento foi realizado fora do reator fotocatalítico, mas de forma análoga aos experimentos com lâmpadas UV, utilizou-se as mesmas quantidades de CZP, $\mathrm{H}_{2} \mathrm{O}_{2}$ e $\mathrm{Fe}^{2+}$ em tubos de quartzo (Figura 19).

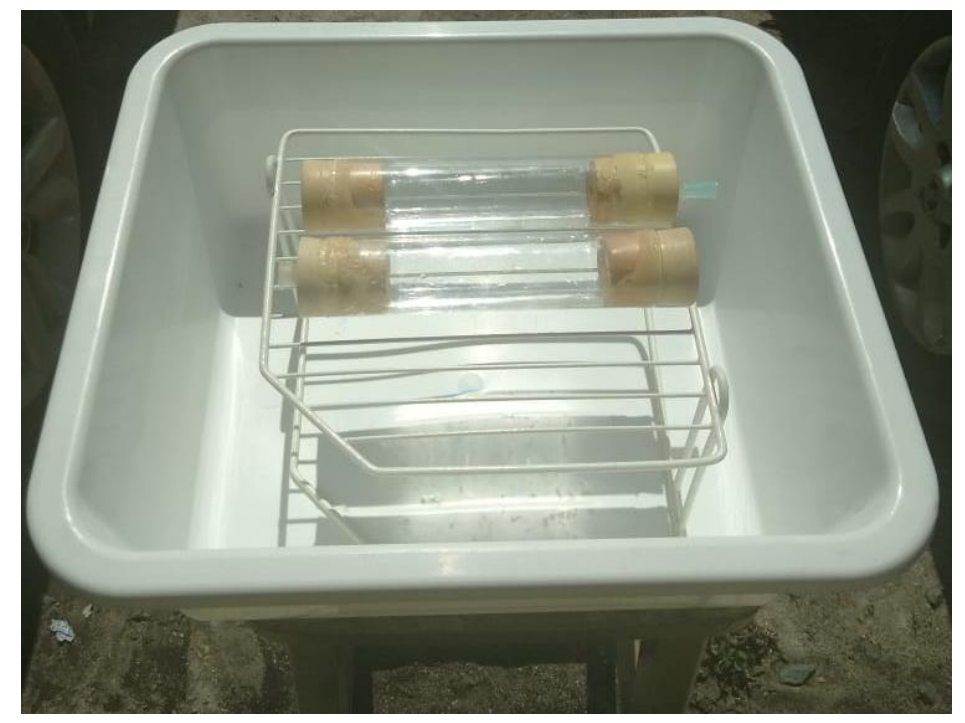

Figura 19. Degradação do CZP por Foto-Fenton Solar com uso de tubos de quartzo para armazenar as amostras 


\subsection{4}

\section{Sistema $\mathrm{H}_{2} \mathrm{O}_{2} /$ Óxidos de Ferro}

$\mathrm{O}$ sistema $\mathrm{H}_{2} \mathrm{O}_{2} /$ Óxidos de Ferro foi realizado sem o uso de radiação, logo fora do reator fotocatalítico, e utilizando o agitador acoplado ao Banho Maria como misturador mecânico. Utilizou-se volumes diferentes $(500 \mathrm{~mL})$ dos experimentos com radiação, pois o agitador seria muito robusto para o experimento (Figura 20). Por se tratar de um método em outras condições, as concentrações de $\mathrm{Fe}_{2} \mathrm{O}_{3}$. $\mathrm{FeO}$ e de $\mathrm{H}_{2} \mathrm{O}_{2}$ foram tomadas de forma diferente da utilizada no Foto-Fenton, com o objetivo de determinar alta conversão do clonazepam nos produtos da reação (Tabela 8).

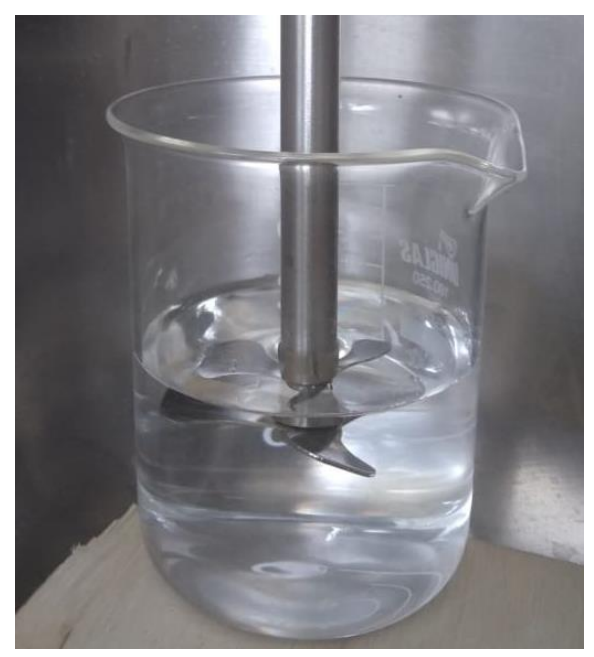

Figura 20. Agitador utilizado para o sistema $\mathrm{H}_{2} \mathrm{O}_{2} /$ Óxidos de Ferro

Outro ajuste que foi feito foi o de $\mathrm{pH}$. Para que os óxidos de ferro pudessem estar disponíveis em forma de $\mathrm{Fe}^{2+}$, baixou-se o $\mathrm{pH}=3,5$ das soluções com $\mathrm{H}_{2} \mathrm{SO}_{4}$ 0,1 M, usando como referência o pHmetro KASVI K39-1014B (Figura 21).

\section{Tabela 8. Condições utilizadas para o sistema $\mathrm{H}_{2} \mathrm{O}_{2} / \mathrm{O} x i d o s$ de Ferro}

\begin{tabular}{cccc}
\hline Condição & {$\left[\mathbf{H}_{2} \mathbf{O}_{2}\right]\left(\mathbf{m g}_{\text {. L }} \mathbf{- 1}^{\mathbf{1}}\right)$} & Massa de $\mathbf{F e}^{\mathbf{0}}(\mathbf{g})$ & {$\left[\mathrm{Fe}^{\mathbf{0}}\right]\left(\mathbf{m g} \cdot \mathbf{~ L}^{-\mathbf{1}}\right)$} \\
\hline$-1 /-1$ & 1,44 & 7,50 & 15,00 \\
$-1 /+1$ & 1,44 & 50,00 & 100,00 \\
$+1 /-1$ & 4,32 & 7,50 & 15,00
\end{tabular}




$\begin{array}{rrrr}+1 /+1 & 4,32 & 50,00 & 100,00 \\ 0 / 0 & 2,88 & 37,25 & 57,50\end{array}$

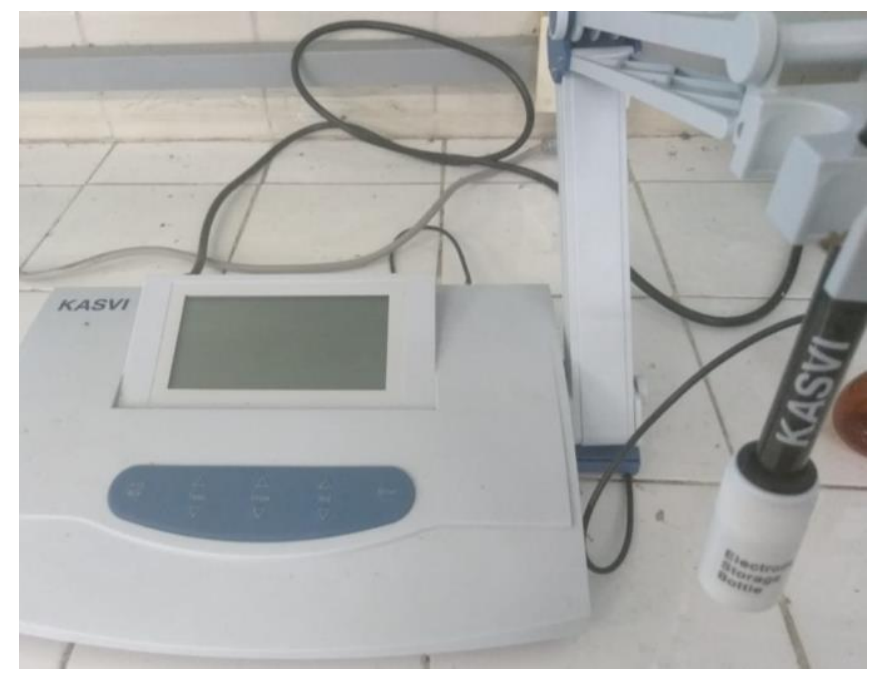

Figura 21. pHmetro utilizado nas análises

\section{4}

\section{Condições cinéticas do experimento}

Os experimentos no reator fotocatalítco foram conduzidos diferentemente dos demais em termos de tempo. A Tabela 9 mostra o tempo decorrido de cada experimento, bem como os intervalos em que as amostras foram retiradas para análise no HPLC. Vale ressaltar que, devido ao processo $\mathrm{H}_{2} \mathrm{O}_{2} /$ Óxidos de Ferro ser heterogêneo, na retirada de cada amostra com um embolo foi utilizado um filtro descartável de papel para seringas da marca KAVSI com poros de 0,45 $\mu \mathrm{m}$ para evitar entupimento da coluna C18 e interferência na análise cromatográfica.

Tabela 9. Tempo decorrido de cada análise e seus intervalos

\begin{tabular}{ccc}
\hline Método & Tempo total (min) & Intervalos (min) \\
\hline Fotólise UVC & 60 & $0 / 1 / 3 / 5 / 7 / 15 / 30$ \\
Foto-Fenton UVA & 30 & $0 / 1 / 3 / 5 / 7 / 15$ \\
Foto-Fenton UVC & 30 & $0 / 1 / 3 / 5 / 7 / 15$
\end{tabular}


Foto-Fenton Solar

$\mathrm{H}_{2} \mathrm{O}_{2} /$ Óxidos de Ferro
30

120
$0 / 1 / 3 / 5 / 7 / 15$

$0 / 15 / 30 / 45 / 60 / 90$

\section{5}

\section{Tratamento dos dados obtidos nas análises}

Os dados obtidos nas análises foram inicialmente transpostos para planilhas no MS Excel e com isso desenvolvido curvas cinéticas experimentais. Então com todas as informações à mão, pode-se utilizar softwares mais robustos e específicos em dados estatísticos (STATISTICA 10) e de modelagem cinética (OriginPro 8). Foi possível a construção de gráficos de Pareto, tabelas de correlação, superfícies de resposta e de modelos ajustados de ordem 1,2 e " $n$ " para cada um dos experimentos usando o ponto central como referência.

\section{6}

\section{Análise de toxicidade}

Foi realizada a análise de toxicidade a partir do método de germinação de sementes de alface para os experimentos que mais se adequaram, considerando o ponto central como referência. Consistiu na medição com uma régua milimetrada dos caules das plantas depois de expostas a 5 dias consecutivos as soluções já degradadas. As sementes foram colocadas em placas de Petri contendo o papel de filtro como suporte para a germinação em cada um dos ensaios dentro de um recipiente vedado à presença de luz artificial ou natural (Figura 22). Para analisar melhor o efeito de toxicidade, utilizaram-se várias diluições da solução estoque em balões volumétricos. A Tabela 10 detalha este procedimento (CAVALCANTI, 2012). 


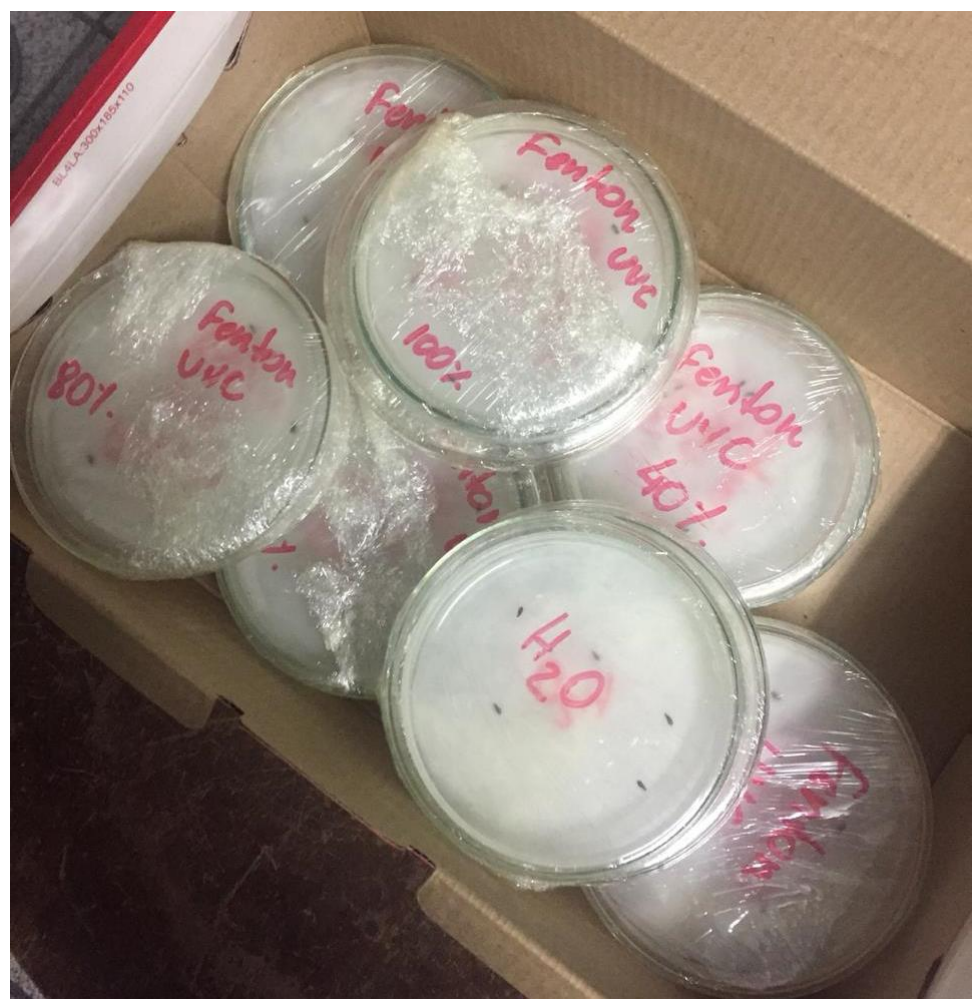

Figura 22. Análise de toxicidade a partir de sementes de alface germinadas em papel de filtro com amostras degradadas de CZP

Tabela 10. Diluições para análise de toxicidade

\begin{tabular}{ccc}
\hline Diluições & $\begin{array}{c}\text { V solução degradada } \\
(\mathbf{m L})\end{array}$ & V água ultrapura $(\mathbf{m L} \mathbf{)}$ \\
\hline 0 ou Controle & 0,00 & 4,00 \\
$10 \%$ & 0,40 & 3,60 \\
$20 \%$ & 0,80 & 3,20 \\
$40 \%$ & 1,20 & 2,80 \\
$60 \%$ & 2,40 & 1,60 \\
$80 \%$ & 3,20 & 0,80 \\
$100 \%$ & 4,00 & 0,00 \\
\hline
\end{tabular}


Depois foi realizada uma razão de inibição do crescimento de cada uma delas a partir da equação 2 abaixo.

$$
\text { Inibição }=\frac{L i-L c}{L c} \times 100
$$

Sendo Li $(\mathrm{i}=10 \%, 20 \%, 40 \% \ldots)$ o comprimento do caule germinado em cada uma das soluções contendo CZP degradado e Lc o comprimento da solução de controle. 


\section{Resultados e discussão}

Este capítulo discorre sobre os resultados obtidos ao longo da experimentação, bem como a discussão pertinente em torno destes.

\section{1}

\section{Curva analítica para o método de análise em HPLC}

A curva analítica montada para a análise do clonazepam no cromatógrafo líquido de alta eficiência teve o seguinte resultado (Figura 23).

\section{Curva analítica}

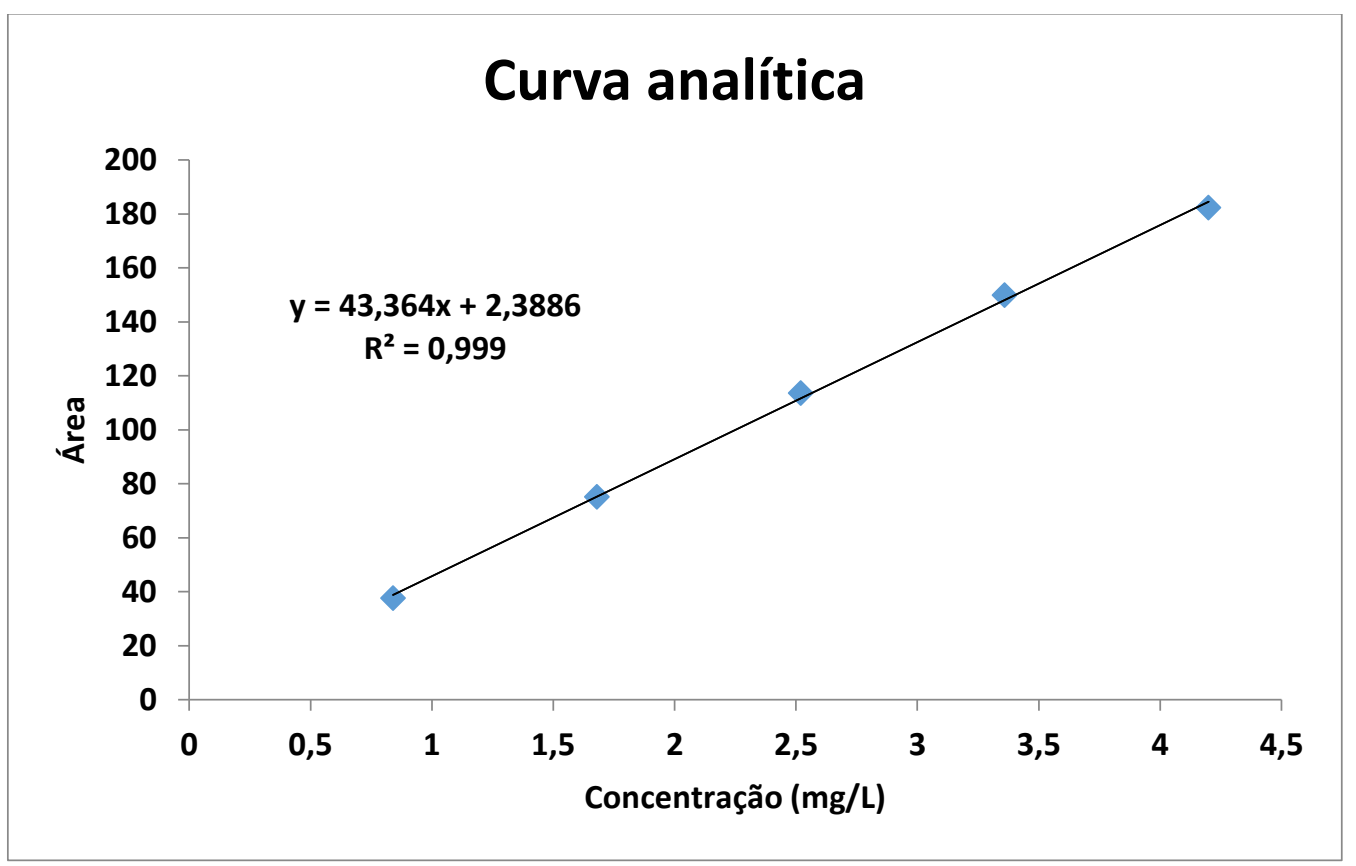

Figura 23. Curva analítica para método em HPLC

Nota-se que a correlação entre a concentração do fármaco e a área aferida nos cromatogramas é boa, tornando assim o método analítico confiável e robusto para medição das amostras subsequentes. $\mathrm{O}$ valor do coeficiente de determinação $\left(\mathrm{R}^{2}\right)$ muito próximo a 1 atesta a afirmação. 


\section{2}

\section{Fotólise UVC}

O primeiro método de degradação do CZP estudado neste trabalho foi a fotólise UVC, por motivos de ser o mais simples analiticamente falando. Por efeitos de comparação, o fato de este ser o primeiro mostra o possível incremento que os demais têm sobre a remoção do fármaco no efluente.

A Figura 24 ilustra a conversão do CZP em subprodutos em função do tempo.

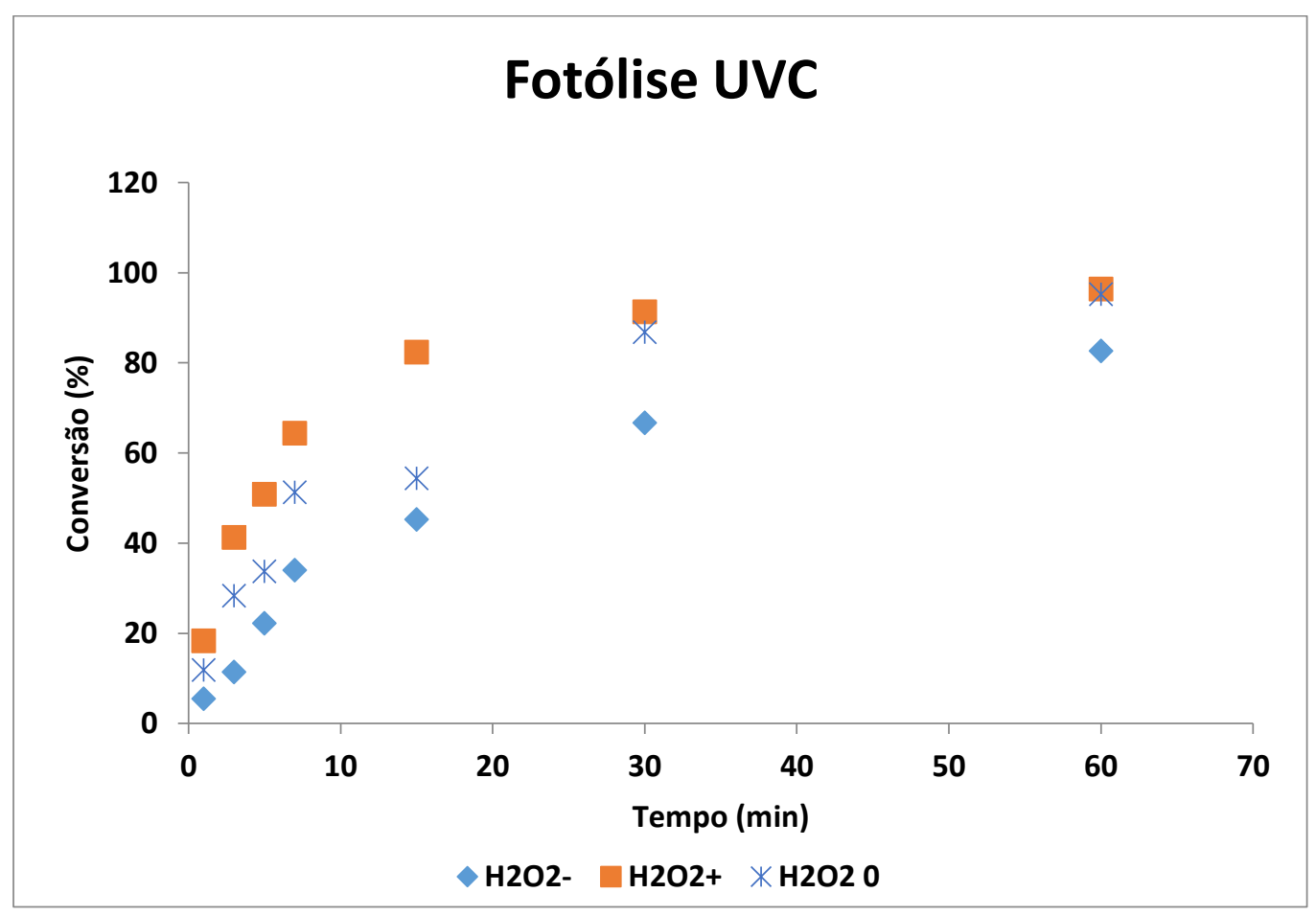

Figura 24. Degradação do CZP pela Fotólise UVC

$\left(\left[\mathrm{H}_{2} \mathrm{O}_{2}-\right]=1,15 \mathrm{mg} \cdot \mathrm{L}^{-1} ;\left[\mathrm{H}_{2} \mathrm{O}_{2} \mathrm{O}\right]=2,02 \mathrm{mg} \cdot \mathrm{L}^{-1} ;\left[\mathrm{H}_{2} \mathrm{O}_{2}+\right]=2,88 \mathrm{mg} \cdot \mathrm{L}^{-1}\right)$

Inicialmente, é possível destacar a eficácia da Fotólise UVC na degradação do CZP para um processo com até 1 hora de duração. Até mesmo em tempos menores (15 e 30 min), a condição com maior concentração de $\mathrm{H}_{2} \mathrm{O}_{2}$ se mostrou suficientemente capaz de deteriorar a droga. Nas condições mais brandas $\left(\left[\mathrm{H}_{2} \mathrm{O}_{2}\right.\right.$ ]) foram atingidas conversões maiores de $80 \%$ ao fim do experimento. Outra conclusão é que a cinética permite aferir que o peróxido de hidrogênio cumpre um papel importante na taxa de remoção do fármaco e que o aumento de sua dosagem 
(concentração) influencia diretamente tanto na velocidade da reação quanto na conversão final do clonazepam em seus subprodutos.

\section{3}

\section{Foto-Fenton UVA}

O Foto-Fenton foi feito com adição do catalisador $\mathrm{Fe}^{2+}$ e trouxe alguns progressos diante da fotólise realizada anteriormente. Além disso, é o primeiro experimento em que se pode aplicar o planejamento experimental. O primeiro avanço do Foto-Fenton UVA é o alcance de conversões mais altas para a degradação do clonazepam em um tempo mais curto, comprovando o papel que os íons ferrosos têm na cinética do processo. Por isso, o experimento foi conduzido na metade do tempo da fotólise. A Figura 25 mostra a curva conversão vs tempo para as diversas condições aplicadas.

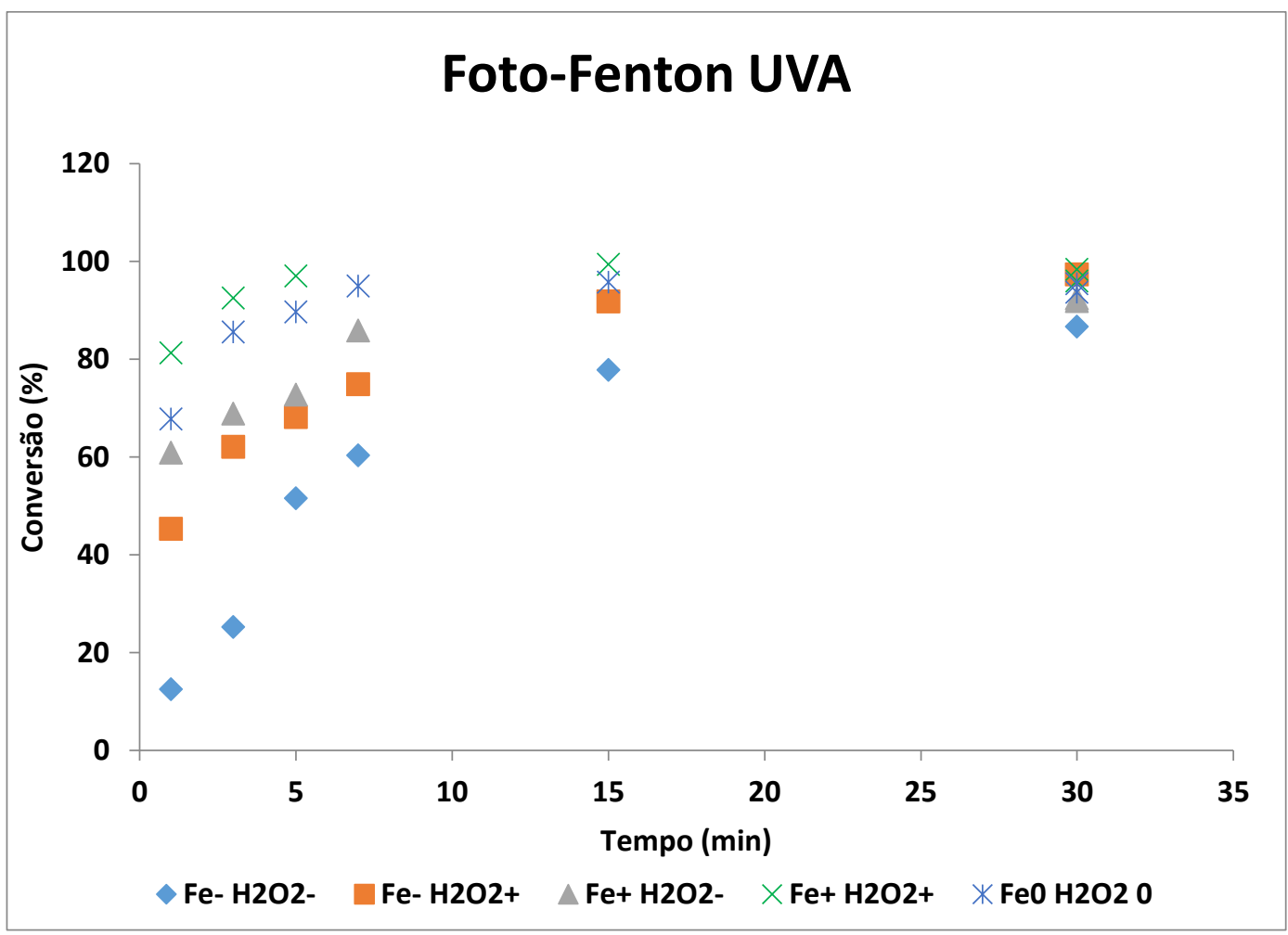

Figura 25. Cinética do método Foto-Fenton UVA

$\left(\left[\mathrm{H}_{2} \mathrm{O}_{2}-\right]=1,15 \mathrm{mg} \cdot \mathrm{L}^{-1} ;\left[\mathrm{H}_{2} \mathrm{O}_{2} \mathrm{0}\right]=2,02 \mathrm{mg} \cdot \mathrm{L}^{-1} ;\left[\mathrm{H}_{2} \mathrm{O}_{2}+\right]=2,88 \mathrm{mg} \cdot \mathrm{L}^{-1} \mathrm{e}\right.$

$\left.[\mathrm{Fe}-]=0,30 \mathrm{mg} \cdot \mathrm{L}^{-1} ;[\mathrm{Fe} 0]=7,65 \mathrm{mg} \cdot \mathrm{L}^{-1} ;[\mathrm{Fe}+]=15,00 \mathrm{mg} \cdot \mathrm{L}^{-1}\right)$ 
Outra informação que é obtida a partir da cinética dos experimentos acima é a predominância do efeito dos íons ferrosos sob a velocidade em que a reação ocorre. Os ensaios que contêm uma maior quantidade de $\mathrm{Fe}^{2+}$ atingem conversões mais altas em menos tempo. Isto não significa que ao final do processo elas serão as com maior taxa de degradação do fármaco. As Figuras 26 e 27 mostram a relação estatística da conversão final com as variáveis analisadas $\left(\mathrm{X}_{1}: \mathrm{Fe}^{2+}\right.$ e $\left.\mathrm{X}_{2}: \mathrm{H}_{2} \mathrm{O}_{2}\right)$ através do gráfico de Pareto e da superfície de resposta. Na Figura 26, a linha vertical vermelha delimita os parâmetros relevantes (Tabela 11) para a equação de regressão (Equação 21) que modela o processo.

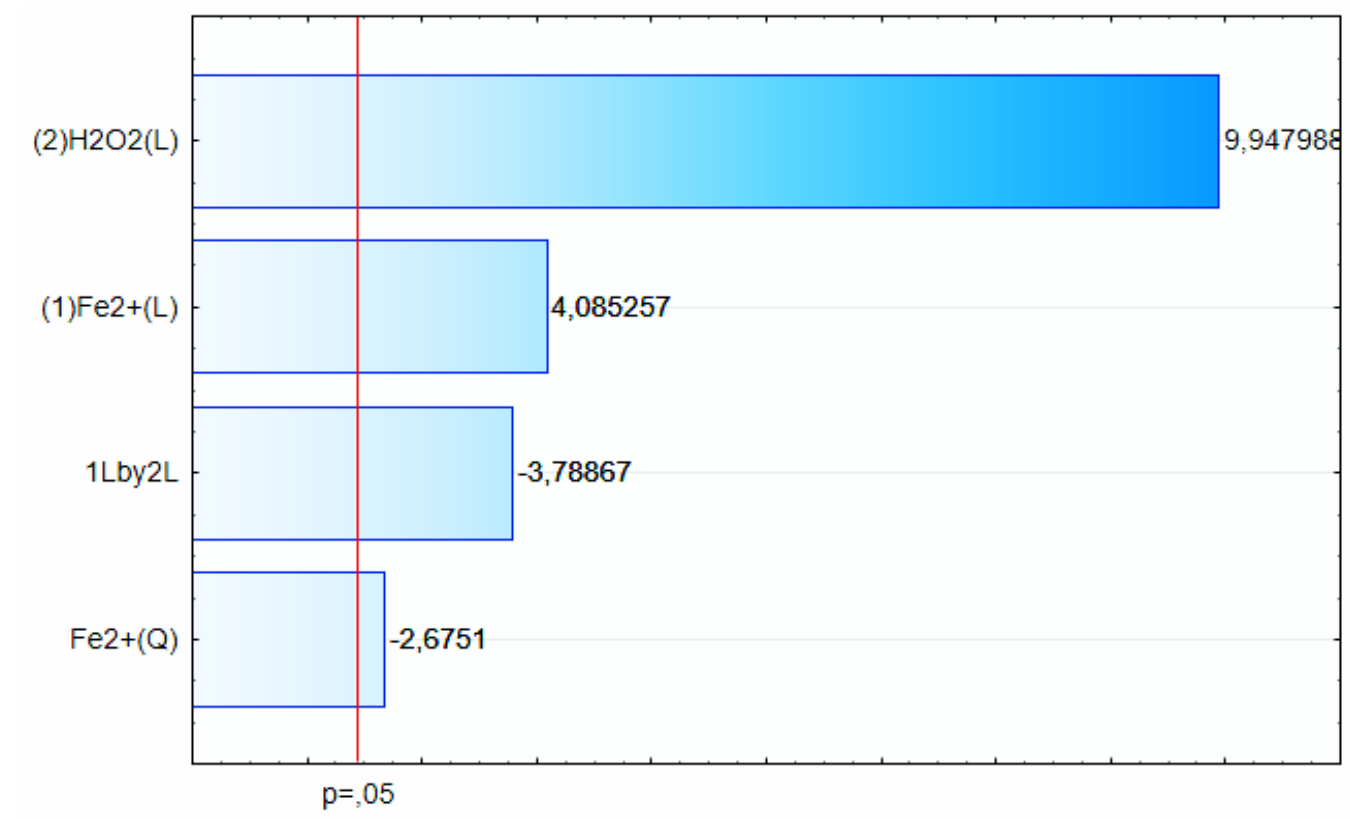

Figura 26. Gráfico de Pareto para conversão final do CZP pelo FotoFenton UVA $\left(R^{2}=0,95809\right.$ e Adj ANOVA = 0,93015)

\section{Tabela 11. Parâmetros estatísticos obtidos através do software STATISTICA 10 para o Foto-Fenton UVA}

\begin{tabular}{cccc}
\hline Variável & $\mathbf{t}(\mathbf{6})$ & Erro Padrão & Coeficiente de regressão \\
\hline Independente & 143,1848 & 0,6641 & 95,0906 \\
$\mathrm{Fe}^{2+}$ & 4,0853 & 0,4067 & 1,6614 \\
$\left(\mathrm{Fe}^{2+}\right)^{2}$ & $-2,6751$ & 0,7787 & $-2,0832$ \\
\hline
\end{tabular}




\begin{tabular}{cccc}
\hline $\mathrm{H}_{2} \mathrm{O}_{2}$ & 9,9480 & 0,4067 & 4,0459 \\
$\mathrm{Fe}^{2+*} * \mathrm{H}_{2} \mathrm{O}_{2}$ & $-3,7887$ & 0,4067 & $-1,5408$ \\
\hline
\end{tabular}

A equação 21 obtida para o Foto-Fenton UVA através dos coeficientes de regressão está representada abaixo, com o domínio das variáveis $X_{1}$ e $\quad X_{2}$ compreendido entre -1 e 1 :

$$
\text { Conv }=95,091+1,661 X 1-2,083 X 1^{2}+4,046 X 2-1,541 X 1 * X 2(21)
$$

Vale ressaltar que a equação 21 e as demais apresentadas representam um modelo quadrático (6 coeficientes) utilizado para se ter um maior ajuste e representatividade entre os fenômenos ocorridos e a matemática associada. Por isso, alguns coeficientes quadráticos podem ser negativos para estabelecer o limite coerente a partir da aplicação das variáveis cruzadas $\left(\mathrm{X}_{1} \mathrm{X}_{2}\right)$. Por exemplo: a conversão de um produto não pode ser maior que $100 \%$ e a utilização de variáveis cruzadas mostra a influência das duas variáveis $\left(\mathrm{Fe}^{2+}\right.$ e $\left.\mathrm{H}_{2} \mathrm{O}_{2}\right)$ juntas que, ao passo do aumento da dose de cada uma das variáveis, ocasiona aumento na conversão além do valor máximo estipulado. Os coeficientes quadráticos tratam de fazer essa compensação com valores negativos e absolutamente menores. Destaca-se também que o modelo deve ser aplicado apenas ao domínio estabelecido. Fora desse intervalo, o modelo é pouco representativo. 


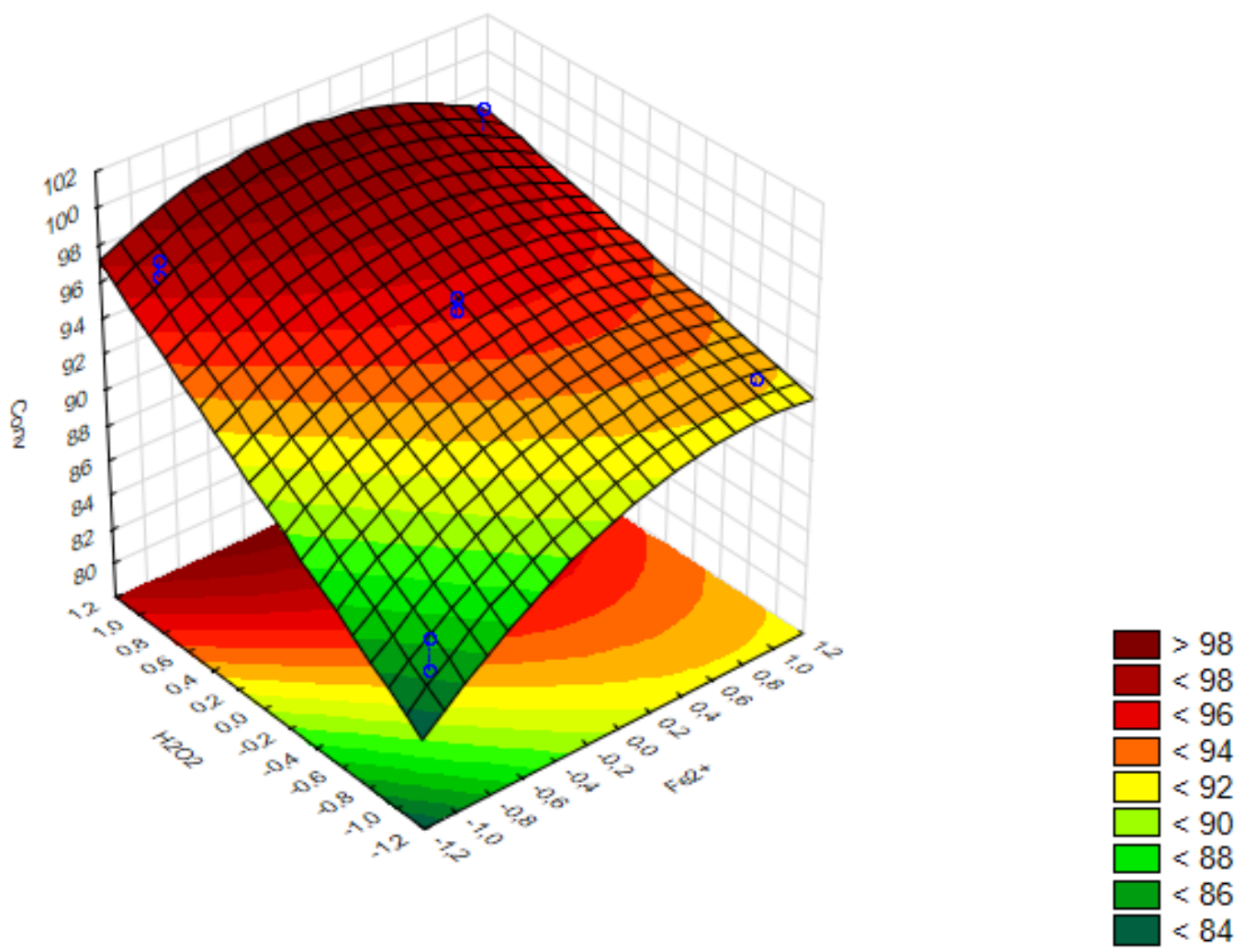

\section{Figura 27. Superfície de resposta para a conversão do CZP através do Foto-Fenton UVA ( $\left.\mathrm{X}_{1}: \mathrm{Fe} 2+\mathrm{e} \mathrm{X}_{2}: \mathrm{H}_{2} \mathrm{O}_{2}\right)$}

Percebe-se que o peróxido de hidrogênio tem participação mais decisivamente na conversão final do CZP. Isto significa que as condições com maior quantidade de $\mathrm{H}_{2} \mathrm{O}_{2}$ para o método Foto-Fenton UVA alcançaram maiores conversões. Entretanto, essa condição só analisa o resultado do processo. A experiência empírica mostra que o $\mathrm{Fe}^{2+}$ tende a ser o parâmetro mais decisivo para o processo. Não se pode descartar, ao mesmo tempo, a falta de eficácia das lâmpadas UVA utilizadas, que não atuaram na fotorredução de $\mathrm{Fe}^{3+}$ a Fe $\mathrm{Fe}^{2+}$ (papel mais significativo da radiação) tornando os íons ferrosos apenas disponíveis uma vez para reação e com a quantidade de peróxido de hidrogênio controlando o processo. 


\section{4}

\section{Foto-Fenton UVC}

Feito de forma análoga ao Foto-Fenton UVA, este método tem como incremento ao anterior o uso de uma radiação de menor comprimento de onda e que fornece mais energia ao fóton para realizar a fotorredução do $\mathrm{Fe}^{3+}$ em $\mathrm{Fe}^{2+}$, a fotólise do peróxido de hidrogênio em radicais hidroxila e a fotodescarboxilação dos complexos de carboxilato férrico. Espera-se então, além de uma conversão mais alta ao fim do processo, uma cinética mais rápida. A Figura 28 mostra como se comporta a degeneração do CZP ao longo do tempo nas condições especificadas.

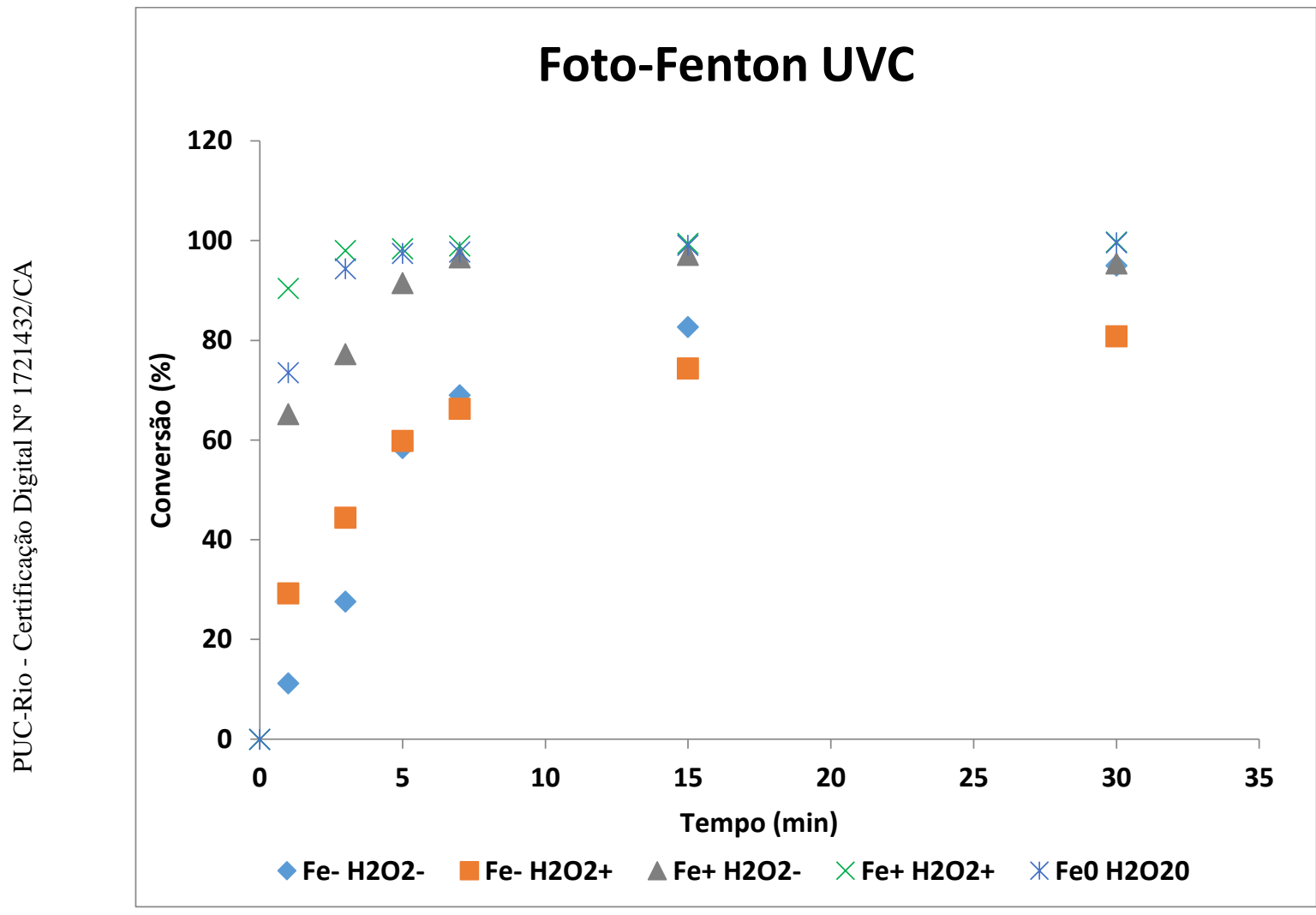

Figura 28. Cinética de conversão do CZP a partir do método FotoFenton UVC

$$
\begin{gathered}
\left(\left[\mathrm{H}_{2} \mathrm{O}_{2}-\right]=1,15 \mathrm{mg} \cdot \mathrm{L}^{-1} ;\left[\mathrm{H}_{2} \mathrm{O}_{2} 0\right]=2,02 \mathrm{mg} \cdot \mathrm{L}^{-1} ;\left[\mathrm{H}_{2} \mathrm{O}_{2}+\right]=2,88 \mathrm{mg} \cdot \mathrm{L}^{-1} \mathrm{e}\right. \\
\left.[\mathrm{Fe}-]=0,30 \mathrm{mg} \cdot \mathrm{L}^{-1} ;[\mathrm{Fe} \mathrm{0}]=7,65 \mathrm{mg} \cdot \mathrm{L}^{-1} ;[\mathrm{Fe}+]=15,00 \mathrm{mg} \cdot \mathrm{L}^{-1}\right)
\end{gathered}
$$

Com a cinética de conversão da degradação de CZP disposta na figura acima é possível atestar que o processo é realmente mais veloz do que o Foto-Fenton UVA. Há o alcance de conversões acima de $90 \%$ em todos os experimentos com maior quantidade de $\mathrm{Fe}^{2+}$ já em 5 minutos e, outra vez, fica latente a influência do 
catalisador na cinética do método Foto-Fenton, perante a quantidade de peróxido de hidrogênio. A exceção fica a cargo do experimento com menos $\mathrm{Fe}^{2+}$ e mais peróxido de hidrogênio. A grande ressalva ao uso da radiação UVC é a exposição ao risco para quem a opera, podendo ocasionar lesões de pele e nos olhos. O sol é a maior fonte desta radiação, que não nos alcança devido a camada de ozônio. Para fontes artificiais é necessária a utilização de EPI adequado (máscaras, roupas, óculos), visto que não há bloqueadores solares comerciais que proteja contra esse tipo de radiação.

Em relação à conversão final do $\mathrm{CZP}$ em seus subprodutos, o gráfico anterior mostra a convergência dos resultados para a degradação completa do composto, exceto na condição $\mathrm{Fe}^{2+}-/ \mathrm{H}_{2} \mathrm{O}_{2}+$. Fica latente que, ao contrário do método Foto-Fenton UVA, os íons ferrosos assumem um papel de protagonismo não só na cinética, mas no resultado final da degeneração do composto.

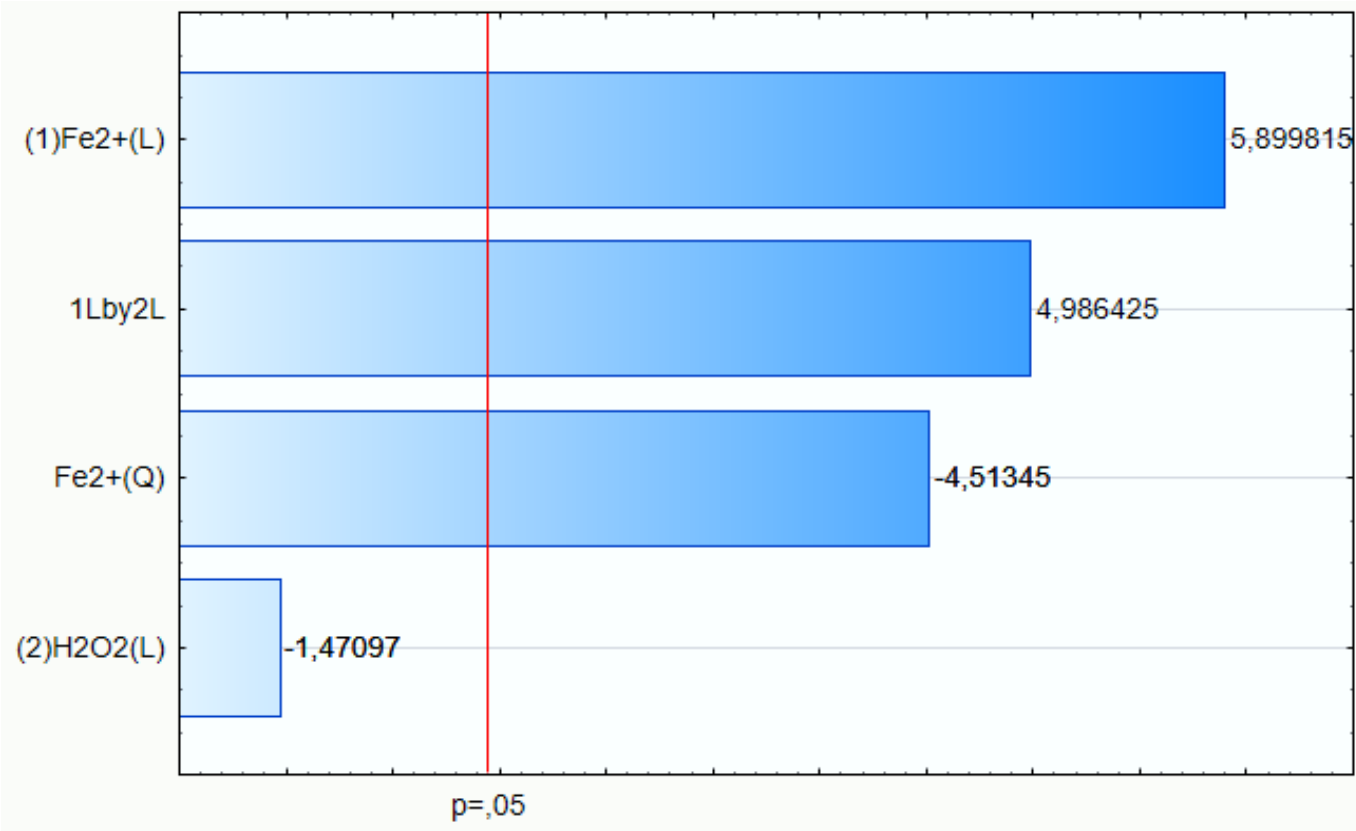

Figura 29. Gráfico de Pareto para conversão do CZP pelo FotoFenton UVC $\left(R^{2}=0,93198\right.$ e Adj ANOVA $\left.=0,88663\right)$ 
Tabela 12. Parâmetros estatísticos obtidos através do software STATISTICA 10 para o Foto-Fenton UVC

\begin{tabular}{cccc}
\hline Variável & $\mathbf{t}(6)$ & Erro padrão & Coeficiente de Regressão \\
\hline Independente & 82,8554 & 1,1982 & 99,2778 \\
$\mathrm{Fe}^{2+}$ & 5,8998 & 0,7337 & 4,3290 \\
$\left(\mathrm{Fe}^{2+}\right)^{2}$ & $-4,5134$ & 1,4050 & $-6,3415$ \\
$\mathrm{H}_{2} \mathrm{O}_{2}$ & $-1,4710$ & 0,7337 & $-1,0793$ \\
$\mathrm{Fe}^{2+} * \mathrm{H}_{2} \mathrm{O}_{2}$ & 4,9864 & 0,7337 & 3,6588 \\
\hline
\end{tabular}

A equação (22) obtida para o Foto-Fenton UVC através dos coeficientes de regressão está representada abaixo, com o domínio das variáveis $\mathrm{X}_{1}\left(\mathrm{Fe}^{2+}\right)$ e $\mathrm{X}_{2}$ $\left(\mathrm{H}_{2} \mathrm{O}_{2}\right)$ compreendido entre -1 e 1 .

$$
\text { Conv }=99,278+4,329 X 1+3,659 X 1 * X 2-6,341 X 1^{2}
$$
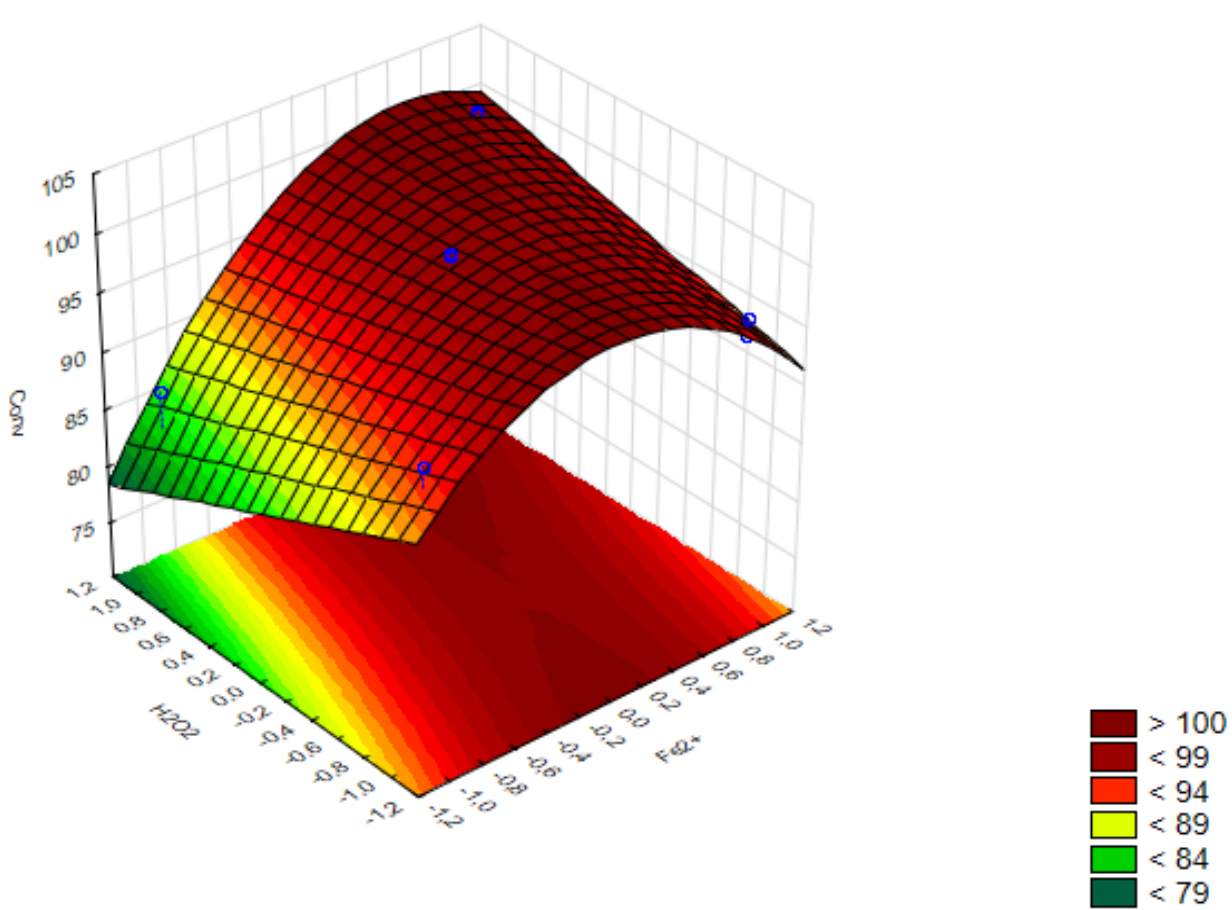

Figura 30. Superfície de Resposta para a conversão do CZP através do Foto-Fenton UVC ( $\mathrm{X}_{1}$ : $\mathrm{Fe} 2+$ e $\left.\mathrm{X}_{2}: \mathrm{H}_{2} \mathrm{O}_{2}\right)$ 
Em comparação com o Foto-Fenton UVA, o Foto-Fenton UVC mostra a capacidade que a radiação UVC possui de realizar, principalmente, a fotorredução dos íons férricos em íons ferrosos tornando o papel destes últimos imprescindíveis na cinética de degradação do CZP. As Figuras 29 e 30 mostram como a influência da quantidade de $\mathrm{Fe}^{2+}$ se sobrepõe à dose aplicada de peróxido de hidrogênio. Mesmo assim, não se pode desconsiderar a fotólise do $\mathrm{H}_{2} \mathrm{O}_{2}$.

Um detalhe que vale a pena chamar à atenção é a curvatura da Figura 30 mais ao centro. Todas as figuras de superfície de resposta são relacionadas à equação de conversão (neste caso, equação 22) e, apesar do modelo maximizar seu ajuste aos fenômenos ocorridos ao longo do processo, alguns pontos podem não traduzir fielmente o que acontece, até porque se trata de um amplo e complexo conjunto de reações.

\section{5}

\section{Foto-Fenton Solar}

O uso da radiação solar como fonte UV é uma melhoria que visa tornar o processo mais eficiente energeticamente, sem contar com o apelo ambiental do uso de uma energia abundante e renovável. Na prática, a radiação artificial tende a ser mais eficaz devido à constância de sua luz, já que a exposição ao sol pode variar (dias nublados, estações com radiação menos intensa). Porém, tratando-se de um país tropical como o Brasil e na região Nordeste cuja proximidade da linha equatorial torna os dias quase sempre ensolarados, a aplicação da radiação natural é mais atrativa. Outro ponto importante é que a radiação solar que chega à superfície terrestre contém as faixas UVA e UVB, sendo a última mais intensa que a primeira.

A cinética de conversão da degradação do CZP pelo processo Foto-Fenton Solar é apresentada na Figura 31. 


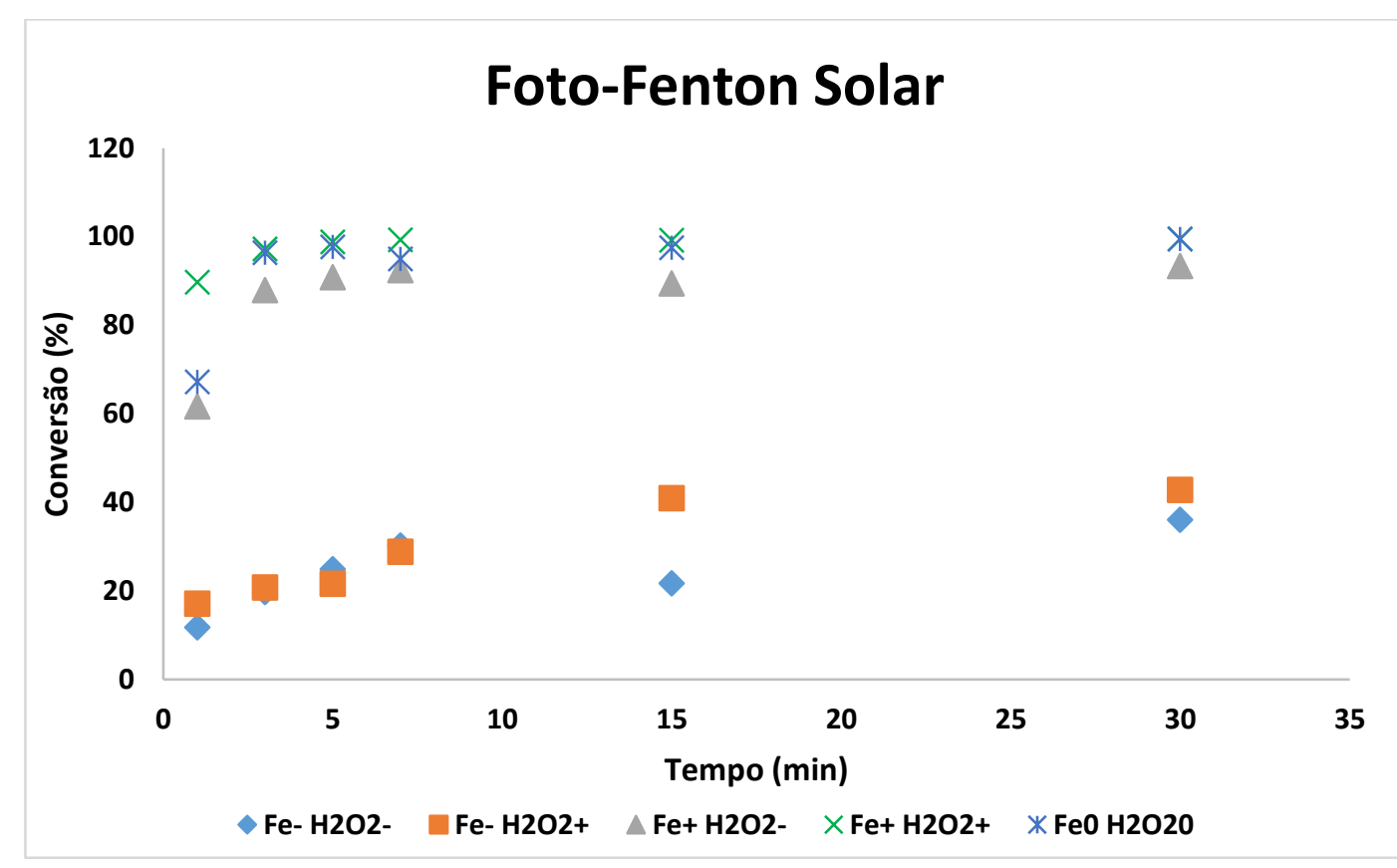

Figura 31. Cinética de conversão da degradação do CZP pelo método Foto-Fenton Solar

$$
\begin{gathered}
\left(\left[\mathrm{H}_{2} \mathrm{O}_{2}-\right]=1,15 \mathrm{mg} \cdot \mathrm{L}^{-1} ;\left[\mathrm{H}_{2} \mathrm{O}_{2} 0\right]=2,02 \mathrm{mg} \cdot \mathrm{L}^{-1} ;\left[\mathrm{H}_{2} \mathrm{O}_{2}+\right]=2,88 \mathrm{mg} \cdot \mathrm{L}^{-1} \mathrm{e}\right. \\
\left.[\mathrm{Fe}-]=0,30 \mathrm{mg} \cdot \mathrm{L}^{-1} ;[\mathrm{Fe} \mathrm{0}]=7,65 \mathrm{mg} \cdot \mathrm{L}^{-1} ;[\mathrm{Fe}+]=15,00 \mathrm{mg} \cdot \mathrm{L}^{-1}\right)
\end{gathered}
$$

A cinética de conversão da degradação do CZP pelo processo Foto-Fenton Solar evidencia os íons ferrosos como agentes limitantes de conversão do método. Outro fator que poderia contribuir para explicar esse fraco desempenho dos experimentos é a intensidade da radiação no dia específico do ensaio. Com relação aos processos com mais íons ferrosos, novamente é notável que são aqueles que têm melhor desempenho de degradação, podendo ser facilmente utilizados como alternativa à radiação artificial.

Com relação à estatística da conversão final do CZP no processo FotoFenton Solar, as Figuras 32 e 33 ilustram os resultados. 


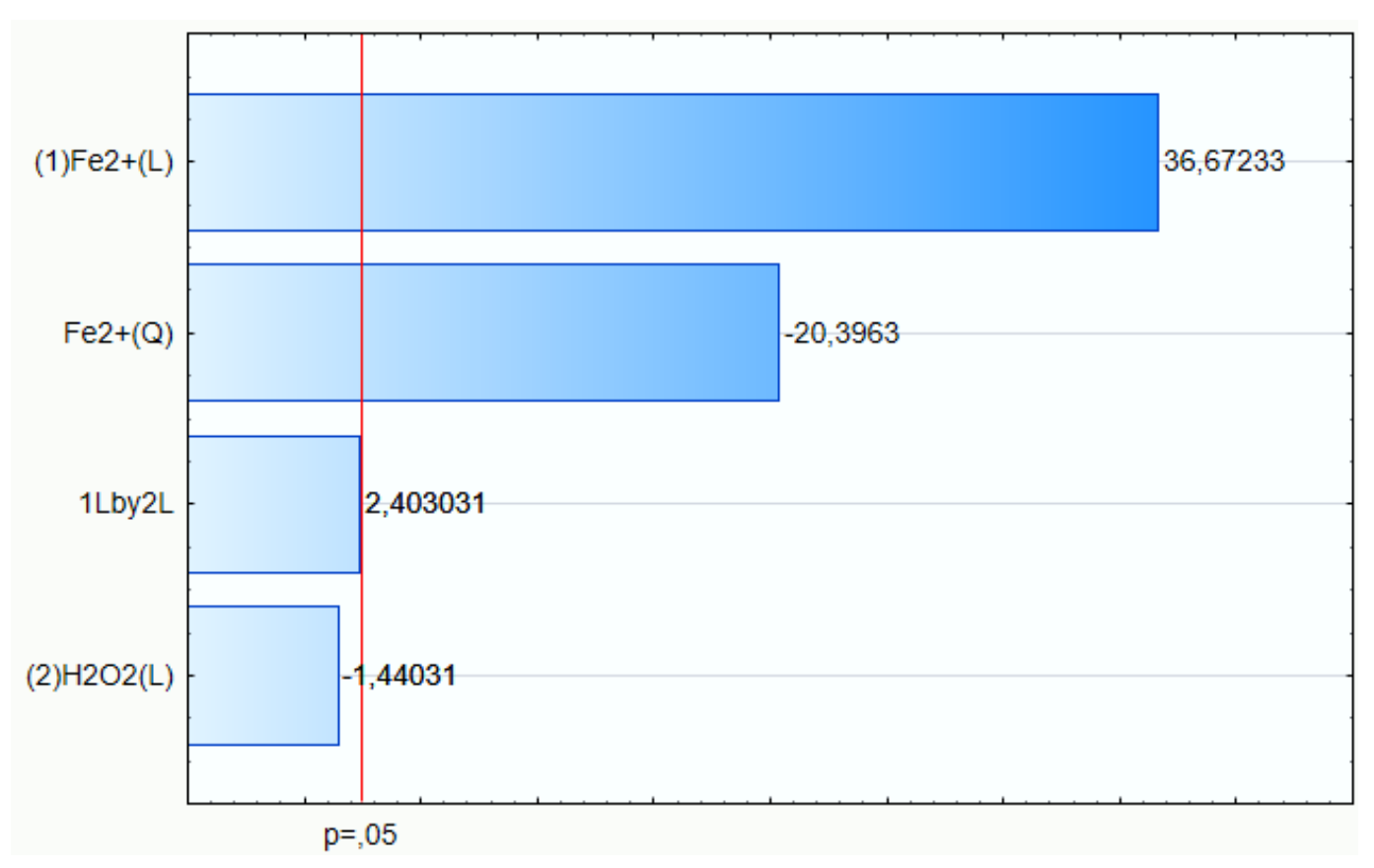

Figura 32. Gráfico de Pareto para o método Foto-Fenton Solar $\left(R^{2}=0,99662\right.$ e Adj ANOVA $\left.=0,99437\right)$

Tabela 13. Parâmetros estatísticos obtidos através do software STATISTICA 10 para o Foto-Fenton Solar

\begin{tabular}{cccc}
\hline Variável & $\mathbf{t}(\mathbf{6})$ & Erro padrão & Coeficiente de regressão \\
\hline Independente & 105,2774 & 0,9374 & 98,6925 \\
$\mathrm{Fe}^{2+}$ & 36,6723 & 0,5741 & 21,0525 \\
$\left(\mathrm{Fe}^{2+}\right)^{2}$ & $-20,3963$ & 1,0992 & $-22,4208$ \\
$\mathrm{H}_{2} \mathrm{O}_{2}$ & $-1,4403$ & 0,5471 & $-0,8268$ \\
$\mathrm{Fe}^{2+} * \mathrm{H}_{2} \mathrm{O}_{2}$ & 2,4030 & 0,5471 & 1,3795 \\
\hline
\end{tabular}

A equação (23) obtida para o Foto-Fenton Solar através dos coeficientes de regressão está representada abaixo, com o domínio das variáveis $X_{1}\left(\mathrm{Fe}^{2+}\right)$ e $\mathrm{X}_{2}$ $\left(\mathrm{H}_{2} \mathrm{O}_{2}\right)$ compreendido entre -1 e 1 : 


$$
\text { Conv }=98,692+21,052 X 1-22,421 X 1^{2}
$$
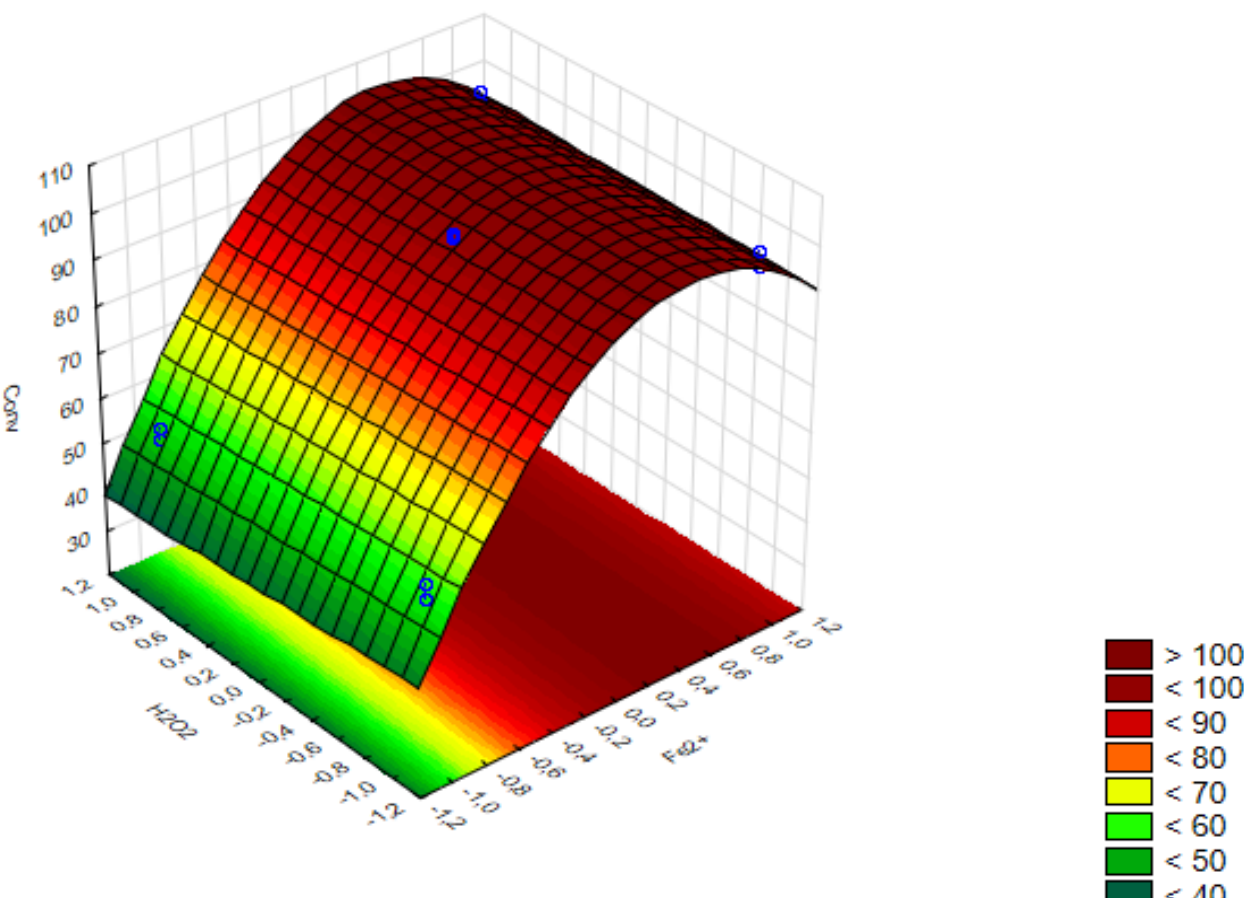

\section{Figura 33. Superfície de resposta para a conversão do CZP através do Foto-Fenton Solar ( $\mathrm{X}_{1}$ : $\left.\mathrm{Fe} 2+\mathrm{e} \mathrm{X}_{2}: \mathrm{H}_{2} \mathrm{O}_{2}\right)$}

De forma análoga ao Foto-Fenton UVC, o processo Foto-Fenton Solar mostra-se extremamente dependente da presença de íons ferrosos em solução. Mais que isso, a pouca disponibilidade de $\mathrm{Fe}^{2+}$ leva a conversão de menos de $50 \%$ do CZP em seus subprodutos. A variação na concentração de peróxido de hidrogênio não se mostrou decisiva para o processo ser mais eficiente. O que pode explicar esta diferença com relação ao Foto-Fenton UVC é que a radiação solar (UVA+UVB) tende a atuar apenas na fotorredução do $\mathrm{Fe}^{3+}$ a $\mathrm{Fe}^{2+}$ e não na fotólise do peróxido de hidrogênio. 


\section{6}

\section{Comparação gráfica entre os métodos Foto-Fenton}

Utilizando os experimentos associados a cada um dos métodos (UVA, UVC e Solar) pode-se construir gráficos comparativos de cada uma das condições determinadas. A Figura 34 mostra essa análise: 

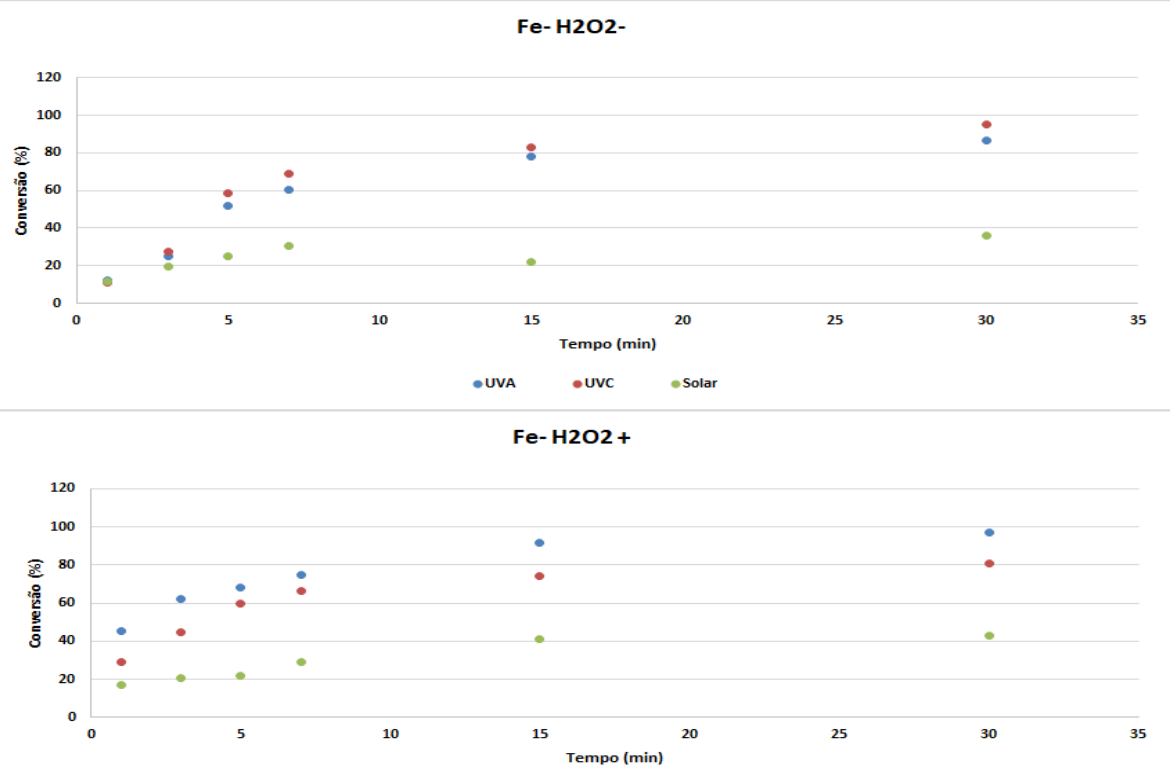

- Uva •uvc osolar

$\mathrm{Fe}+\mathrm{H} 2 \mathrm{O} 2$ -
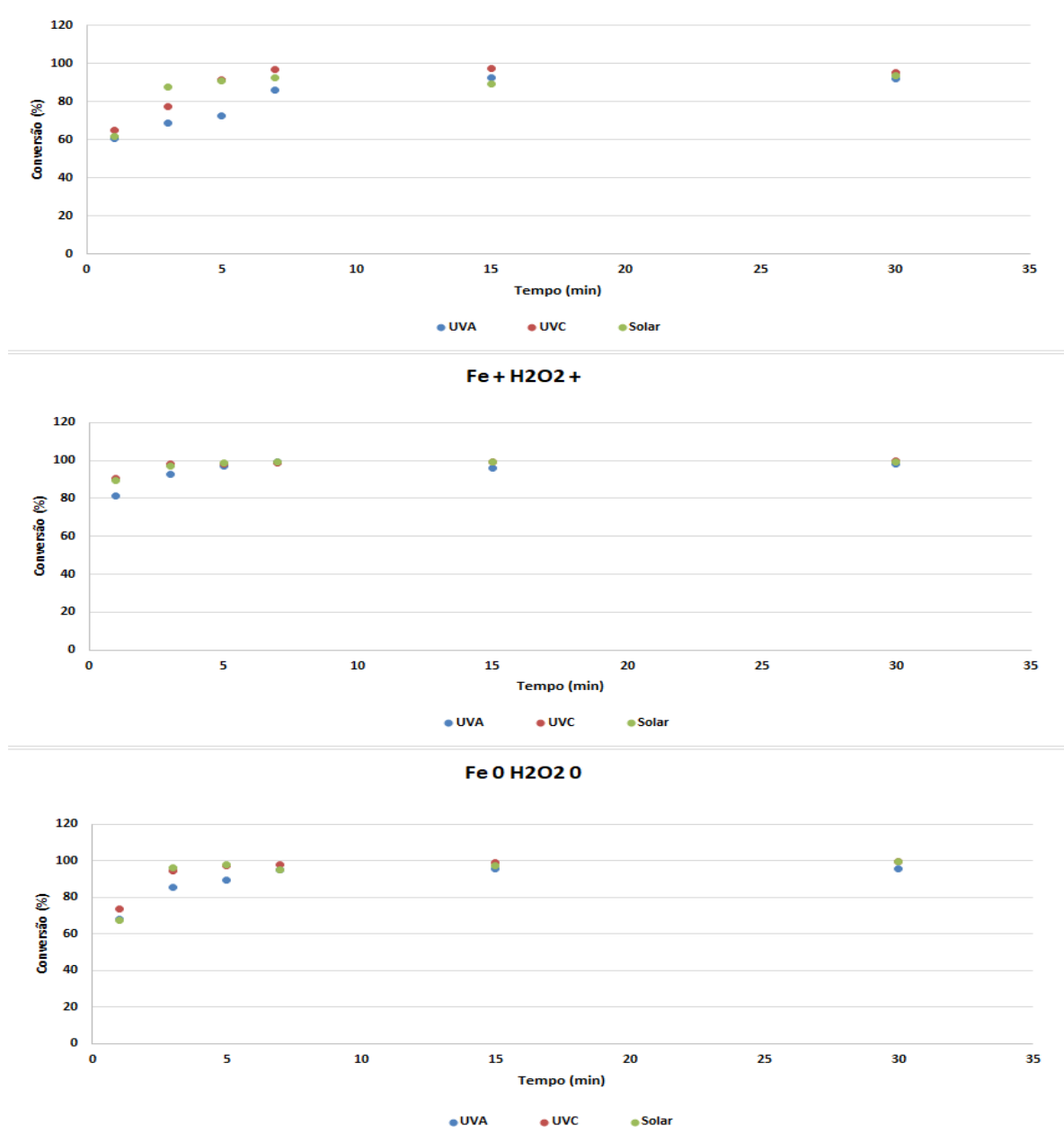

Figura 34. Comparação gráfica dos métodos Foto-Fenton com relação à radiação e suas conversões ao longo do tempo 
Compilando os gráficos em função da fonte de radiação, pode-se avaliar de fato que, em geral, há uma preponderância da radiação UVC diante das demais em relação não só a cinética, mas às conversões finais de CZP em seus subprodutos. O Foto-Fenton Solar mostrou-se bem competitivo se comparado aos métodos artificiais quando aplicada com a devida quantidade de catalisador. Na verdade, quando há íons ferrosos na quantidade necessária, qualquer um dos métodos se torna eficiente. O que varia é o tempo em que a degradação ocorre. Mesmo assim, todos levam a conversões acima de $90 \%$.

\section{7}

\section{Sistema $\mathrm{H}_{2} \mathrm{O}_{2} / O$ xidos de Ferro}

$\mathrm{O}$ sistema $\mathrm{H}_{2} \mathrm{O}_{2}$ /Óxidos de Ferro tem como propósito apresentar uma alternativa ao processo Fenton homogêneo amplamente difundido. Outra característica é facilitar a operação de degradação do CZP, sem o uso da radiação. Além disso, a aplicação de óxido de ferro no processo possibilita a reciclagem deste material advindo de fontes alternativas. A fim de caracterizar a superfície do reagente/catalisador empregado, foram realizadas análises da área superficial e dos tipos de óxido presentes na palha de aço utilizada. Foi medida a área superficial da palha antes e depois de ser queimada por BET. Os resultados mostram um aumento de $0,203 \mathrm{~m}^{2} \cdot \mathrm{g}^{-1}$ para $4,815 \mathrm{~m}^{2} \cdot \mathrm{g}^{-1}$, depois de ter sido queimada e, por consequência, mais finamente dividida. Apesar disso, ainda assim pode-se considerar essa uma área superficial muito pequena se comparada com, por exemplo, o carvão ativado. A caracterização foi feita por Difração de Raio X (DRX) e a Figura 35 mostra o resultado: 


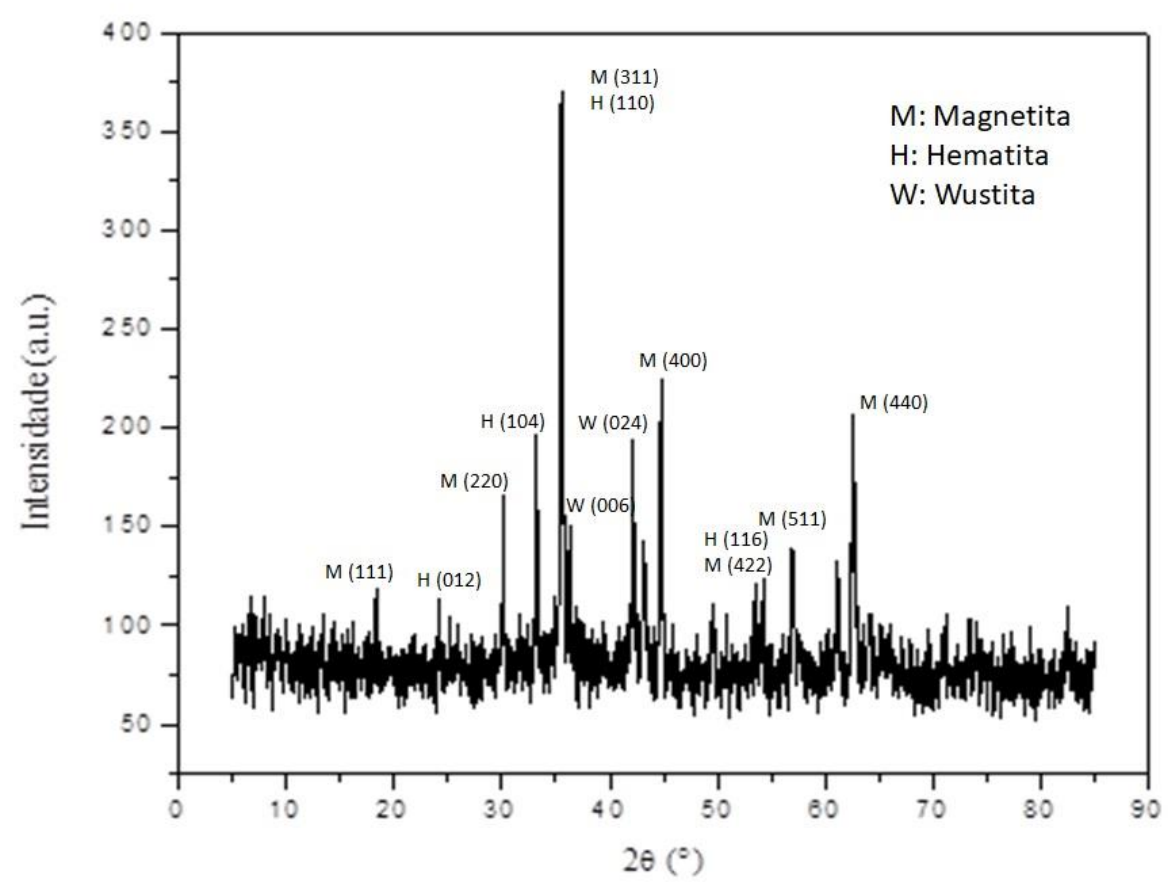

Figura 35. Análise de DRX para a palha de aço após pirólise com

\section{atmosfera redutora de $\mathrm{CO}_{2}$}

A caracterização por DRX mostrou que a palha de aço queimada tem uma estrutura com a presença de 3 óxidos de ferro, de acordo com a comparação por padrão do software X'pert HighScore Plus. A predominante é a magnetita (ICSD: 082434) com 74\%, em seguida vem a hematita (ICSD: 064599) com 14\% e, por fim, a wustita (ICSD: 082235) com 12\% (Figura 36). Isso mostra que apesar da atmosfera redutora, a temperatura alcançada durante a queima não foi suficiente para transformar toda magnetita em hematita ou wustita.

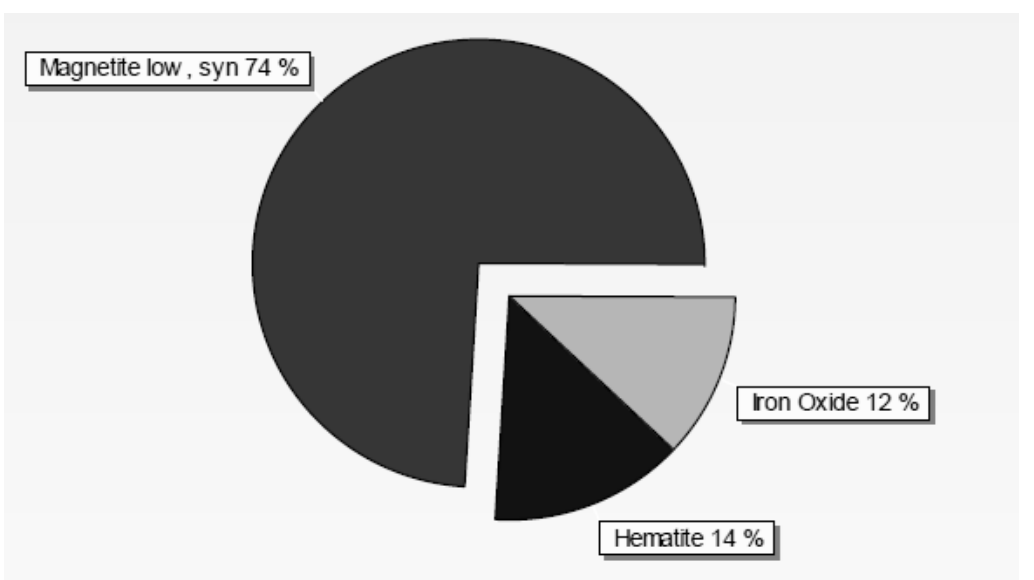

Figura 36. Gráfico das fases presentes no catalisador após pirólise com atmosfera de $\mathrm{CO}_{2}$ 
No $\mathrm{H}_{2} \mathrm{O}_{2} /$ Óxidos de $\mathrm{Fe}$, há uma maior demanda por tempo, visto que a cinética de conversão da degradação do CZP é mais lenta do que os processos irradiados. A Figura 37 demonstra isso:

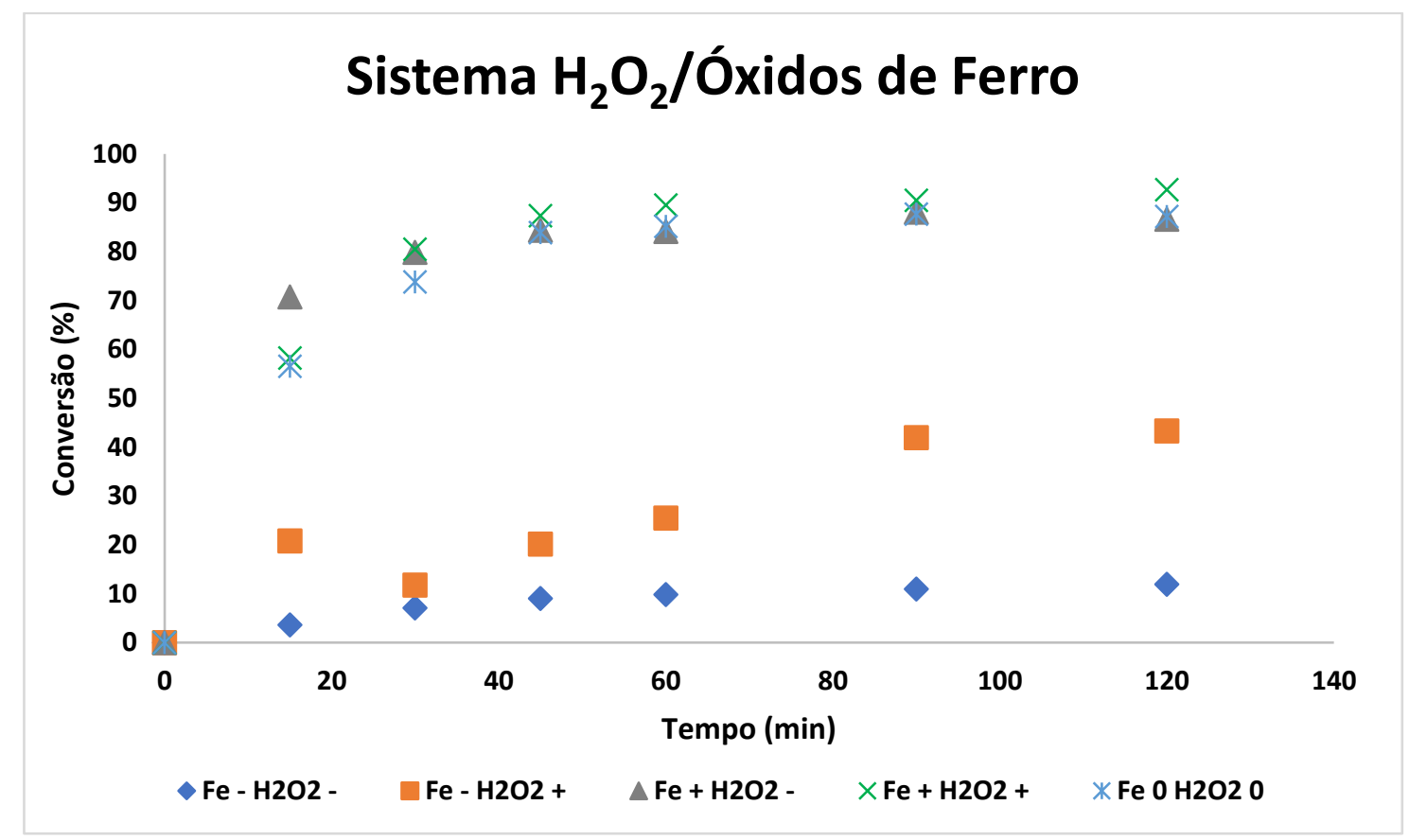

Figura 37. Cinética de conversão do CZP a partir do Sistema $\mathrm{H}_{2} \mathrm{O}_{2} /$ Óxidos de Ferro

$$
\begin{gathered}
\left(\left[\mathrm{H}_{2} \mathrm{O}_{2}-\right]=1,44 \mathrm{mg} \cdot \mathrm{L}^{-1} ;\left[\mathrm{H}_{2} \mathrm{O}_{2} 0\right]=2,88 \mathrm{mg} \cdot \mathrm{L}^{-1} ;\left[\mathrm{H}_{2} \mathrm{O}_{2}+\right]=4,32 \mathrm{mg} \cdot \mathrm{L}^{-1} \mathrm{e}\right. \\
\left.[\mathrm{Fe}-]=15,00 \mathrm{mg} \cdot \mathrm{L}^{-1} ;[\mathrm{Fe} 0]=57,50 \mathrm{mg} \cdot \mathrm{L}^{-1} ;[\mathrm{Fe}+]=100,00 \mathrm{mg} \cdot \mathrm{L}^{-1}\right)
\end{gathered}
$$

Com o gráfico anteriormente exposto é possível aferir que o íon ferroso cumpre o papel de agente limitante da reação. Com a adição de quantidades menores do catalisador óxido de ferro $\left(15 \mathrm{mg} . \mathrm{L}^{-1}\right)$, o processo se torna ineficaz. Outro fator que vale ser ressaltado é a necessidade de uma concentração muito maior de ferro (a partir de 57,50 mg. $\mathrm{L}^{-1}$ ) presente no sistema $\mathrm{H}_{2} \mathrm{O}_{2} /$ Óxidos de $\mathrm{Fe}$ para que se tenha boa disponibilidade de $\mathrm{Fe}^{2+}$ como agente catalisador. Por fim, a cor foi um parâmetro em que houve um aumento visível ao final do processo. A Figura 38 apresenta essa diferença provavelmente devida à presença de ferro dissolvido: 


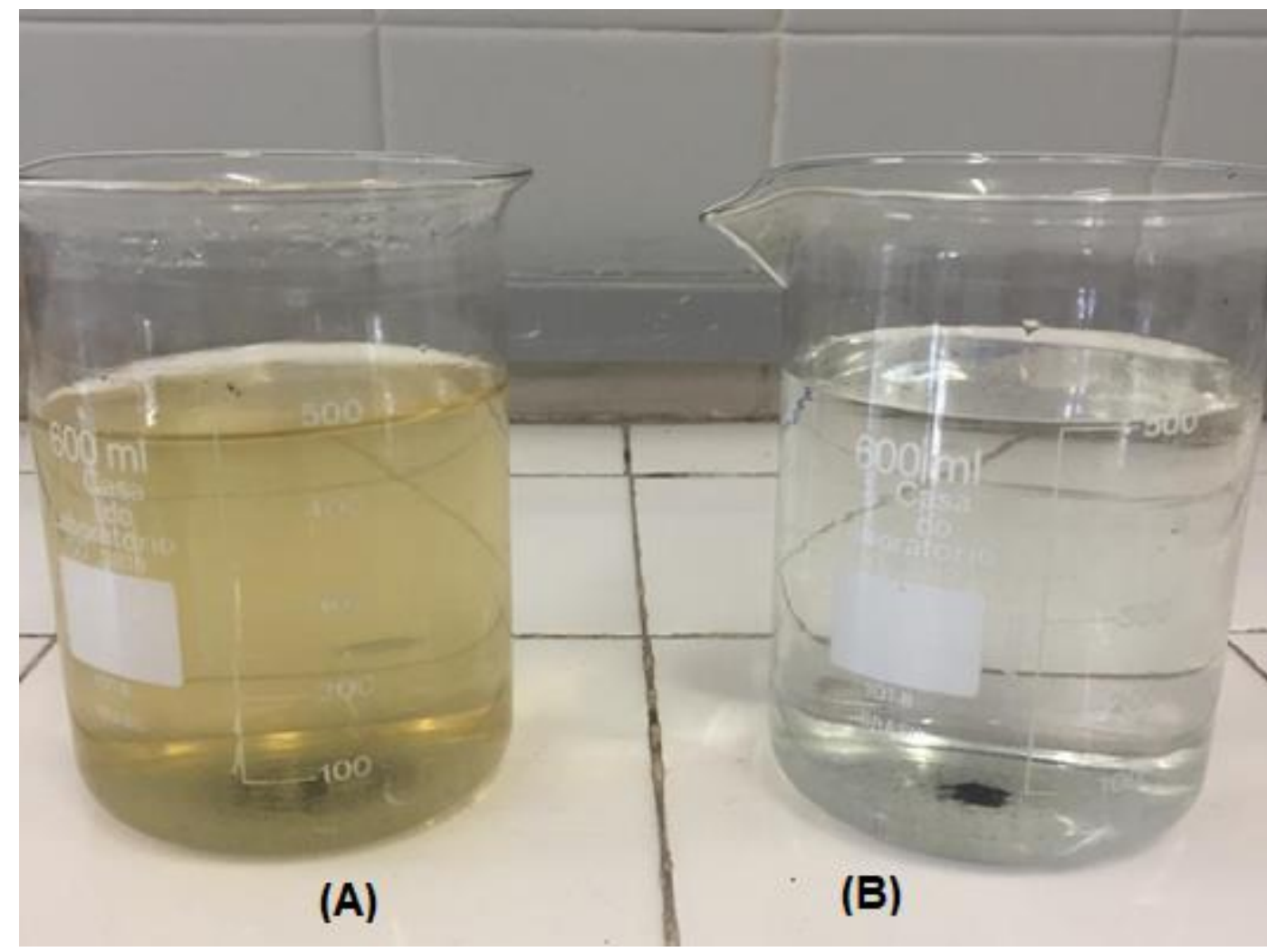

Figura 38. Condição final (A) e inicial (B) das amostras submetidas ao Sistema $\mathrm{H}_{2} \mathrm{O}_{2} /$ Óxidos de Ferro

Assim como nos demais métodos, foi realizada a análise estatística do sistema $\mathrm{H}_{2} \mathrm{O}_{2} /$ Óxidos de Ferro. As Figuras 39 e 40 demonstram os resultados obtidos: 


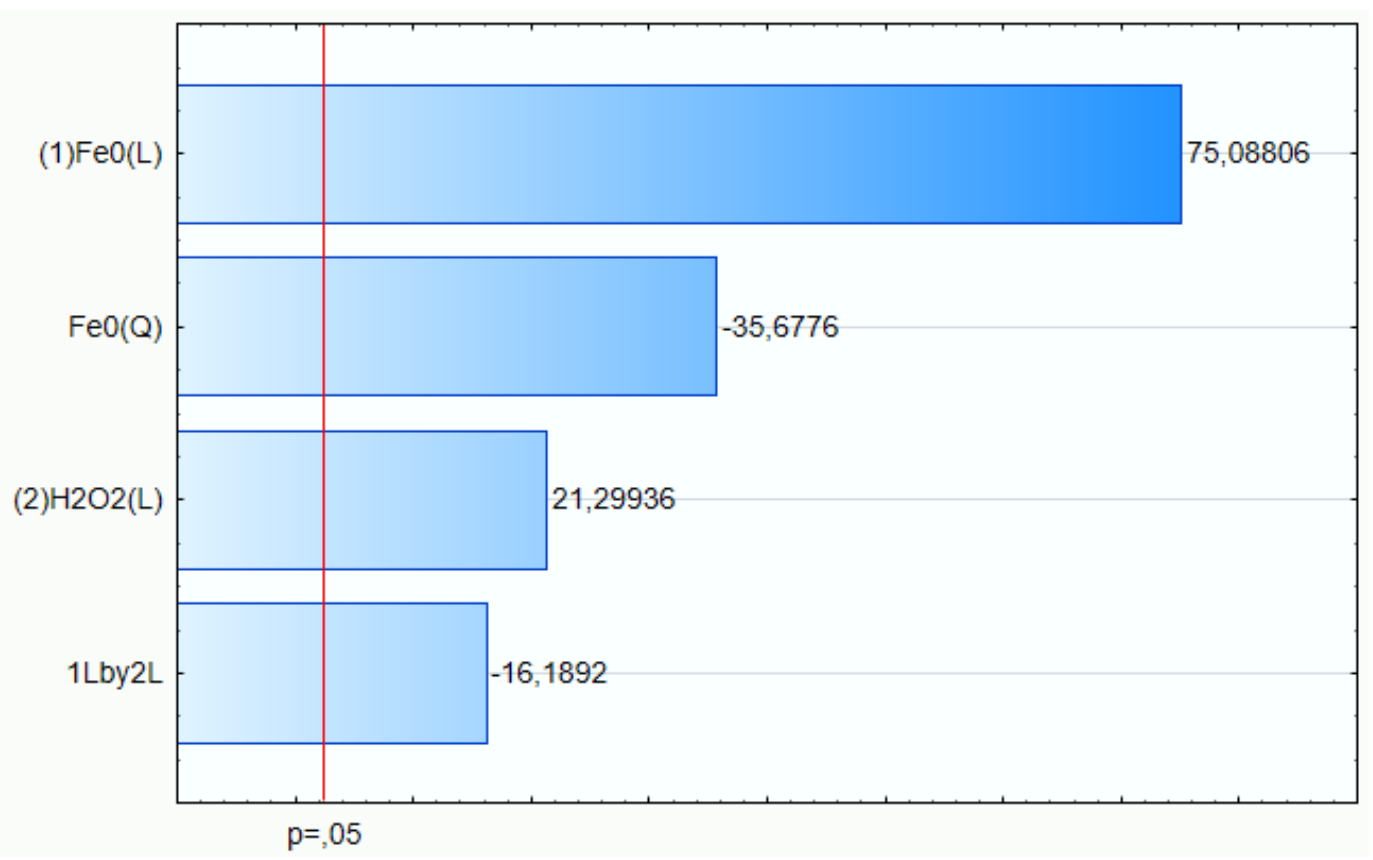

Figura 39. Gráfico de Pareto para o Sistema $\mathrm{H}_{2} \mathrm{O}_{2}$ /Óxidos de Ferro $\left(R^{2}=0,99921\right.$ e Adj ANOVA $\left.=0,99869\right)$

\begin{tabular}{|c|c|c|c|}
\hline Variável & $\mathbf{t}(\mathbf{6})$ & Erro padrão & Coeficiente de regressão \\
\hline Independente & 127,5978 & 0,6794 & 86,6874 \\
\hline $\mathrm{FeO}$ & 75,0881 & 0,4160 & 31,2391 \\
\hline$(\mathrm{FeO})^{2}$ & $-35,6776$ & 0,7966 & $-28,4224$ \\
\hline $\mathrm{H}_{2} \mathrm{O}_{2}$ & 21,2994 & 0,4160 & 8,8612 \\
\hline $\mathrm{FeO} * \mathrm{H}_{2} \mathrm{O}_{2}$ & $-16,1892$ & 0,4160 & $-6,7352$ \\
\hline
\end{tabular}

A equação (24) obtida para o Sistema $\mathrm{H}_{2} \mathrm{O}_{2}$ /Óxidos de $\mathrm{Fe}$ através dos coeficientes de regressão está representada abaixo, com o domínio das variáveis $\mathrm{X}_{1}$ $(\mathrm{FeO})$ e $\mathrm{X}_{2}\left(\mathrm{H}_{2} \mathrm{O}_{2}\right)$ compreendido entre -1 e 1 : 
Conv $=86,687+31,239 X 1-28,422 X 1^{2}+8,861 X 2-6,735 X 1 * X 2$

Observando-se a equação 24, fica evidente que o coeficiente quadrático e o coeficiente das variáveis cruzadas $\left(\mathrm{X}_{1} \mathrm{X}_{2}\right)$ são negativos por um mero ajuste matemático do modelo ao fenômeno ocorrido no processo. Isso significa a imposição de um limite superior para a conversão em um valor dentro da realidade (no caso da conversão, 100\%). Caso não ocorresse, o aumento indefinido das duas variáveis ao mesmo tempo levaria em valores irreais para conversão dentro do domínio estabelecido.

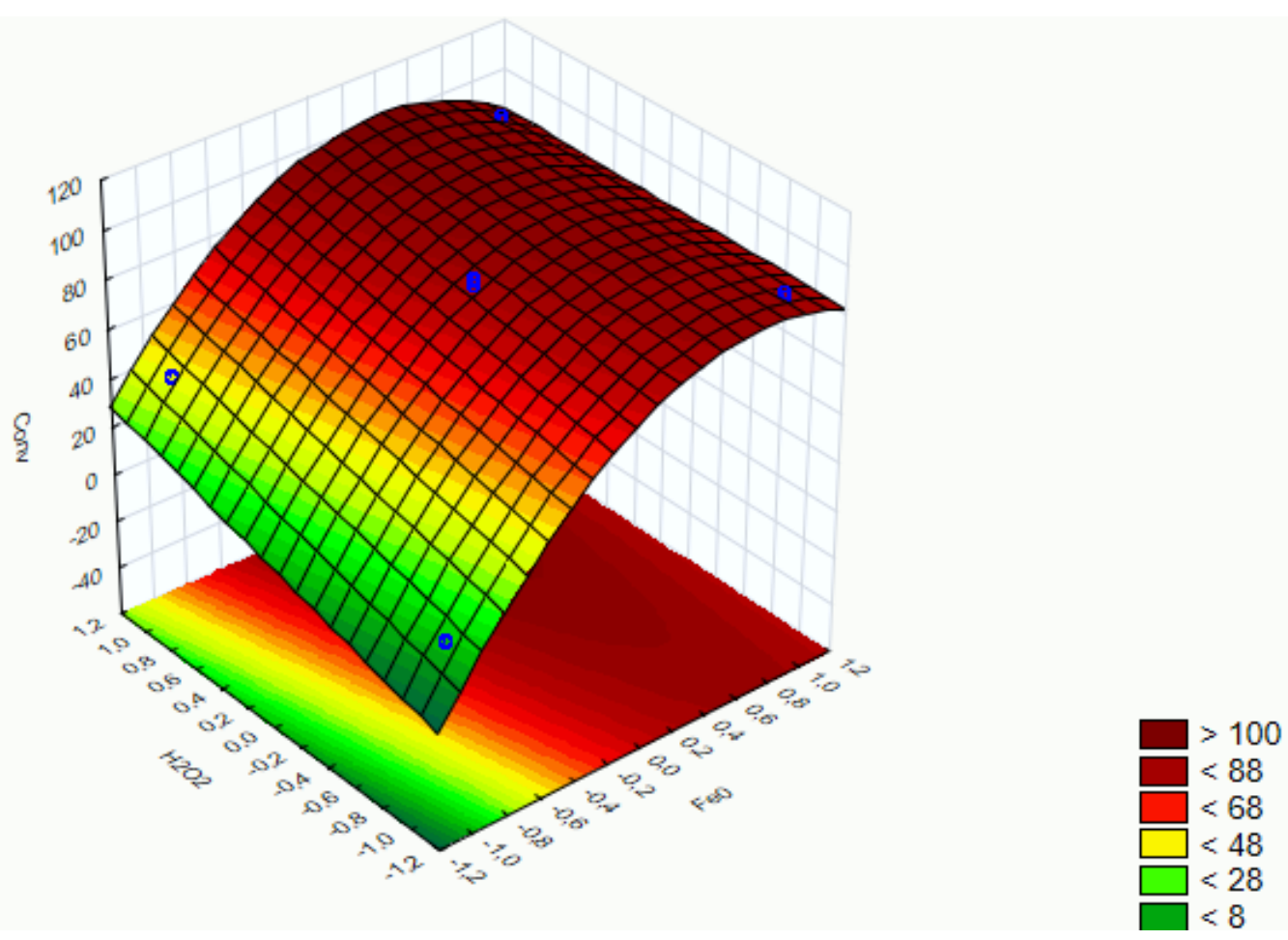

Figura 40. Superfície de Resposta para a degradação do CZP através do Sistema $\mathrm{H}_{2} \mathrm{O}_{2} /$ Óxidos de Ferro $\left(\mathrm{X}_{1}: \mathrm{Fe} 2+\right.$ e $\left.\mathrm{X}_{2}: \mathrm{H}_{2} \mathrm{O}_{2}\right)$

Observando os dados da conversão final do CZP pelo Sistema $\mathrm{H}_{2} \mathrm{O}_{2} /$ Óxidos de Ferro nas Figuras 39 e 40, fica explícito que há, mais uma vez, a predominância do ferro (neste caso como óxidos de ferro) perante o agente oxidante $\left(\mathrm{H}_{2} \mathrm{O}_{2}\right)$ na degradação do fármaco. A disponibilidade dos íons ferrosos deve ser uma limitação ao processo, visto que em concentrações menores há menor $\mathrm{Fe}^{2+}$ apto para as reações e consequentemente a conversão se torna mais branda. $\mathrm{O}$ aumento da 
concentração de peróxido de hidrogênio em condições com menos óxidos de ferro fez com que a conversão fosse favorecida, embora a limitação claramente se encontre na presença ou não do catalisador. A leve curvatura presente no meio da superfície de resposta advém do modelo matemático quadrático proposto com a finalidade de aumentar o ajuste ao processo e não denota necessariamente que há uma maximização da conversão nesta região ou um decaimento nos pontos mais próximos do limite superior do domínio.

\section{8}

\section{Análise de variância dos experimentos}

A partir dos dados estatísticos obtidos no software STATISTICA 10, podese observar a qualidade do ajuste realizado para confecção dos gráficos utilizados acima. A Tabela 11 demonstra os resultados. $\mathrm{O}$ ajuste foi considerado adequado em todos os experimentos, visto que os coeficientes de ajuste apresentaram valores acima de $85 \%$ em cada um dos métodos.

\section{Tabela 15. Coeficientes estatísticos obtidos na análise da variância}

\begin{tabular}{|c|c|c|c|c|}
\hline \multirow[b]{2}{*}{ Método } & & Coeficiente de & & \\
\hline & $\begin{array}{c}\text { Coeficiente de } \\
\text { Ajuste do } \\
\text { Modelo } \\
S Q_{R} /\left(S Q_{R}+\right. \\
\left.S Q_{r}\right)\end{array}$ & $\begin{array}{c}\text { Máxima } \\
\text { Variação } \\
\text { Explicável } \\
\left(S Q_{R}+S Q_{r}-\right. \\
\left.S Q_{e p}\right) /\left(S Q_{R}+\right. \\
\left.S Q_{r}\right)\end{array}$ & $\begin{array}{c}\mathbf{F}_{\text {calculado }} \\
M Q_{f a j} / M Q_{e p}\end{array}$ & $\begin{array}{c}\text { Teste } \mathbf{F} \\
\text { para ajuste } \\
\text { do modelo: } \\
F_{c a l}<F_{t a b} \\
(5 \%)\end{array}$ \\
\hline $\begin{array}{l}\text { Foto- } \\
\text { Fenton } \\
\text { UVA }\end{array}$ & 0,93015 & 0,95809 & 3,999 & $\begin{array}{c}3,999< \\
5,987\end{array}$ \\
\hline
\end{tabular}


Foto-

\begin{tabular}{|c|c|c|c|}
\hline Fenton & 0,88663 & 0,93198 & 2,000 \\
\hline
\end{tabular}

UVC

Foto-

Fenton

0,99437

0,99662

1,330

$1,330<$

Solar

$\mathrm{H}_{2} \mathrm{O}_{2} /$

Óxidos de

0,99869

0,99921

4,029

$4,029<$

Ferro

Além disso, os testes $\mathrm{F}$ realizados atestam que os modelos propostos são estatisticamente significativos.

\section{9}

\section{Análise cinética dos processos estudados}

Com os dados de degradação foi possível escolher um dos experimentos como referência para uma análise dos parâmetros cinéticos (ordem de reação, constante de velocidade) e o ajuste aos modelos propostos ( $1^{\mathrm{a}}$ ordem, $2^{\mathrm{a}}$ ordem e ordem "N"). O experimento em questão foi o ponto central $(0 / 0)$, justamente para desconsiderar qualquer favorecimento a um dos parâmetros, embora já tenha sido observada a predominância dos íons ferrosos na conversão do CZP em seus subprodutos. A Tabela 12 mostra como se comportaram cada um dos métodos estudados. Foi utilizado o software OriginPro 8 para esse estudo.

Tabela 16. Parâmetros obtidos através da modelagem cinética

\begin{tabular}{ccccc}
\hline & Parâmetro & $\mathbf{1}^{\mathbf{a}}$ Ordem & $\mathbf{2}^{\mathbf{a}}$ Ordem & Ordem N \\
\hline \multirow{2}{*}{ Fotólise } & $\mathrm{n}$ & 1 & 2 & 1,643 \\
UVC & $\mathrm{k}$ & $0,15 \pm 0,01 \mathrm{~min}^{-1}$ & $0,01 \pm 0,01 \mathrm{mg}$. & $0,08 \pm 0,01 \mathrm{mg}$. \\
& $\mathrm{R}^{2}$ & 0,98023 & $\mathrm{~L}^{-1} \cdot \mathrm{min}^{-1}$ & $\mathrm{~L}^{-1} \cdot \mathrm{min}^{-1}$ \\
& $\left(\sum \text { Res }\right)^{2}$ & 0,29425 & 0,99352 & 0,99793 \\
\hline
\end{tabular}




\begin{tabular}{ccccc}
\hline & $\mathrm{n}$ & 1 & 2 & 2,416 \\
$\begin{array}{c}\text { Foto- } \\
\text { Fenton }\end{array}$ & $\mathrm{k}$ & $0,97 \pm 0,18 \mathrm{~min}^{-1}$ & $\begin{array}{c}1,81 \pm 0,29 \mathrm{mg} . \\
\mathrm{L}^{-1} \cdot \mathrm{min}^{-1}\end{array}$ & $\begin{array}{c}0,37 \pm 0,02 \mathrm{mg} . \\
\mathrm{L}^{-1} \cdot \mathrm{min}^{-1}\end{array}$ \\
UVA & $\mathrm{R}^{2}$ & 0,9472 & 0,98192 & 0,99923 \\
& $\left(\sum \mathrm{Res}\right)^{2}$ & 0,70142 & 0,24017 & 0,00877 \\
\hline Foto- & $\mathrm{n}$ & 1 & 2 & 1,664 \\
Fenton & $\mathrm{k}$ & $1,30 \pm 0,08 \mathrm{~min}^{-1}$ & $3,27 \pm 0,38 \mathrm{mg}$. & $0,95 \pm 0,03 \mathrm{mg}$. \\
UVC & $\mathrm{R}^{2}$ & 0,99556 & $\mathrm{~L}^{-1} \cdot \mathrm{min}^{-1}$ & $\mathrm{~L}^{-1} \cdot \mathrm{min}^{-1}$ \\
& $\left(\sum \mathrm{Res}\right)^{2}$ & 0,06247 & 0,99654 & 0,99975 \\
& $\mathrm{n}$ & 1 & 0,04888 & 0,00299 \\
Foto- & $\mathrm{k}$ & $1,11 \pm 0,06 \mathrm{~min}^{-1}$ & $2,65 \pm 0,44 \mathrm{mg}$. & $0,96 \pm 0,12 \mathrm{mg}$. \\
Fenton & $\mathrm{R}$ & 0,99579 & $\mathrm{~L}^{-1} \cdot \mathrm{min}^{-1}$ & $\mathrm{~L}^{-1} \cdot \mathrm{min}^{-1}$ \\
Solar & $\mathrm{R}^{2}$ & 0,9871 & 0,99556 \\
& $\left(\sum \mathrm{Res}\right)^{2}$ & 0,06244 & 0,19131 & 0,05648 \\
\hline \multirow{2}{*}{$\begin{array}{c}\text { Sistema } \\
\text { H2O }\end{array}$} & $\mathrm{n}$ & 1 & 2 & 2,087 \\
Óxidos & $\mathrm{k}$ & $0,04 \pm 0,07 \mathrm{~min}^{-1}$ & $0,09 \pm 0,01 \mathrm{mg}$. & $0,02 \pm 0,01 \mathrm{mg}$. \\
de Ferro & $\mathrm{R}^{2}$ & 0,93562 & $\mathrm{~L}^{-1} \cdot \mathrm{min}^{-1}$ & $\mathrm{~L}^{-1} \cdot \mathrm{min}^{-1}$ \\
& $\left(\sum \mathrm{Res}\right)^{2}$ & 0,69188 & 0,99402 & 0,99308 \\
\hline
\end{tabular}

De uma forma geral, o ajuste dos resultados a modelos cinéticos convergiu para modelos de $2^{\mathrm{a}}$ ordem aparente ou próximos.

Com relação à constante de velocidade, $\mathrm{k}$, entre os modelos de segunda ordem, percebe-se que os métodos mais rápidos são os Foto-Fenton UVA e UVC.

A ordem aparente $n$ obtida para cada processo testado pode sugerir que a etapa controladora da reação seja de primeira ou segunda ordem. $\mathrm{O}$ que de fato aconteceu, pois nos modelos de $2^{\mathrm{a}}$ ordem, fotólise UVC, foto-Fenton UVA, fotoFenton UVC e o Sistema $\mathrm{H}_{2} \mathrm{O}_{2} /$ Óxidos de Ferro, $\mathrm{n} \cong 2$. Já no foto-Fenton solar, $\mathrm{n} \cong$ 1 , indicando uma reação de $1^{\mathrm{a}}$ ordem.

Outro gráfico ilustrativo e que se torna interessante é a comparação entre a cinética experimental observada para cada um dos processos (utilizando as condições do ponto central como referência para comparação) e o que foi obtido a partir do modelo matemático de ordem n. A Figura 41 apresenta o gráfico.

O gráfico permite aferir uma diferença entre o modelado no software e o que foi obtido experimentalmente: o processo Foto-Fenton Solar é mais lento do que o Foto-Fenton UVC e isso é o que se espera devido à maior energia da radiação 
UVC perante as radiações UVA e UVB solar. No mais, o gráfico também ilustra um ordenamento coerente para as constantes de velocidade calculadas no OriginPro 8. 


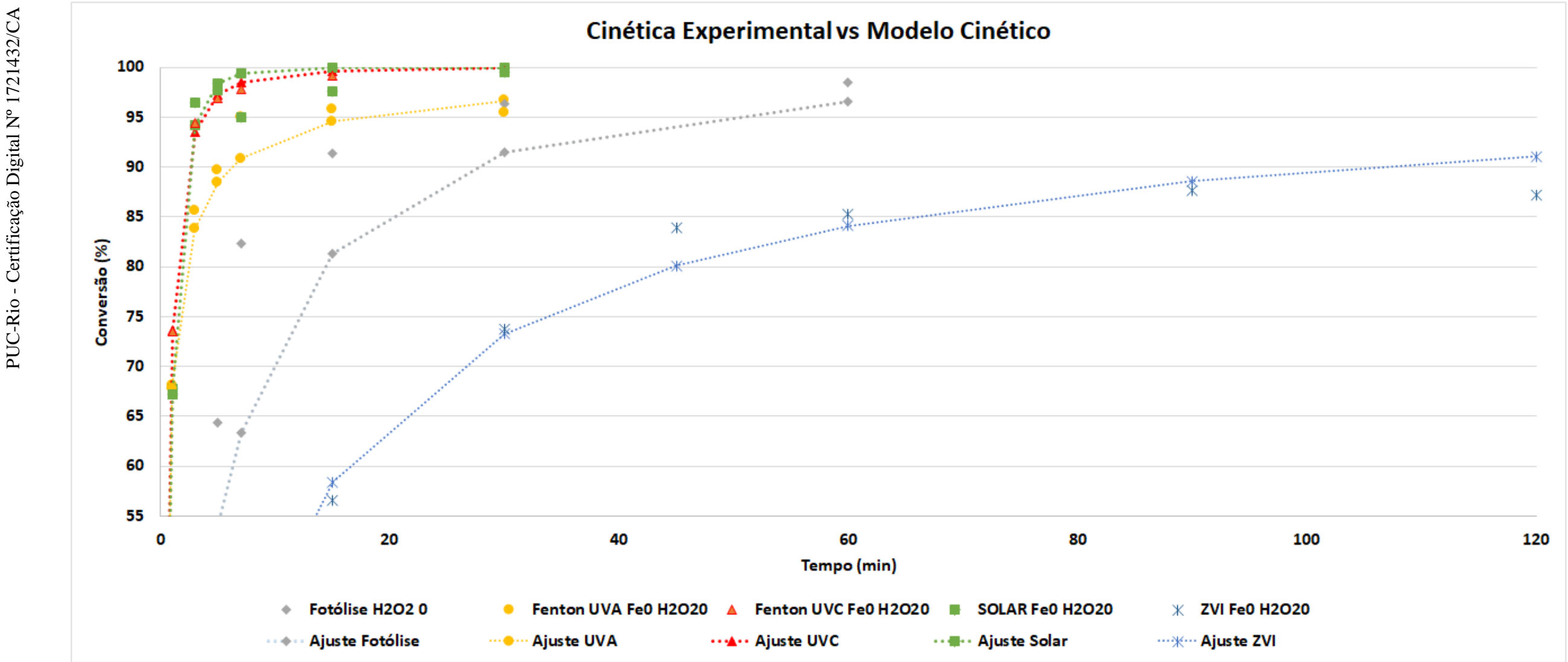

Figura 41. Cinética Experimental vs Ajuste Cinético obtido pelo software OriginPro 8 para ordem $n$ 


\subsection{0}

\section{Análise de toxicidade}

O ensaio de toxicidade utilizando a germinação de sementes de alface foi realizado na Fotólise UVC, no Foto-Fenton UVC e no Sistema $\mathrm{H}_{2} \mathrm{O}_{2} /$ Óxidos de Ferro. Utilizou-se apenas um dos métodos do Foto-Fenton devido ao fato de o mecanismo da reação para cada uma delas ser o mesmo. Optou-se pela lâmpada UVC por demonstrar os melhores resultados de conversão. A Tabela 13 mostra a inibição do crescimento dos caules de alface em termos percentuais, após 5 dias expostos a cada um dos métodos em diferentes concentrações.

\section{Tabela 17. Inibição do crescimento das sementes de alface}

\begin{tabular}{cccc}
\hline Diluição & $\begin{array}{c}\text { Fotólise UVC } \\
(\%)\end{array}$ & $\begin{array}{c}\text { Foto-Fenton } \\
\text { UVC }(\%)\end{array}$ & $\begin{array}{c}\text { Sistema } \mathbf{H}_{2} \mathbf{O}_{2} / \text { Óxidos de } \\
\text { Ferro (\%) }\end{array}$ \\
\hline $10 \%$ & 0,00 & 5,19 & 30,96 \\
$20 \%$ & 0,74 & 10,52 & 35,11 \\
$40 \%$ & 2,81 & 12,3 & 38,96 \\
$60 \%$ & 13,48 & 24,15 & 39,26 \\
$80 \%$ & 14,67 & 34,81 & 40,00 \\
$100 \%$ & 16,44 & 39,56 & 44,59 \\
\hline
\end{tabular}

Percebe-se que o Sistema $\mathrm{H}_{2} \mathrm{O}_{2} /$ Óxidos de Ferro é um método que apresenta valores de toxicidade maiores do que os demais, muito pela alta concentração do catalisador utilizado. Por si só, a presença de ferro (seja da forma bivalente ou trivalente) já caracteriza um aumento na toxicidade, visto que a Fotólise UVC não tem esse elemento químico no processo. Neste último, pode-se observar que a inibição deve estar relacionada aos intermediários gerados na reação, ou até à presença residual do peróxido de hidrogênio. No Foto-Fenton, já com íons ferrosos 
presentes, mostra-se um aumento substancial na toxicidade em relação a Fotólise UVC.

\subsection{1}

\section{Análise comparativa entre os processos}

Entre os processos estudados, diversas vantagens e desvantagens podem ser apontadas, na escolha do mais adequado para cada situação. O fato de todos alcançarem altas conversões propicia um amplo leque de opções. Por isso é pertinente listar os prós e contras encontrados em cada método. A Tabela 14 discrimina estas informações:

Tabela 18. Vantagens e desvantagens dos métodos estudados

\begin{tabular}{|c|c|c|}
\hline Método & Vantagens & Desvantagens \\
\hline $\begin{array}{c}\text { Fotólise } \\
\text { UVC }\end{array}$ & $\begin{array}{ll}\text { - } & \text { Simples operação } \\
\text { - } & \text { Sem catalisador } \\
\text {. } & \text { Baixa toxicidade final }\end{array}$ & $\begin{array}{ll}\cdot & \text { Radiação UVC } \\
\text {. } & \text { Lento }\end{array}$ \\
\hline $\begin{array}{c}\text { Foto-Fenton } \\
\text { UVA }\end{array}$ & $\begin{array}{ll}\cdot & \text { Rápido } \\
\text { · } & \text { Radiação menos } \\
& \text { agressiva } \\
\text { - } & \text { Método robusto }\end{array}$ & $\begin{array}{ll}\text {. } & \text { Toxicidade final } \\
\text {. } & \text { Uso de catalisador }\end{array}$ \\
\hline $\begin{array}{c}\text { Foto-Fenton } \\
\text { UVC }\end{array}$ & $\begin{array}{ll}\text { - } & \text { Muito rápido } \\
\text { · } & \text { Degradação completa } \\
\text { - } & \text { Método robusto }\end{array}$ & $\begin{array}{ll}\text { - } & \text { Radiação UVC } \\
\text {. } & \text { Uso de catalisador } \\
\text {. } & \text { Toxicidade }\end{array}$ \\
\hline $\begin{array}{c}\text { Foto-Fenton } \\
\text { Solar }\end{array}$ & $\begin{array}{ll}\cdot & \text { Rápido } \\
\cdot & \text { Energeticamente } \\
& \text { eficiente } \\
\cdot & \text { Radiação menos } \\
& \text { agressiva }\end{array}$ & $\begin{array}{ll}\text {. } & \text { Suscetível ao local } \\
\text {. } & \text { Sazonal } \\
\text {. } & \text { Uso de catalisador } \\
\text {. } & \text { Toxicidade }\end{array}$ \\
\hline
\end{tabular}




\begin{tabular}{clll}
\hline & & & Lento \\
Sistema & $\cdot$ & Reaproveita material & Gasto energético \\
$\mathrm{H}_{2} \mathrm{O}_{2} /$ Óxidos & como catalisador & com agitador \\
de Ferro & $\cdot$ & Sem radiação & Alta toxicidade \\
& $\cdot$ & Simples operação & $\cdot$ Gera lodo residual \\
& & $\cdot$ Aumento na cor \\
\hline
\end{tabular}

\subsection{2}

\section{Comparação dos resultados obtidos com os de outros trabalhos}

Outros trabalhos já foram realizados com relação à degradação do clonazepam, outras benzodiazepinas ou compostos similares utilizando os processos oxidativos avançados empregados nesta dissertação. A comparação dos resultados obtidos com os de outros trabalhos reforça a eficiência dos processos aplicados, bem como destaca a robustez de cada um deles.

Em um único trabalho que aborda a degradação de clonazepam dentre outros fármacos, Hey et al. (2012) utilizam dióxido de cloro como oxidante em um efluente tratado por processos biológicos em duas ETEs. A concentração aplicada do $\mathrm{ClO}_{2}$ variou ao longo do experimento e serviu como parâmetro de classificação (facilmente oxidável, moderadamente oxidável, fracamente oxidável e não oxidável) de cada composto. Os fármacos que necessitavam de uma menor concentração de oxidante eram considerados facilmente oxidáveis e assim de forma subsequente até os que não oxidaram com altas doses de $\mathrm{ClO}_{2}$. O CZP foi considerado um fármaco não oxidável com taxa de degradação entre 50-60\% em concentrações de $20 \mathrm{mg} . \mathrm{L}^{-1}$ de $\mathrm{ClO}_{2}$. O presente trabalho apresentou conversões acima de $85 \%$ para degradação do clonazepam em todos os processos.

Já em trabalhos que utilizam outros benzodiazepínicos como alvo de degradação, Subedi et al. (2017) avaliaram a eficiência da remoção de fármacos e produtos de higiene pessoal em duas ETEs no sul da Índia. Entre os fármacos, algumas benzodiazepinas, como o diazepam, foram avaliados. O tratamento de uma das ETEs consistia em uma etapa biológica por lodos ativados seguido por uma clarificação e desinfecção com cloro. A outra envolvia um reator anaeróbico de fluxo ascendente (RAFA ou UASB) seguindo por lodos ativados, clarificação e 
desinfecção por cloro. Os resultados obtidos mostraram que a ETE continha a etapa de oxidação anaeróbica que apresentou remoção média de $62 \%$ para o diazepam, enquanto na ETE sem a presença do RAFA não houve degradação deste composto.

Bautitz e Nogueira (2010) estudaram a degradação do diazepam através da aplicação da fotólise UVA e Foto-Fenton UVA em efluente de ETEs $\left(1 \mu \mathrm{g} . \mathrm{L}^{-1}\right) \mathrm{e}$ águas de rio e potável (10 ng. $\left.\mathrm{L}^{-1}\right)$. A conversão alcançada pela fotólise UVA foi próxima a $20 \%$. Para o Foto-Fenton houve conversão acima de $95 \%$. Todos os resultados anteriores se referem a um tempo final de 60 minutos. A constante de velocidade (k) para modelo de degradação de pseudo-primeira ordem utilizando ferrioxalato como fonte de íons ferrosos no Foto-Fenton UVA foi de 0,39 $\mathrm{min}^{-1}$, mesma ordem de grandeza deste trabalho. Não foi relatada influência do tratamento por ETE à degradação do diazepam perante um efluente simulado com matriz de água destilada.

Em um estudo mais específico, Bautitz et al. (2012) estudaram a degradação do diazepam pelo processo Ferro Zero Valente, um sistema heterogêneo, que envolve a reação do ferro metálico tanto na produção de $\mathrm{H}_{2} \mathrm{O}_{2}$ para geração de radicais hidroxila quanto como fonte de íons ferrosos para a catálise da reação de Fenton. As variáveis consideradas no processo foram a concentração de $\mathrm{Fe}^{0}$, a presença de agente complexante (EDTA) e a injeção de oxigênio no sistema. As condições que apresentaram maior degradação do diazepam foram as que tinham maior concentração de $\mathrm{Fe}^{0}$ (pré-tratado com $\mathrm{H}_{2} \mathrm{SO}_{4} 1 \mathrm{M}$ ), a presença do EDTA e a injeção do $\mathrm{O}_{2}$ de forma artificial. A conversão alcançada foi acima de $90 \%$. 


\section{Conclusões}

Com a alta demanda por benzodiazepínicos nos últimos anos, em especial o clonazepam, este trabalho joga luz acerca da problemática deste fármaco no meio ambiente, mais especificamente em matrizes aquosas. Ao longo da fundamentação teórica, foi discutida a relevância do estudo sobre contaminantes emergentes, desde as causas até as consequências da presença destes compostos nos rios, lagos e mares. Em seguida, os benzodiazepínicos e o clonazepam foram dissecados a fim de enriquecer o debate. Por fim, as bases dos processos oxidativos avançados utilizados na experimentação, do planejamento fatorial e do método cinético foram apresentadas.

A investigação de cinco processos de oxidação avançada, desde os mais reconhecidos até outros mais inovadores, foi realizada para degradação do clonazepam em um efluente simulado. Além disso, 4 planejamentos fatoriais $2^{2}$ foram realizados (Foto-Fenton UVA/UVC/Solar e Sistema $\mathrm{H}_{2} \mathrm{O}_{2} /$ Óxidos de Ferro), analisando-se as principais características de cada processo e a influência de cada parâmetro. A curva analítica utilizada apresentou alta correlação entre a concentração do fármaco e a área mensurada pelo HPLC.

Tratando da degradação do clonazepam, todos os métodos alcançaram pelo menos $85 \%$ de conversão em certas condições, o que mostra a eficiência dos POAs na remoção deste contaminante emergente. $\mathrm{O}$ destaque fica para o Foto-Fenton UVC que mostrou, além da maior conversão do fármaco em seus subprodutos, a cinética mais veloz $\left(\mathrm{k}=0,95 \pm 0,03 \mathrm{mg} \cdot \mathrm{L}^{-1} \cdot \mathrm{min}^{-1}\right)$. A combinação da potente radiação UVC com a presença de catalisador $\mathrm{Fe}^{2+}$ é crucial para a eficiência. Aliás, o reagente/catalisador se mostrou a principal variável na degradação do CZP, frente ao peróxido de hidrogênio.

Com relação ao modelo cinético proposto de ordem aparente $n$, foi apurado que a ordem que mais se ajusta aos processos de degradação do clonazepam foi a segunda ordem. Apenas o processo Foto-Fenton Solar apresentou um melhor ajuste para a primeira ordem. 
Outras considerações que valem ser ressaltadas são: a cinética de degradação do Foto-Fenton Solar $\left(\mathrm{k}=0,96 \pm 0,12 \mathrm{mg}\right.$. $\left.\mathrm{L}^{-1} \cdot \mathrm{min}^{-1}\right)$ ser mais veloz do que o Foto-Fenton UVA $\left(\mathrm{k}=0,37 \pm 0,02 \mathrm{mg} \cdot \mathrm{L}^{-1} \cdot \mathrm{min}^{-1}\right)$, devido à presença da radiação UVB; a boa eficiência da fotólise UVC, considerando que este é um processo sem presença de catalisador e o reuso de palha de aço como fonte de ferro para o Sistema $\mathrm{H}_{2} \mathrm{O}_{2} /$ Óxidos de Ferro.

Este último, por se tratar de um método não irradiado também deve ter seu resultado final exaltado, mesmo que com um alto tempo, devido à sua facilidade de operação. Além disso, o resultado da caracterização do catalisador heterogêneo mostrou que a área superficial passa de $0,203 \mathrm{~m}^{2} \cdot \mathrm{g}^{-1}$ para $4,815 \mathrm{~m}^{2} \cdot \mathrm{g}^{-1}$ à medida em que se queima sob atmosfera redutora a palha de aço, tornando-a mais finamente dividida. Os óxidos na superfície foram analisados por DRX e percebeu-se a presença predominante da magnetita. Apesar do uso de atmosfera redutora atrelada ao aumento da temperatura, pouco da lã de aço foi convertida em hematita e wustita.

A análise de toxicidade concluiu que a presença do ferro como reagente/catalisador nos processos utilizados contribui para o aumento da inibição do crescimento das sementes de alface. Mais do que isso, há uma correlação diretamente proporcional entre a concentração em que o elemento se apresenta com o nível de toxicidade, visto que o Sistema $\mathrm{H}_{2} \mathrm{O}_{2} /$ Óxidos de Ferro (Fe mais concentrado) teve valores maiores, $\mathrm{I}_{100 \%}=44,6 \%$, do que o Foto-Fenton UVC (Fe menos concentrado), $\mathrm{I}_{100 \%}=39,6 \%$. A fotólise UVC se mostrou o método menos tóxico de todos com $\mathrm{I}_{100 \%}=16,4 \%$. 


\section{Sugestão para trabalhos futuros}

Para os trabalhos subsequentes, é sugerida a análise qualitativa e quantitativa dos intermediários gerados nas reações de degradação do Clonazepam através de cromatografia líquida de alta eficiência acoplado a uma série de espectrômetros de massa (HPLC/MS/MS) com a finalidade de identificar e avaliar a toxicidade destes compostos.

Para a Fotólise, tentar aplicá-la com o uso de radiação solar e compará-la com os resultados obtidos com o da lâmpada UVC.

Outra sugestão é incorporar a medição de cor para analisar a variação deste parâmetro ao fim do Sistema $\mathrm{H}_{2} \mathrm{O}_{2} /$ Óxidos de Ferro.

Analisar a taxa de adsorção do reagente/catalisador durante o Sistema $\mathrm{H}_{2} \mathrm{O}_{2} /$ Óxidos de Ferro, visto que, em se tratando de um método heterogêneo, seus sítios ativos podem ser suficientemente relevantes para adsorção, apesar da baixa área superficial perante a outros adsorventes comumente empregados tais como carvão ativado.

Por fim, realizar a avaliação quanto à quantidade e à qualidade do lodo gerado durante o Sistema $\mathrm{H}_{2} \mathrm{O}_{2} /$ Óxidos de Ferro, proveniente em grande parte do reagente/catalisador adicionado. Analisar a possibilidade de reuso deste não só neste processo, mas como fonte para outras aplicações. 


\section{Referências bibliográficas}

ANDREOZZI, R. et al. Advanced oxidation processes (AOP) for water purification and recovery. Catalysis Today, v. 53, p. 51-59, 1999.

ASHTON, H. The diagnosis and management of benzodiazepine dependence. Current opinion in psychiatry, v. 18, n. 3, p. 249-55, 2005.

BARBUSIŃSKI, K. Henry John Horstman Fenton - short biography and brief history of Fenton reagent discovery. Chemistry Didatics Ecology Metrology, v. 14, n. 1-2, p. 101-105, 2009.

BARROS NETO, B.; SCARMINIO, I. S.; BRUNS, R.E. Como fazer experimentos: pesquisa e desenvolvimento na ciência e na indústria. 2 ed. Campinas: Editora da UNICAMP, p. 296, 2002.

BAUTITZ, I. R.; NOGUEIRA, R.F.P. Photodegradation of lincomycin and diazepam in sewage treatment plant effluent by photo-Fenton process. Catalysis Today, v. 151, p. 94-99, 2010.

BAUTITZ, I. R.; VELOSA, A. C.; NOGUEIRA, R. F. P. Zero valent iron mediated degradation of the pharmaceutical diazepam. Chemosphere, v. 88, n. 6 , p. 688$692,2012$.

BEEK, T.A.D. et al. Pharmaceuticals in the environment - global ocurrences and perspectives. Environmental Toxicology and Chemistry, v. 35, n. 4, p. 823-835, 2016.

BELL, K. et al. Emerging Pollutants. Water Environment Research, v. 83, n. 10, p. 1906-1984, 2011.

BERNIK, M.A. Benzodiazepínicos: quatro decadas de experiência. São Paulo: EdUSP, p. 256, 1999.

BILA, D. M., DEZOTTI, M. Fármacos no meio ambiente - Revisão. Química Nova, v. 26, n. 4, p. 523-530, 2003.

BIN, A.K., SOBERA-MADEJ, S. Comparison of the Advanced Oxidation Processes ( UV , UV / H2O2 and O3 ). Ozone: Science \& Engineering, v. 34, n. 
2, p. 136-139, 2012.

BRASIL. Ministério do Meio Ambiente. Resolução CONAMA No 430, de 13 de maio de 2011, Dispõe sobre as condições e padrões de lançamento de efluentes. Conselho Nacional do Meio Ambiente - CONAMA. Diário Oficial da União, Brasília, 16 de maio de 2011.

BRASIL. Ministério da Saúde. Portaria de Consolidação nº 5, de 28 de setembro de 2017, Consolidação das normas sobre as ações e os serviços de saúde do Sistema Único de Saúde. Diário Oficial da União. Brasília, 03 de outubro de 2017.

BRASIL. Sistema Nacional de Gerenciamento de Produtos Controlados ANVISA, Boletim de Farmacoepidemiologia do SNGPC, v. 2, ano 1, p. 01-09, 2011.

BRASIL. Transtornos de ansiedade. Saúde \& Economia, v. 10, p. 1-5, 2013.

CAVALCANTI, J.V.F.L. Tratamento por oxidação avançada de solo argiloso contaminado por derivados do petróleo. Recife, 2012. 126 f. Tese de Doutorado (Doutorado em Engenharia Química) - Universidade Federal de Pernambuco.

CHÈZE, M.; VILLAIN, M.; PÉPIN, G. Determination of bromazepam, clonazepam and metabolites after a single intake in urine and hair by LC-MS/MS: Application to forensic cases of drug facilitated crimes. Forensic Science International, v. 145, n. 2-3, p. 123-130, 2004.

CHIEN, Y.H., LAI, H.T., LIU, S.M., Modeling the effects of sodium chloride on degradation of chloramphenicol in aquaculture pond sediment. Science of The Total Environment, v. 239, p. 81-87, 1999.

CRUZ, N. L. DE M. Clonazepam, um campeão de vendas no Brasil. Por quê? São Paulo, 2016. 74 f. Dissertação de Mestrado (Mestrado em Ciências) Universidade Federal de São Paulo.

CUNICO, M.W.M. et al. Planejamento Fatorial: uma ferramenta estatística valiosa para a definição de parâmetros experimentais empregados na pesquisa científica. Visão Acadêmica, v. 9, p. 23-32, 2008.

DE PAULA, N.C. et al. Biosynthesis of human diazepam and clonazepam 
metabolites. Bioorganic and Medicinal Chemistry Letters, v. 25, n. 5, p. 10261029, 2015.

DIEHL, A., CORDEIRO, D.C., LARANJEIRA, R. Dependência química: prevenção, tratamento e políticas públicas. $1^{\mathrm{a}}$ ed. Porto Alegre: Artmed. 2011. p. 528

FOYE, W.O. et al. Foye's Principles of Medicinal Chemistry. 7. ed. Filadélfia: Lippincott Williams \& Wilkins. 2013, p. 1479.

HEY, G et al. Oxidation of pharmaceuticals by chlorine dioxide in biologically treated wastewater. Chemical Engineering Journal, v. 185-186, p. 236-242, 2012.

HOUTMAN, C.J.. Emerging contaminants in surface waters and their relevance for the production of drinking water in Europe. Journal of Integrative Environmental Science, v. 7, p. 271-295, 2010.

JARDIM, W.F., CANELA, M.C. Fundamentos da Oxidação Química no Tratamento de Efluentes e Remediação de Solos. 1 ed. Campinas - Unicamp. 2004, p. 11

JOO, S.H.E.E.; FEITZ, A.J. Quantification of the Oxidizing Capacity of Nanoparticulate Zero-Valent Iron. Environmental Science \& Technology, v. 39, n. 5, p. 1263-1268, 2005.

JORGENSEN, S.E., HALLING-SORENSEN, B. Drugs in the environment. Chemosphere, v. 40, p. 691-699, 2000.

KIM, D.J.; NEDELJKOVIC, S.S. Benzodiazepines. Pain Medicine: An Essential Review, p. 173-174, 2017.

KOLÁR, M., URBÁNEX, K., LÁTAL, T. Antibiotic selective pressure and development of bacterial resistance. International Journal of Antimicrobial Agents, v. 15, p. 357-363, 2001.

LACERDA, A. et al. Psicofarmacologia clínica. 3 ed. Rio de Janeiro: Medbook, 2011, p. 263

LIN, A. E. et al. Clonazepam use in pregnancy and the risk of malformations. Birth Defects Research Part A: Clinical and Molecular Teratology, v. 70, n. 8, p. 534- 
536, 2004.

MAGALHÃES, E.J. DESENVOLVIMENTO DE MÉTODOS PARA QUANTIFICAÇÃO DE DROGAS EM MATRIZES DE INTERESSE FORENSE. Belo Horizonte, 2012. 126 f. Tese de Doutorado (Doutorado em Ciências - Química) - Universidade Federal de Minas Gerais.

MALLET, J.D.; ROCHETTE, P.J. Wavelength-dependent ultraviolet induction of cyclobutane pyrimidine dimers in the human cornea. Photochemical \& Photobiological Sciences, v. 12, n. 8, p. 1310, 2013.

MCKEON, D.M., CALABRESE, J.P., BISSONNETTE, G.K. Antibiotic resistant gram-negative bacteria in rural groundwater supplies. Water Research. v. 29, p. 1902-1908, 1995.

MENDES, C. M. DE M. ESTUDO FARMACOEPIDEMIOLÓGICO DE USO E PRESCRIÇÃO DE BENZODIAZEPÍNICOS EM TERESINA. Fortaleza, 2015. 149 f. Tese de Doutorado (Doutorado em Farmacologia) - Universidade Federal do Ceará.

MIRANDA, C.D., CASTILLO, G. Resistance to antibiotic and heavy metals of motile aeromonads from Chilean freshwater. Science of The Total Environment. v. 224 , p. $167-173,1998$.

NASCIMENTO, R.F.; BARROS, A.L.; ABDALA, E.F. Processos oxidativos avançados: fundamentos e aplicações em matrizes ambientais. Fortaleza: Imprensa Universitária, 2017. 280 p.

NOGUEIRA, R.F.P. et al. Fundamentos e aplicações ambientais dos processos Fenton e Foto-Fenton. Química Nova, v. 30, n. 2, p. 400-408, 2007.

ONU. OMS registra de casos de depressão em todo o mundo; no Brasil são 11,5 milhões de pessoas. ONU Brasil. 23 de fevereiro de 2017. Disponível em: $<$ https://nacoesunidas.org/oms-registra-aumento-de-casos-de-depressao-em-todoo-mundo-no-brasil-sao-115-milhoes-de-pessoas/>. Acesso em: 13 de fev. de 2019

OPAS/OMS Brasil. Folha Informativa - Transtornos Mentais. Abril de 2018. Disponível em 
$<$ https://www.paho.org/bra/index.php?option=com_content\&view=article\&id=56 52:folha-informativa-transtornos-mentais \&Itemid=839>. Acesso em: $14 \mathrm{de} \mathrm{fev.} \mathrm{de}$ 2019.

OLIVEIRA, M. C. DE et al. Um estudo termodinâmico da corrosão dos aços carbono pelo sulfeto de hidrogênio: explorando conceitos de equilíbrio químico. Quimica Nova, v. 41, n. 5, p. 594-599, 2018.

OLIVEIRA, L.C.A., FABRIS, J.D., PEREIRA, M.C. Óxidos de ferro e suas aplicações em processos catalíticos: uma revisão. Química Nova, v. 36, n. 1, p. 123-130, 2013.

PERALTA-ZAMORA, P. MORAIS, J. L. NAGATA, N. Por que otimização multivariada? Engenharia Sanitária e Ambiental. v. 10, p. 106-110, 2005.

PERINI, J.A.D.L. DEGRADAÇÃO DOS FÁRMACOS CIPROFLOXACINO E SERTRALINA PELOS PROCESSOS FERRO ZERO E FOTO-FENTON APLICAÇÃO EM AMOSTRAS DE EFLUENTES DE ESTAÇÃO DE TRATAMENTO DE ESGOTO. Araraquara, 2013. 180 f. Tese de Doutorado (Doutorado em Química) - Universidade Estadual Paulista.

PRODUTOS ROCHE QUÍMICOS E FARMACÊUTICOS. Rivotril: Clonazepam. Rio de Janeiro, 2016.

PUBCHEM. Clonazepam. Disponível em: < https://pubchem.ncbi.nlm.nih.gov/compound/Clonazepam>. Acesso em: 24 de mar. de 2019.

ROCHA, M.D.L.P. Uso de processos oxidativos avançados para o tratamento de efluente de indústria de celulose. Rio de Janeiro, 2017. 152 f. Dissertação de Mestrado (Mestrado em Engenharia de Materiais e de Processos Químicos e Metalúrgicos) - Pontifícia Universidade Católica do Rio de Janeiro.

RUST, K.Y. et al. Detection and validated quantification of 21 benzodiazepines and 3 "z-drugs" in human hair by LC-MS/MS. Forensic Science International, v. 215, n. 1-3, p. 64-72, 2012.

SANTOS, C.E.M. Priorização de fármacos em água destinada ao consumo 
humano baseada em avaliação da toxicidade e do comportamento ambiental por meio de modelos computacionais (in silico) para fins de gestão ambiental: priorização de fármacos em água destinada ao consumo. São Paulo, 2015. 118 f. Dissertação de Mestrado (Mestrado em Ciências) - Univesidade de São Paulo.

SAUVÉ, S., DESROSIERS, M. A review of what is an emerging contaminant. Chemistry Central Journal. v. 8, n. 15, p. 1-7, 2014.

SILVA, J.A.C. História dos Benzodiazepínicos. In: BERNIK, Márcio Antonini. Benzodiazepínicos: Quatro Décadas de Experiência. São Paulo: Edusp, 1999. Cap. 1, p. 15-28.

SMITH, P., SAMUELSEN, O.B. Estimates of the significance of outwashing of oxytetracycline from sediments under Atlantic salmon sea-cages. Aquaculture, v. 144, p. 17-26, 1996.

SNYDER, S.A. Analytical methods for detection of selected estrogenic compounds in aqueous mixtures. Environmental Science \& Technology, v. 33, p. 2814-2820, 1999.

STORHAUG, L.W. et al. Prolonged excretion of 7-aminoclonazepam in urine after repeated ingestion of clonazepam: A case report. Forensic Science International, v. 222, n. 1-3, p. 33-35, 2012.

STUMPF, M. et al. Polar drug residues in sewage and natural waters in the state of Rio de Janeiro, Brazil. Science of The Total Environment, v. 225, p. 135-141, 1999.

SUBEDI, B. et al. Mass loading and removal of pharmaceuticals and personal care products including psychoactives, antihypertensives, and antibiotics in two sewage treatment plants in southern India. Chemosphere, v. 167, p. 429-437, 2017.

TAHERAN, M. et al. Environmental Nanotechnology, Monitoring \& Management Emerging contaminants: Here today, there tomorrow! Environmental Nanotechnology, Monitoring \& Management, v. 10, n. February, p. 122-126, 2018. 
TEIXEIRA, C.P.A.B.; JARDIM, W.F. Processos Oxidativos Avançados: Conceitos Teóricos. 1. ed. Campinas: Unicamp, 2004. p. 65.

TEODOSIU, C. et al. Emerging pollutants removal through advanced drinking water treatment: A review on processes and environmental performances assessment. Journal of Cleaner Production, v. 197, p. 1210-1221, 2018.

TERNES, T.A. et al. Behavior and occurrence of estrogens in municipal sewage treatment plants: Investigations in Germany, Canada and Brazil. Science of The Total Environment, v. 225, p. 81-90, 1999.

TÓTH, K. et al. Optimization of Clonazepam Therapy Adjusted to Patient's CYP3A Status and NAT2 Genotype. International Journal of Neuropsychopharmacology, v. 19, n. 12, p. 1-9, dez. 2016.

\section{U.S. EPA. Handbook Advanced Photochemical Oxidation Processes.}

Cincinnati: Center of Environmental Research Information, 1998. 96 p.

VARDANYAN, R.S., HURBY, V.J. Synthesis of Essential Drugs. Amsterdam: Elsevier, 2006.

WILKINSON, J. et al. Occurrence, fate and transformation of emerging contaminants in water: an overarching review of the field. Environmental Pollution, v. 231, p. 954-970, 2017.

WU, R.S.S. The environmental impact of marine fish culture: Towards a sustainable future. Marine Pollution Bulletin. v. 31, p. 159-166, 1995.

ZHANG, Y. et al. Removal of bisphenol A by a nanofiltration membrane in view of drinking water production. Science Direct, v. 40, p. 3793-3799, 2006. 